\title{
Three Essays on Immigrant Families in Canada
}

\author{
by
}

Maoqiong Lin

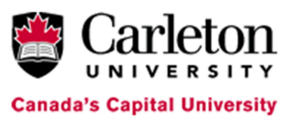

A thesis submitted to the Faculty of Graduate and Postdoctoral Affairs in partial fulfilment of the requirements for the degree of

\section{Doctor of Philosophy}

in

\section{Economics}

\author{
Department of Economics \\ Carleton University \\ Ottawa, Ontario, Canada
}

(C) 2014

Maoqiong Lin 


\section{Acknowledgements}

I am grateful to my thesis supervisor, Professor Christopher Worswick, for his help and encouragement throughout my study in Carleton University. He trained me to do research in Economics. He helped me practice in English-speaking and writing.

I would like to thank my committee members, Professor David Gray and Professor Marcel Voia, for reading my thesis carefully and providing helpful feedback. I thank Professor Ted McDonald for his help during my thesis research.

I am thankful to Professor Lynda Khalaf and Professor Jean-Thomas Bernard, for the research opportunities which strengthened my knowledge and research skills in Econometrics. I enjoyed to work with them.

I am grateful to Professor Armstrong for providing me a teaching opportunity for different courses in Department of Economics, Carleton University. Thanks to Professor Richard Brecher, Professor Till Gross, Professor Michel Demers, Professor Konstantinos Metaxoglou and Professor Jiankang Zhang from Department of Economics and Dr. Samah Sabra from Education Development Centre of Carleton University for helping me improve my teaching skills.

I thank John Baldwin, Maxime Fougere, Nicolas Tremblay-Ct, Alejandro DeMaioSukic, Marjorie Forsythe, Ian Melzer, Nancy Walker, Hugo Gomes, for providing me with working opportunities at government Canada; and Mark Brown, Wulong $\mathrm{Gu}$, Mohsen Bouaissa and Louis-David Ct, for supervising my work in government Canada.

I am grateful to COOL RDC and FRDC of Statistics Canada for providing environment to work with data used in my thesis research and government projects. 
I benefit a lot to discuss with my classmates and friends, Sophie (Yue) Xing, Afshan Dar, Abeer Reza, Kim Huynh, Luke Ignaczak, Haizhen Mou, Sui Sui, Xiaonan Li, Xue Zhao, Ting Zhang, Lili Hao, Wen Ci, Gang Li, Yao Qin, Zhenjiang Lin, Chaohui Lu, Marie-Hlne Felt, Sarah Mohan, Vincent Paquet, Beatriz Peraza Lopez, Mihailo Radoman, Charles Saunders, Muhammad Ariffin, Anand Acharya, Heng Xu, Yang Zou, Samira Hasanzadeh, James Splinter, Alexander Maslov, Anderson Nzabandora, Parisa Pourkarimi. Thanks for all of their help and encouragement.

Thanks to Dawn Bjornson, Marge Brooks, Erin Johnston, Rene E. Lortie, Amanda Wright and Maria Dabboussy of the Economics department at Carleton University for their encouragement and support.

I am deeply grateful to my parents, Xiangwan Lin and Shulan Li, for their love and support. Thanks especially to my grandmother, Zhenglun Li, for teaching me to have a good personality.

Thanks to my daughter Emily and my son Emery, for being good kids.

I thank my husband, Jingshan Fu, for his support and taking care of our family. 


\section{Abstract}

In this thesis, I compared income, consumption, savings, dwelling ownership and equity between immigrant families and Canadian born families. I studied the families' consumption behaviour and labour supply under credit constraint.

In the first chapter of this thesis, the income, consumption and savings behaviour of immigrant and Canadian-born households are analysed using data from the Family Expenditure Surveys (FAMEX) of Statistics Canada for the years of 1969, 1974, 1982, 1984, 1986, 1990 and 1992. Immigrant households have significantly lower income and consumption levels compared to Canadian-born households. Savings are generally found to be similar between immigrant and Canadian-born households. There are no clear differences in the saving rates between immigrant and Canadianborn households. There are no significant changes in income, savings, or changes in assets as immigrants stay longer in Canada.

The second chapter of this thesis analyses an intertemporal labor supply model for immigrant families allowing for the possibility of credit constraints. The withinperiod MRS condition for the wife's hours and family consumption and the interperiod Euler equation are estimated using the Canada's Family Expenditure Survey from 1984-1992. The results indicate that recent cohorts of married immigrant women work longer hours than earlier arrival cohorts and Canadian-born wives. Immigrant wives from non-traditional source countries work about 100 hours longer and have about $\$ 5$ lower hourly wage rates than those from the UK, US, North and West Europe and the Canadian-born wives. The immigrant families are more likely to be credit constrained. The credit constraint is important for immigrant families food 
consumption behavior.

The final chapter of this thesis analyzes the differences in home ownership and housing equity between immigrant and Canadian-born households, using data from the Family Expenditure Surveys (FAMEX) of Statistics Canada for the years 1969, 1974, 1982, 1984, 1986, 1990 and 1992 as well as more recent data from the Survey of Financial Security (SFS) for the years 1999 and 2005. Recent immigrant households are less likely to own their dwelling and hold 44, 000 to 51,000 for FAMEX and 42, 000 to 59, 000 for SFS less equity in owned dwellings than do Canadian-born households. The probability of owning a dwelling and the equity held in the dwelling grow quickly with years-since-migration. The more recent arrival cohorts are much less likely to own their dwelling and this is consistent with the findings of very low incomes for these cohorts in the immigrant earnings literature. However, among immigrant households who own their dwellings, housing equity is in fact higher for the more recent arrival cohorts. These differences disappear once the home equity model is extended to include the sample of households that rent their dwelling (assigning them a value of zero for their housing equity). The findings are consistent with there being large barriers to access to credit for immigrant households from the recent arrival cohorts. 


\section{Contents}

Acknowledgements $\quad$ i

$\begin{array}{ll}\text { Abstract } & \text { iii }\end{array}$

1 Income, Consumption and Savings of Immigrant Families in Canada 2

1.1 Introduction . . . . . . . . . . . . . . . . . 2

1.2 Data and Empirical Strategy _... . . . . . . . . . 6

1.3 Estimation Approach . . . . . . . . . . . . . . . . . . . 9

1.3.1 Theoretical Framework and Reduced Form Estimation Approach 9

1.3.2 General Specification of Savings Equations . . . . . . . . 9

1.4 Empirical Results . . . . . . . . . . . . . . . . . . . 12

1.4 .1 Income . . . . . . . . . . . . . . . . . . . . 12

1.4.2 Consumption Expenditure and Savings _. . . . . . . . 14

1.4.3 Sample Selection Problem and Out-Migration . . . . . . . . 16

1.5 Concluding Remarks . . . . . . . . . . . . . . . . . . 17

2 Family Strategies and the Labor Supply of Married Immigrant Women 19

2.1 Introduction . . . . . . . . . . . . . . . . . . . . . . . . . . 19

2.2 The Model . . . . . . . . . . . . . . . . . . . . . . . . . . . . . . . . 24

2.3 Derivation of the Estimating Equations . . . . . . . . . . . 27

2.3.1 Endogeneity of the Wifes Wage and Family Consumption . . 29

2.3.2 Heckman Selection Model . . . . . . . . . . . . . . . . . 31

2.4 The data and Empirical Strategy _ . . . . . . . . . . . . . 34 
2.4.1 Choice of Instrumental Variable . . . . . . . . . . . . . . . . . 39

2.5 Empirical Results . . . . . . . . . . . . . . . . . 39

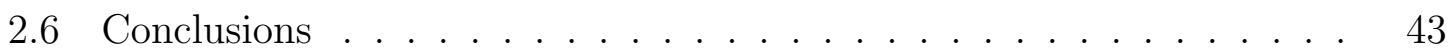

3 Dwelling Ownership and Housing Equity of Immigrant Families in Canada $\quad 45$

3.1 Introduction . . . . . . . . . . . . . . . . . . 45

3.2 Data and Empirical Strategy . . . . . . . . . . . . 48

3.3 Estimation Approach . . . . . . . . . . . . . . . 50

3.3.1 Theoretical Framework and Reduced From Estimation Approach 50

3.3.2 General Specification of the Estimating Equations . . . . . 51

3.3.3 Family Income and Sources of Income Variation . . . . . . . . 53

3.3.4 Decision to Own the Household Dwelling and Accumulation of Housing equity ..................... 54

3.3.5 Choice of Instrumental Variable . . . . . . . . . . . . . . 54

3.4 Empirical Results . . . . . . . . . . . . . . . . 55

3.4.1 Dwelling Ownership and the Accumulation of Housing equity 55

3.5 Concluding Remarks . . . . . . . . . . . . . . . . . 65

$\begin{array}{lll}\text { A } & \text { Tables for Chapter } 1 & 78\end{array}$

B Tables for Chapter 2 $\quad 82$

C Tables for Chapter $3 \quad 99$

$\begin{array}{ll}\text { D Figures for Chapter } 1 & 107\end{array}$

$\begin{array}{lll}\text { E } & \text { Figures for Chapter } 3 & 117\end{array}$ 


\section{Chapter 1}

\section{Income, Consumption and Savings of Immigrant Families in Canada}

\section{$1.1 \quad$ Introduction}

Immigrants contribute to the host economy in many ways, such as in the supply of labour services and human capital, the generation of new demand for goods and services, and through savings and borrowing to support their consumption behaviour at different stages of the life cycles of their families. The economics literature on the experiences of immigrants in their new countries has focused primarily on the earnings of immigrants relative to the earnings of comparable native born. These studies often contain estimates of human capital earnings equations, typically pooled across sets of cross-sectional datasets, and focus on the relationships between an immigrant's year of arrival, years since migration, and the immigrant's earnings. ${ }^{1}$ A number of these studies find a decline in the success of recent immigrant arrival cohorts in terms of their labour market outcomes for the same number of years of residence in Canada. In essence, the process of assimilation appears to be progressively weakening over time.

\footnotetext{
${ }^{1}$ For Canadian evidence, see, for example, Baker and Benjamin (1994), McDonald and Worswick (1998), Bloom, Grenier, and Gunderson (1995), Aydemir and Skuterud (2005), and Green and Worswick (2012).
} 
The fact that recent immigrants to Canada have fared worse in terms of earnings relative to earlier cohorts naturally raises the question of whether the low earnings performance also leads to low consumption expenditures and consequently no real impact on savings behaviour. Alternatively, it may be that immigrant families anticipate high earnings growth once the family's earners have had a chance to become established in the Canadian labour market. Hence, in the first years after arrival in Canada, the immigrant family may have lower annual savings than otherwise similar Canadian-born families if the immigrant families are using assets or loans to support family consumption at a higher level than what would otherwise be possible given the family's low income immediately after arrival. Immigrant families may be able to offset the impacts of negative income shocks on family consumption by maintaining consumption expenditure through: 1) running down the assets they hold, 2) borrowing against future income, or 3) increasing labour supply. However, immigrant families may lack the assets to use in this capacity and may have difficulty accessing credit, so that the low incomes observed immediately after arrival in Canada may be associated with low consumption expenditure and low welfare.

There are many more studies on earnings of male immigrants than that of female immigrants (see for example, Chiswick (1978), Borjas (1985), LaLonde and Topel (1992), Baker and Benjamin (1994a) and Green and Worswick (2012)). A number of studies have focused on the wealth accumulation patterns of immigrants. Shamsuddin and DeVoretz (1998) study the wealth accumulation of Canadian-born and foreignborn households from 1977 to 1984 using data from the Survey of Consumer Finances of Statistics Canada. They find evidence of an inverted 'U'-shaped wealth-age profile for both Canadian and immigrant households. Using data from the 1979 Youth Cohort of the National Longitudinal Surveys, Amuedo-Dorantes and Pozo (2002) examine the wealth accumulation patterns of younger cohorts. Immigrants are found to accumulate less wealth and have less precautionary savings than native-born Americans.

Zhang (2003) investigates whether differences in wealth levels exist between immi- 
grants and the Canadian born. Using data from the 1999 Survey of Financial Security, Zhang finds that among married families, immigrants have higher wealth levels than their Canadian-born counterparts from the 40th to 90th percentiles of the distribution, with the wealth gap ranging between $\$ 20,000$ and $\$ 78,000$. Focusing on single families, a wealth gap of $\$ 14,000$ and $\$ 145,000$ is found in the $55^{\text {th }}$ to $95^{\text {th }}$ percentile range. Recent immigrants are found to have lower wealth levels than comparable Canadian-born families, whereas immigrants from the pre-1976 arrival cohorts have higher wealth levels.

Cobb-Clark and Hildebrand (2002) analyze similar issues using the US Survey of Income and Program Participation (SIPP). They find that the median wealth of American-born couples is 2.3 times larger than the median wealth level of immigrant couples. They also find a great deal of diversity in wealth levels across different immigrant families, and that this diversity is correlated with the source country. Immigrants from earlier arrival cohorts are found to hold relatively less wealth, while recent immigrants are found to hold more wealth. However, the opposite is true when the focus is on real estate wealth. ${ }^{2}$

A paper that is closely related to the current analysis is the study by Carroll, Rhee, and Rhee (1994). They analyze the savings behaviour of immigrants to Canada using the Survey of Family Expenditures (FAMEX) of Statistics Canada. Their focus is on seeing if immigrants retain their national attitudes towards saving after they arrive in the new country or whether their savings behaviour quickly assimilates towards the savings behaviour of the native born in the receiving country. They do not find evidence of cultural effects on the savings of immigrants in Canada. In a later paper using data from the 1980 and 1990 US Census, Carroll, Rhee, and Rhee (1999) find strong evidence that immigrants to the US from high-savings countries have higher savings than immigrants from low-saving countries. This result is in stark contrast to what they found in their earlier paper using Canadian data. However, the methods

\footnotetext{
${ }^{2}$ Finally, a related literature within economics relates to attempts to measure the impact of immigration on house prices and on rental prices. See, for example, Akbari and Aydede (2009) and Saiz (2003).
} 
and data used in the two studies are quite different, with the US Census data not containing information on consumption behaviour. The authors instead based their measures of savings on imputed changes in wealth holdings for immigrant groups between the two Census years.

Finally, the literature on the Family Investment Hypothesis (FIH) and, more generally, household decisions in immigrant married couples, is relevant for this current study. The central idea in this literature is that immigrant married women (assumed to be secondary earners in their families) may take on jobs shortly after arrival in the new country that provide reasonable earnings and support family consumption, but which may not have good opportunities for career advancement and earnings growth. This behavioural phenomenon is thought to facilitate the career advancement of their husbands (assumed to be the primary earner in the family), leading to higher wage growth, likely through the channel of investments in human capital accumulation. It is assumed that recent immigrant families are likely to be credit constrained and rely on the secondary earner in the household to support consumption while the primary earner invests in his own career. This idea of recent immigrant families facing credit constraints seems plausible given that they often have low incomes. Families that are credit-constrained will tend to have higher savings than what would otherwise be the case, since they will wish to borrow more at that particular point in time to finance higher consumption expenditure. A number of papers have attempted to find evidence in favour of the Family Investment Hypothesis with mixed results (see, for example, Baker and Benjamin, 1994, Worswick, 1999, Cobb-Clark and Crossley, 2004 and Goldner, Gottibovski and Kahana, 2009).

The current paper's main contribution is to test for differences in income, consumption and savings between immigrant and native-born families in Canada. To the best of our knowledge, this is the first time that consumption expenditure data has been used in a cross cohort analysis of the economic outcomes of immigrants in Canada. Also, given the fact that the Canadian Family Expenditure Survey has both detailed immigrant information and detailed education information (unlike many 
other data sets such as the Australian and American equivalents), the reduced form analysis of this chapter makes an important contribution to not only the Canadian literature on immigrant economic outcomes but also to the international literatures. Using information on consumption expenditure, it is possible to delve more deeply in the question of whether the low income experienced by many new immigrants also coincides with low consumption expenditure. The data employed are taken from the cross-sections spanning the years 1969 through 1992 of Family Expenditure Survey. Reduced form models of consumption expenditure, savings and changes in net assets are estimated that allow for differences by the immigrant status of the reference person of the household as well as by the arrival cohort, years-since-migration, and the source country region of the immigrant reference person.

\subsection{Data and Empirical Strategy}

In the empirical analysis, data are employed from the public use files of the Family Expenditure Surveys (FAMEX) (1969, 1974, 1982, 1984, 1986, 1990 and 1992)33. The survey has the advantage over other data available for immigrants because it contains detailed expenditures by Canadian households that cover their complete budgets for the reference year. Family expenditures include information on housing type, value of dwelling, mortgage, additions, renovations and installations; income by source, occupation, employment for reference person and spouse; household members, employment insurance and social assistance indicators; food and shelter; household communication, child care, household supplies; household furnishings and equipment; clothing; transportation; health care; personal care; recreation; reading materials and other printed matter; education; tobacco products and alcoholic beverages; interest

\footnotetext{
${ }^{3}$ For the 1978 FAMEX reference year, the information on the immigrant's year of arrival is highly aggregated, and so this year was not used as part of the regression analysis. The survey was also carried out in 1996; however, the immigration questions were not asked in that survey, so it is not useful for the current study. Unfortunately, the survey was discontinued after that year and replaced by the Survey of Household Spending which does not contain questions related to the immigration status of the household members.
} 
payments, games of chance, taxes, insurance payments and pension contributions, money gifts and contributions; and total expenditure. In each survey year, the sample is restricted to couples (married or common law) in economic families where the household reference person and the reference person's spouse are each between the ages of 22 and 64 . The FAMEX sample contains economic families residing in the 10 provinces of Canada, and the FAMEX is restricted to households residing in the 14 largest cities (all with populations of more than 100,000 people). All variables expressed in dollars were converted into 2007 equivalents using the Consumer Price Index for Canada.

I analyze two main dimensions of savings and wealth accumulation. First, I define a family's savings to be the difference between the family's after-tax income and expenditure. I then estimate reduced form expenditure and savings regressions in order to see how consumption and savings behaviour differs between immigrant and Canadian-born families. Second, I analyze net changes in assets and liabilities based on the answers to survey questions in the FAMEX data, and use regression analysis to compare the changes in the net assets over time of immigrant and Canadian-born families.

Table 1.1 contains sample means of the main variables in the analysis broken down by the immigrant status of the male reference person. We define a household as being an immigrant household if the male reference person is an immigrant. ${ }^{4}$ Compared to Canadian-born households, immigrant households earn $\$ 2,800$ less in term of total income. Mean after-tax income is very similar between immigrant and Canadianborn households, with immigrant households earning roughly $\$ 900$ less in terms of after-tax income. Immigrant households earn $\$ 4,900$ less in terms of wage and salary income than do the Canadian-born households. Immigrant households earn about $\$ 1,800$ more in terms of self-employment income than Canadian-born households.

\footnotetext{
${ }^{4}$ An alternative approach would be to define the immigrant status of the household based on the immigrant status of both the husband and the wife or of the household head. Unfortunately, we only have the immigrant status of the household head for the earlier FAMEX years and, in those years, the household head was always male. In order to maintain consistency, we define immigrant status for the family based on the immigrant status of the male household reference person.
} 
Mean consumption expenditures are very similar between immigrant and Canadianborn households, with immigrant households having roughly $\$ 700$ lower consumption spending levels than Canadian-born households. The savings variable is defined as the difference between household after-tax income and household consumption. ${ }^{5}$ Immigrant households have $\$ 220$ lower saving levels each year than do Canadian-born households, and this is consistent with the finding that after-tax income is lower for immigrants.

The change in net assets variable is defined as the net change in assets and liabilities. The change in net assets variable is positive for both groups of households, but it is greater $(\$ 4,860)$ for immigrants households than for Canadian-born households $(\$ 4,620)$. Combined with the sample means for the savings variable, this is preliminary evidence that over this stage of the life cycle (head and spouse between the ages of 22 and 64), immigrant households may have lower net savings than Canadian-born households.

From the proportions of households cross-tabulated by region of residence, it is clear that immigrant households are much more likely to reside in Ontario and British Columbia than are Canadian-born households. Given the differences in housing costs across the provinces, with both cities of Toronto and Vancouver having especially high costs of housing relative to other provinces in Canada, it is important to control for the region of residence in the analysis.

Immigrant reference persons are older on average than their Canadian-born counterparts, with the difference being approximately three years across the two samples. The educational distribution for immigrants is more dispersed, with more immigrant reference persons having 0 to 9 years of education and more having a university degree relative to the educational distribution for Canadians.

Figures 1.1 through 1.3 contain the non-parametric Kernel density estimates of the distributions of: after-tax income, savings, and change in assets. There are no

\footnotetext{
${ }^{5}$ The FAMEX surveys include detailed questions on different types of consumption expenditure. The consumption variable is aggregated from these questions and is reported in the FAMEX data file. Unlike the total expenditure variable, it does not include taxes.
} 
noticeable distributional differences in the after-tax income, savings, change in assets between immigrant and Canadian-born households. Since the early 1970s, the source country composition of immigrants to Canada has changed dramatically away from English language countries and European countries towards countries in Asia, Africa and Latin America. This demonstrates the need to control for immigrant source country in an analysis of the income, savings and wealth of immigrant households in Canada.

\subsection{Estimation Approach}

\subsubsection{Theoretical Framework and Reduced Form Estimation Approach}

While reduced-form analysis is employed in this paper, it is important to be clear about the kind of underlying economic framework that is being used to motivate the analysis. I have in mind a dynamic utility maximization problem for the married couple in which consumption, labour supply, and human capital investment decisions are being made in each period subject to a lifetime budget constraint and possibly also credit constraints. ${ }^{6}$ The married couple may have accumulated wealth that can be used to finance current consumption in excess of current income. In the absence of such wealth, consumption expenditure can only exceed current income if the family has access to credit.

\subsubsection{General Specification of Savings Equations}

I analyse the consumption and savings decisions of immigrant and Canadian-born households using a specification of an equation whose explanatory variables are consistent with the literature on immigrant earnings. I also estimate an equivalent model using the total income of the household so as to compare the income outcomes of im-

\footnotetext{
${ }^{6}$ See Worswick (1999) for an example.
} 
migrants in the FAMEX data to those found in earlier studies using other data such as the Census and the SCF. This also allows us to see whether or not the patterns found in the income analysis are similar to what is found in the consumption expenditure data or whether the patterns instead appears in the saving data (or perhaps in both the consumption and savings analyses). If both income cohort differences and consumption cohort differences are present then the income cohort patterns are affecting the expenditure behavior of the households and could be due to the income cohort effects reflecting differences in permanent income across the cohorts. Instead, if the income cohort effects are showing up in the savings data rather than in the consumption data then this would suggest that the income cohort effects are in fact temporary in nature and can be smoothed using assets and borrowing and so are not affecting the consumption behaviour of the household.

The general specification has the following basic form:

$$
Y_{i t}=X_{i t} \alpha+\alpha_{1} F B_{i}+\alpha_{2} Y S M_{i t}+\alpha_{3} Y S M_{i t}^{2}+\Sigma_{c=1}^{C-1}+\alpha_{4 i} d_{c i}+u_{i t}
$$

where $Y_{i t}$ represents one of the following variables: income, consumption, savings, and change in net assets. The vector $X_{i t}$ is a vector of household characteristics that includes five region of residence indicator variables (with Ontario as the default

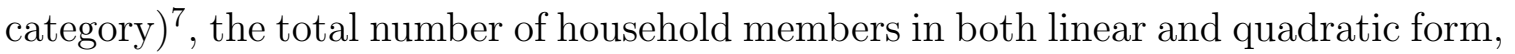
and a complete set of survey year indicator variables to allow for flexible periodspecific effects that are common to all households in the survey year (with the default year being 1986), the age, age squared, and education level of the husband and wife, and dummy variables for country of origin categories. The foreign-born indicator variable, $F B_{i}$, equals zero for the Canadian-born household heads. $Y S M_{i t}$ is the years-since-migration (capturing assimilation effects) of the male household reference

\footnotetext{
${ }^{7}$ While the sample is restricted to residents of the 14 largest cities in Canada, considerable variation in the cost of housing across these cities is present. Unfortunately, using the public use versions of the FAMEX, we cannot control for the actual city in which the household resides using the public use files and confidential versions of the FAMEX data are not available.
} 
person if he/she is an immigrant, and equals zero for the Canadian-born households. It enters in a linear/quadratic form and allows for variation in the dependent variable according to the duration of residence of immigrant households independent of the life cycle effects modelled through the age variables.

The $d_{c i}$ are immigrant arrival cohort dummy variables to capture arrival cohort effects (see Borjas (1985) for a discussion). The cohorts are identified as intervals of five years: 1) before 1946, 2) 1946-55, 3) 1956-60, 4) 1971-65, 5) 1966-70, 6) 1971-75, 7) 1976-80,8) 1981-85 and 9) 1986-90. Ideally, I would have liked to have used the same arrival cohort year groupings in my analysis. I do not include the arrival year in the regression, which could capture the period effect, to avoid collinearity problem, because year since migration can be treated as the difference between the period effect and arrival cohort effect. Also note that I deleted immigrant households who arrived in Canada in 1991 and 1992 from the 1992 sample, since it would have been difficult to attribute these households to the arrival cohort categories defined above. Finally, $\mathrm{u}_{i t}$ is an error term.

Identification of the years-since-migration effects from the arrival cohort effects relies on the assumption that period effects are common to all immigrants and the native born. Also, the fact that I have multiple years of cross-sectional data allows for the separate identification of arrival cohort effects from the years-since-migration effects. The former should be thought of as variation cross immigrant arrival groups that does not vary through time and cannot be explained by the other right-handside variables. The latter should be thought of as the dynamic adaptation of the dependent variable with more time as a resident in Canada that is common across all immigrant arrival cohorts. 


\subsection{Empirical Results}

\subsubsection{Income}

In Table 1.2, income regression estimates results are presented based on estimation over the pooled FAMEX data. The dependent variables are: total income, after-tax income, wage and salary income, and net self-employment income. The specification of the right-hand side variables follows the structure of equation (1). In addition, controls for region of birth of the male reference person are also included in the estimation whose results are listed in columns (2), (4), (6) and (8). The default category contains immigrants born in the United States, the United Kingdom, Western Europe or Northern Europe.

Based on the results listed in the first columns of each variable in Table 1.2, I calculate that immigrant households from the default arrival cohort (1966-70) had $\$ 6,520$ less total income, $\$ 4,150$ less after-tax income, $\$ 8,190$ less wage and salary income, $\$ 870$ higher self-employment income after 10 years in Canada than did otherwise similar Canadian-born households.

Predicted differences between immigrants and Canadian-born are calculated as follow:

$$
\text { Difference }=\alpha_{1}+\alpha_{2} * Y S M+\alpha_{3} * Y S M^{2}
$$

Predicted differences between each arrival cohort and Canadian-born are calculated as follow:

$$
\text { Difference }=\alpha_{1}+\alpha_{2} * Y S M+\alpha_{3} * Y S M^{2}+\alpha_{4 i},
$$

where $\alpha_{i}$ s are the same as that in equation 1.

Immigrant households that arrived in Canada after 1975 had significantly lower total income, after-tax income and wage income than the default arrival cohort (196670) with the largest differences relating to the most recent cohort (1986-90). The coefficients on the age variables indicate a convex relationship between total income, 
after-tax income, wage income and age of the household husband and wife. The coefficients on the years-since-migration variables for total income, after-tax income, and wage income are not statistically significant indicating that these variables do not appear to vary by duration of residence in Canada. All of the coefficients related to education of the household couple are statistically significant for total income, aftertax income and wage income. The higher is the education level the household couple, the higher is total income, after-tax income, wage income. The coefficients on household size are positive for total income and after-tax income, which is not surprising since this reflect a greater number of household members who can potentially work to generate income.

Based on the estimates presented in the second columns of each variable, we see significant variation in total income, after-tax income and wage income across the three country of origin groups. The dummy variables for country of origin in the regression measure the income of various immigrant groups relative to the income of immigrant households from the default group which is from the United States, the United Kingdom, Western Europe or Northern Europe - countries whose languages and educational institutions are reasonably similar to their Canadian equivalents. The coefficients on the immigrant indicator variable for the equations for after-tax income, wage income and self-employment income are not statistically significant, indicating that this group of immigrants are not significantly different once control for country of origin along each of these dimensions relative to the Canadian-born households, ceteris paribus. Immigrant households from the Southern and Eastern region have on average $\$ 4,230$ lower total income, $\$ 3,370$ lower after-tax income and $\$ 4,100$ lower wage income. Immigrant households whose source country is in the other region have $\$ 10,900$ lower total income, $\$ 8,080$ lower after-tax income, and $\$ 10,500$ lower wage income.

The coefficients on the immigrant arrival cohort dummy variables are generally not significant with the exception of the two 1980s cohorts for total income, aftertax income and wage income. The estimated magnitude falls when the country of 
origin indicators are included. Also, the coefficients on the age, household size and education variables are similar to what was found in the models without source country controls, exhibiting a convex and increasing relationship between total income, after-tax income, wage income and age.

In Figure 1.4, predicted differences are presented between an immigrant household and a Canadian-born household by years-since-migration and arrival cohort for each of the income measures considered in Table 1.2. In Figure 1.4, the strong negative cohort effects in the total income, after tax income and wage income analyses are apparent, as the curves for more recent arrival cohorts lie below the curves for the earlier arrival cohorts. This pronounced deterioration in incomes across immigrant arrival cohorts for the same duration in Canada is consistent with the findings in the immigration literature (see, for example, Aydemir and Skuterud, 2005, and Green and Worswick, 2012).

\subsubsection{Consumption Expenditure and Savings}

Next, my attention switches from income to consider the evolution of consumption and savings over time in Canada for immigrant families. Table 1.3 contains the regression estimates of models of consumption, net change in assets, the saving rate, and savings using the same specification of the right-hand side variables as in Table 1.2. Based on the results listed in the first column of Table 1.3, we can show that immigrants from the default arrival cohort (1966-70) had lower consumption expenditure, net change in assets and savings after 10 years in Canada than did otherwise similar Canadian-born households with the difference being roughly $\$ 4,900, \$ 1,990$ and $\$ 2,250$, respectively. The more recent arrival cohorts have lower consumption, net change in assets and savings than did the default arrival cohort (1966-70), indicating that the pronounced declines in the incomes earned by these families, as shown in the analysis of Table 1.2, did result in negative consequences both in terms of family consumption expenditures and in terms of saving.

In contrast, we do not see large differences in the savings rate (as shown in column 
5) between immigrant households and Canadian-born households. In addition, crosscohort differences in the savings rate equation are not statistically significant. The coefficients on the cohorts in the 1980s are negative and large in absolute value, but the standard errors are sufficiently large that the estimates are not significant different from zero. It may be that the actual savings behaviour, holding income fixed, does not differ significantly between immigrant and native born households, or between immigrant households across arrival cohorts. The large differences in the net change in assets and savings listed in column (3) and column (7) may simply be driven by the fact that the more recent cohorts have very low relative incomes, and this leads to low savings. However, this need not apply to the savings rate analysis, where the total level of savings is divided by the level of after-tax income. The coefficients on the years-since-migration variables are not statistically significant in any of these specifications, indicating that the differences in consumption, net change in assets, savings and saving rate between immigrants and the Canadian-born families do not appear to vary by duration of residence in Canada.

Switching attention to columns 2, 4, 6 and 8, we see significant variation in consumption, net change in assets, savings and the saving rate by source country. The coefficients on the immigrant indicator variables are not statistically significant after the inclusion of these indicators, indicating that immigrant families from the United States, the United Kingdom, Western Europe and Northern Europe do not differ significantly from Canadian-born households in terms of their consumption, net change in assets, savings, and saving rate, ceteris paribus. Immigrant families whose source country is in the Southern and Eastern European regions have significantly lower consumption each year at $-\$ 3,510$. Immigrant families whose source country is in the "other region" have significantly lower consumption levels, lower net change in assets, lower savings and lower saving rate each year at $-\$ 8,580,-\$ 2,030,-\$ 2,960$ and $15.1 \%$, respectively.

In Figure 1.5, predicted, differences are presented by arrival cohort and yearssince-migration, in the consumption, net change in assets, savings, and the savings 
rate between immigrant and Canadian-born households based on the estimates listed in the odd-numbered columns of Table 1.3. In Figure 1.5, the strong negative cohort effects are apparent as the profiles for more recent arrival cohorts lie below and to the left of the profiles for the earlier arrival cohorts. This pattern indicates that more recent arrival cohorts have lower consumption, net change in assets, savings, and savings rate relative to earlier arrival cohorts for the same number of years-sincemigration. It is worth noting that for the pre-1980 cohorts, the patterns are less clear for the variables of the net change in assets, savings and the savings rate.

\subsubsection{Sample Selection Problem and Out-Migration}

There are different categories of immigrants to Canada, including skilled worker class, refugee class, investment class and family support class. Investment class immigrants are more likely to be self-employed than are immigrants admitted under other categories. It is relatively harder for a refugee or family support class immigrant to find a job in Canada than skilled worker class because of their language, educational and work experience background. Some investment class immigrants return to their home country for some reason but leave their other family members in Canada and have housing in Canada. These cases may affect the regression results for immigrant income. The investment class immigrants generally have assets and/or housing equity in Canada or their home country and some of them have business in other countries. Even if they have low income in Canada, their consumption, asset change and saving may not be low. But FAMEX data does not include the category information about immigrants. If it is possible to know the immigrant category, the difference between each category and Canadian-born families can be figured out by adding a set of dummy variable for the category.

Picot, G. and Piraino P. (2013) study the selection bias in cross-section estimates of immigrants earning growth in Canada and find that the earning growth for lowearning immigrants is biased using cross-sectional data because of the selection effect,

while the estimation using longitudinal data has little bias which is in contrast with 
the existing literature in the US. Their results suggest that when we study on immigrants assimilation, we should take the different labour market, immigrant policies and immigrant characteristics into consideration.

\subsection{Concluding Remarks}

The income, savings, and wealth outcomes of immigrants in Canada have been examined using seven cross-sections of the Survey of Family Expenditures of Statistics Canada spanning the years 1969 to 1992. Recent immigrant households have significantly lower total income, after-tax income, and wage income than otherwise comparable Canadian-born households. Immigrant households have lower levels of consumption, net changes in assets, and savings. After controlling for the country of origin, there are no significant differences in the levels of consumption, net change in assets, and savings between immigrant households from the United States, the United Kingdom, Western Europe or Northern Europe. The savings rate is generally found to be similar between immigrant and Canadian-born households. No evidence is found of significant changes in savings with increases in the years-since-migration to Canada.

The result that recent immigrants to Canada perform worse than earlier arrival cohorts and Canadian-born is consistent with existing literature in Canada. Aydemir and Skuterud (2005) find low establishment wage effects for male immigrants although they are more educated and have more labour market experience than native-born counterparts. While female immigrants experience relatively large within-establishment wage disadvantages which is not explained by either lower returns to human capital or the types of jobs. They also find that evidence of negative sorting across establishments within Canadas major cities and regions and large unexplained wage gaps within establishments for recent immigrants and immigrants from non-traditional source regions. Green and Worswick (2012) find decline earnings across immigrant cohorts entering Canada in the 1980s and 1990s labour-market 
entry cohorts declining earnings shortly after arrival of recent immigrants.

Taken together, immigrants are found to have a disadvantage in terms of income, consumption and savings relative to natives. This disadvantage is greater for the most recent arrival cohorts compared to those who have been in the country longer. The results indicate that immigrant households from recent arrival cohorts are unable to insulate their consumption expenditures from the relatively low incomes received on average shortly after arrival in Canada. Savings rate behaviour is very similar in general between recent immigrant cohorts and the Canadian-born households indicating that the low savings levels of recent arrival cohorts are driven primarily by their relatively low incomes and not by differences in their propensities towards saving. This further emphasizes the need to reform immigration policy or provide them with more or better support once they arrive in Canada in order to lead to better income outcomes for new immigrants, since the historical evidence indicates the low household incomes result in low household consumption for recent cohorts of immigrant households.

The poor performance of recent immigrants to Canada may be partly driven by the selection criteria for immigrants. When employers hire workers, they do not consider immigrants working experiences and education in their home country. They prefer to hiring people who can make contribution to the company immediately or need less training. For skilled worker category, their English or French background, work experiences related to Canadian labour market, age at immigration and the country of origin are important factors to determine their assimilation process in Canada. Increasing the requirement of language fluency and working experiences, reducing immigrants age, improving the credential recognition, changing the source country composition, or changing the immigration system similar to other immigrant countries like New Zealand and Australia, may improve new immigrants economic outcome. 


\section{Chapter 2}

\section{Family Strategies and the Labor Supply of Married Immigrant \\ Women}

\section{$2.1 \quad$ Introduction}

It is important for immigration policy makers to understand married immigrant women's role in the Canadian labor market during their family's assimilation in Canada. Using an inter-temporal labor supply model, this paper aims to evaluate the strategies of immigrant families and tries to find out whether the new immigrant family's inability to borrow affects their labor market decisions. In the first years after arrival in Canada, immigrant families may face credit-constraints and thus be unable to smooth their consumption by borrowing against future labor income.

Long (1980) finds that the earnings of foreign-born females are higher than that of their native-born counterparts. He concluded that immigrant wives may have to work to help finance family consumption during their husbands' initial investments in schooling or job skills required in U.S. labor markets from the analysis of 1970 U.S. Census. To explain this labor supply pattern, later researchers referred to Long's findings as the Family Investment Hypothesis (FIH): immigrant families fac- 
ing credit-constraints may adopt a family investment strategy in the first years after immigration. Immigrant wives may work more hours to support family consumption if their husbands choose to invest in his human capital (for example, going to school or job training). The condition of being unable to borrow is necessary for the Family Investment Hypothesis (FIH). There are lots of researches on FIH after that. Some studies find supportive evidence to the Family Investment Hypothesis while others do not. For example, Beach and Worswick (1993) find a double-negative effect on the earnings for highly educated female immigrants by analyzing data from 1973 Job Mobility Survey of Statistics Canada and the empirical results support the Family Investment Hypothesis. Duleep and Sanders (1993) find that a married Asian female immigrant's decision to work is affected by whether she has a husband who invests in skills specific to the U.S. labor market by analyzing the 1980 U.S. Census data. Wooden and VandenHeuvel (1997) find that the presence of young children has a smaller effect on the full-time labor market decision for married immigrant women from non-English-speaking backgrounds by using Australian Population Census data. By analyzing the 1990 Survey of Income, Housing Costs and Amenities of Australia, Shamsuddin (1998) finds that immigrant women from non-English-speaking backgrounds are less likely to be employed and work more hours than native women or immigrant women from English-speaking backgrounds and labor supply of immigrant women is sensitive to government benefits. Worswick (1996) finds only weak evidence for the FIH by analyzing the 1981 and 1991 Census of Canada surveys using reducedform estimation for wages and labor supply. Baker and Benjamin (1997) find support for the Family Investment Hypothesis that immigrant wives take on "dead-end" jobs to finance their husbands' investments in human capital by analyzing data from the 1986 and 1991 Canadian Survey of Consumer Finances (SCF). Kim \& Varanasi (2010, Current Population Survey 1996-2002) find results consistent with FIH. Andersson (2011) finds that single immigrant women in Sweden with low income increase their working hours while those with high income reduce their working hours compared to native women, especially for non-European and Eastern and Southern European 
women by using a simulation approach.

Blau, Kahn, Moriarty and Souza (2003) find that the Family Investment model does not explain the immigrant behavior in the United States through the analysis of microdata from the U.S.Census of Population for 1980 and 1990. Cobb-Clark and Crossley (2004) examine Family Investment Hypothesis via another technique by analyzing data from the Longitudinal Survey of Immigrants to Australia (LSIA). They use principal applicant status rather than gender to identify the primary and secondary worker in the family. Their results imply that Family Investment Hypothesis is not well developed to explain all immigrant behaviour. Basilio, Bauer and Sinning (2009) do not find support for the Family Investment Hypothesis for immigrant families with credit constraints based on their analysis of data for West Germany. Kim and Varanasi (2010) find results consistent with Family Investment Hypothesis by analyzing data from the matched March Current Population Survey for 1996-2002.

The literature on the Family Investment Hypothesis (FIH) and, more generally, household decisions in immigrant married couples, is relevant for this current study. The central idea in this literature is that immigrant married women (assumed to be secondary earners in their families) may take on jobs shortly after arrival in the new country that provide reasonable earnings and support family consumption, but which may not have good opportunities for career advancement and earnings growth. This behavioural phenomenon is thought to facilitate the career advancement of their husbands (assumed to be the primary earner in the family), leading to higher wage growth, likely through the channel of investments in human capital accumulation. It is assumed that recent immigrant families are likely to be credit constrained and rely on the secondary earner in the household to support consumption while the primary earner invests in his own career. This idea of recent immigrant families facing credit constraints seems plausible given that they often have low incomes. Families that are credit-constrained will tend to have higher savings than what would otherwise be the case, since they will wish to borrow more at that particular point in time to finance higher consumption expenditure. A number of papers have attempted to find 
evidence in favour of the Family Investment Hypothesis with mixed results (see, for example, Baker and Benjamin, 1994, Worswick, 1999, Cobb-Clark and Crossley, 2004 and Goldner, Gottibovski and Kahana, 2009).

The differences in labor supply decisions between immigrant families and nonimmigrant families may be due to differences in preferences with respect to labor supply or due to credit constraint effects. Many of these studies, which employed reduced-form models, are not able to determine which one is the right explanation for any observed immigrant/non-immigrant labor supply differences. Some researchers use an inter-temporal model to explain people's labor supply under the assumption of perfect capital markets (Heckman and MaCurdy (1980), Jakubson (1988), and MaCurdy (1981,1983), Browning, Deaton and Irish (1985), Altonji (1986) and Reilly (1994)).

This paper is motivated in part by the analysis of Worswick (1999) of the effect of credit constraints on the hours of work of immigrant married couples and also the analysis of Zeldes (1989) of the effect of liquidity constraints on consumption. Worswick finds that credit constraints distort the immigrant wifes labor supply. Zeldes (1989) finds that liquidity constraints affect consumption in American families. While Runkle (1991) finds no evidence of liquidity constraints in his analysis of data from the Panel Study on Income Dynamics (PSID). Faruqui and Torchani (2012) find that about 23 percent of Canadian households are liquidity constrained in their analysis of data merged from two Canadian household surveys: the Canadian Financial Monitor (CFM) Survey and the Survey of Household Spending (SHS). Unlike Worswick (1999), who uses data only on labour supply, and Zeldes (1989), who uses only consumption data, I analyze both the hours of work and consumption expenditure decisions of the household in my empirical analysis. The census data used by Worswick (1999) did not contain consumption information, so he assumes separability between consumption and leisure which allows for the structural estimation equations (derived from the first order conditions of the household optimization problem) to be free of consumption information. Worswick (1999) is not able to test 
the credit constraint effects because there is no information on immigrants assets in the census data. The FAMEX data has a number of advantages relative to census data for the current research because it has detailed consumption expenditure data and asset information for immigrants. With this information, it is possible to test immigrants consumption smoothing behaviour and credit constraint effects. In this paper, I examine whether the credit constraints affect the immigrant wife's working hour decision and the family's consumption decisions.

This paper will evaluate the empirical support for the Family Investment Hypothesis for immigrant married couples in Canada, and has three contributions: First, a structural model of inter-temporal labor supply of immigrant and non-immigrant families decisions is constructed. In this model, the immigrant family maximizes the expected lifetime utility by choosing how many hours to work and how much to consume subject to the asset accumulation constraint and credit constraint. With this model, it is possible to find out whether the differences in labor supply decisions between immigrant and non-immigrant families are driven by the family's preferences or credit constraints and whether the credit constraints affect family's consumption behaviour. Second, estimation equations are derived; and finally, estimation of the model is carried out by analyzing data from the Family Expenditure Surveys (FAMEX) of Statistics Canada for the years 1984, 1986, 1990 and 1992. As noted in the preview chapter, the other survey years they do not have immigrant spouses information and are thus excluded.

This paper is structured as follows. Section 2 presents a structural model of intertemporal labor supply decisions in married couples which allows for credit constraints and endogenous labour force participation decisions by the wife. Section 3 describes our method to estimate an intertemporal substitution condition using synthetic cohort data. Section 4 describes the data and sample used in estimation. Section 5 presents the results of the estimation of the model. Conclusions are presented in Section 6. 


\subsection{The Model}

Tobit type models are most often used to analyze labor supply for married women. Heckman and MaCurdy (1980) and Blundell and Walker (1986) use a Tobit model to analyze the married women's work decision. Cogan (1981) provides a model of female labor supply and participation with a fixed cost to work. Moffitt (1982) develops a labor supply model with minimum hours constraint. Zabel (1993) studies the relationship between labor force participation and working hours for married women by comparing Heckman's model, Cogan's fixed-cost model, and Moffiitt's minimum constraint model, and finds the simple Tobit-type models do not fit the data well. The model of this paper differs from many standard dynamic labor supply models that have the assumption of perfect capital markets (see Heckman and MaCurdy (1980), MaCurdy (1981), Browning, Deaton and Irish (1985), Altonji (1986), Jakubson (1988) and Reilly (1994)).

The model below is based on that of Worswick (1999). The family maximizes its expected lifetime utility by choosing family consumption and working hours for both the husband and the wife.

$$
\max E_{t} \sum_{k=0}^{T-t} \frac{U\left(C_{t+k}, L_{H, t+k}, L_{W, t+k}\right)}{(1+\rho)^{k}}
$$

Subject to the asset accumulation constraint:

$$
A_{t+k}-\left(1+r_{t+k}\right) A_{t+k-1}=W_{H, t}\left(\bar{T}-L_{H}\right)+W_{W, t}\left(\bar{T}-L_{W}\right)-P_{t+k} C_{t+k}
$$

and the credit constraint (modelled as a wealth non-negativity constraint following Zeldes (1989)):

$$
A_{t+k} \geqslant 0, \quad k=0,1,2, \cdots, T-t
$$

where $U\left(C_{t+k}, L_{H, t+k}, L_{W, t+k}\right)$ is the family utility function, $C_{t}$ is family consumption, $L_{H, t}$ is the husband's leisure time, $L_{W, t}$ is the wife's leisure time, $\rho$ is the rate of time 
preference, $E_{t}$ is the expectation operator conditional on information available at time period $t, T$ is the final time period, $A_{t}$ is non-human wealth at the end of the time $t$, $r_{t}$ is the interest rate, $W_{H, t}$ is the husband's wage rate, $W_{W, t}$ is the wife's wage rate, $P_{t}$ is the price of the commodity and is normalized to be 1 , and $\bar{T}$ is the maximum hours people can work in each time period, which is set to be a year ()24*365 $=8760$ hours) in our empirical analysis. Let $H_{H, t}$ and $H_{W, t}$ be the husband's and wife's working hours, then $\bar{T}=L_{H, t}+H_{H, t}=L_{W, t}+H_{W, t}$. We also assume that the real interest rate is constant, $r_{t}=r$.

The family can sell its assets at an interest rate of $r$ in the beginning of each period but cannot let its assets be negative at the end period. The family will choose for the wife not to work if the return on the wife's work is less than the disutility from the wife's work.

For simplicity, we assume that the husband works in all periods. Assume that the wife's working hours are non-negative for all periods, allowing for the possibility that she may not always work for wages.

$$
H_{W, t+k} \geqslant 0, \quad k=0,1,2, \cdots, T-t
$$

The first order necessary conditions are:

$$
\begin{gathered}
U_{C, t}=\lambda_{t} \\
U_{L_{H}, t}=\lambda_{t} W_{H, t} \\
U_{L_{W}, t}=\lambda_{t} W_{W, t}+\mu_{t}
\end{gathered}
$$


and the Euler equation (see Zeldes (1989) for the derivation):

$$
\begin{gathered}
U_{C, t}=E_{t} \frac{U_{C, t+1}\left(1+r_{t}\right)}{1+\rho}+\delta_{t} \\
\lambda_{t}=\frac{1}{1+\rho} E_{t} \lambda_{t+1}\left(1+r_{t+1}\right)+\delta_{t}
\end{gathered}
$$

where $U_{C, t}, U_{L_{H}, t}, U_{L_{W}, t}$ are the partial derivatives of $U$ with respect to consumption, husband's leisure time and the wife's leisure time, $\lambda_{t}$ is the Lagrange multiplier for the asset accumulation constraint, $\mu_{t}$ is the Lagrange multiplier for the nonnegativity constraint on the wife's working hours, and $\delta_{t}$ is the Lagrange multiplier for the non-negative asset constraint (2.3). If the family is credit constrained at time $t$, then $\delta_{t}>0$; otherwise, $\delta_{t}=0$. If $\delta_{t}$ is positive, then the credit constraint is binding, and the end of period assets equal zero. $\delta_{t}$ is the extra utility gained by relaxing the credit constraint. If the family is not credit constrained at time $t$, then $\delta_{t}=0$, which implies that the marginal utility today equals the expected discounted marginal utility tomorrow (see equation 2.8). If the family is credit constrained, this condition does not hold. The family would like to borrow against future income which will drive the end of period assets to below zero. So the family would choose to allocate more assets to future periods under the credit constraint than what would be the case without the credit constraint binding.

The Euler equation (2.8) implies that if the family is credit constrained, the marginal utility of consumption is higher today relative to tomorrow than what would be the case with no credit constraint. If the wife works a positive number of hours, then $\mu_{t}=0$. The ratio of equation (2.7) and (2.5) becomes:

$$
\frac{U_{L_{W}, t}}{U_{C, t}}=W_{W, t}
$$


This states that at the solution, if the wife works positive hours, then the family's marginal rate of substitution between the wife's leisure time and family consumption equals the wife's wage. Equation (2.10) shows that the family is willing to trade the leisure time of the wife with the family consumption according to the wife's wage rate. This condition holds only for families with positive hours worked for the wife.

\subsection{Derivation of the Estimating Equations}

Assume that the family utility function is separable and has the following form:

$$
U\left(C_{t} ; L_{H, t} ; L_{W, t}\right)=\Phi_{t}\left\{\frac{L_{W, t}^{\alpha_{W}}}{\alpha_{W}}+\Psi_{t} \frac{L_{H, t}^{\alpha_{H}}}{\alpha_{H}}+\Theta_{t} \frac{C_{t}^{\alpha_{C}}}{\alpha_{C}}\right\}
$$

where $\Phi_{t}, \Psi_{t}$ and $\Theta_{t}$ are age-specific modifiers of taste, $\alpha_{H}, \alpha_{W}$ and $\alpha_{C}$ are fixed parameters related to both spouses' leisure time and to consumption. This specification has been used by Heckman and MaCurdy (1981), MaCurdy (1983), Altonji (1986), Reilly (1994) and Worswick (1999).

Assume the following functional form for the taste shifters:

$$
\begin{aligned}
& \Phi_{t}=\exp \left\{X_{1 t} \beta+\varepsilon_{t}\right\} \\
& \Psi_{t}=\exp \left\{X_{2 t} \gamma+\mu_{t}\right\} \\
& \Theta_{t}=\exp \left\{X_{3 t} \theta+\nu_{t}\right\}
\end{aligned}
$$

where $X_{t}$ is a vector of exogenous characteristics which can be the number of children, age, etc. $\beta, \gamma$ and $\theta$ are parameter vectors, $\varepsilon_{t}, \mu_{t}$ and $\nu_{t}$ are error terms.

The $X_{1 t}$ in $\Phi_{t}$ will shift the weight on both spouses' leisure time and family consumption between period $t$ and all other periods. The $X_{2 t}$ in $\Psi_{t}$ will shift the weight on 
the wife's leisure time relative to the husband's leisure time and family consumption. The $X_{3 t}$ in $\Theta_{t}$ will shift the weight on family consumption relative to both spouses' leisure time.

Then equation (2.10) can be expressed as:

$$
\frac{L_{W, t}^{\alpha_{W}-1}}{\Theta_{t} C_{t}^{\alpha_{C}-1}}=W_{W, t}
$$

Taking the natural logarithm of both sides and rearranging:

$$
\ln L_{W, t}=X_{3 t} \beta^{*}+\alpha_{C}^{*} \ln C_{t}+\alpha_{W}^{*} \ln W_{W, t}+\nu_{t}^{*}
$$

where $\beta^{*}=\frac{\theta_{t}}{\alpha_{W}-1}, \nu_{t}^{*}=\frac{\nu_{t}}{\alpha_{W}-1}$ and

$$
\begin{aligned}
& \alpha_{C}^{*}=\frac{\alpha_{C}-1}{\alpha_{W}-1} \\
& \alpha_{W}^{*}=\frac{1}{\alpha_{W}-1}
\end{aligned}
$$

Equation (2.16) implies that the wife's leisure time is a function of family characteristics, $X_{3 t}$, the log of family consumption, and the log of the wife's wage. Equation (2.16) can be estimated using data for period $t$. Therefore, it can be estimated using cross-sectional data. The above equations are derived under the assumption of the wife working positive hours. So a sample selection method is used to estimate equation (2.16). 


\subsubsection{Endogeneity of the Wifes Wage and Family Consump- tion}

Following the approach of Worswick (1999), I treat both the hourly wage rate of the wife and the family consumption expenditure variable as potentially endogenous. The hourly wage rate could be statistically endogenous since the wife's working hours are calculated by the summation of part-time weeks multiplied by $16^{1}$ and fulltime weeks multiplied by $40^{2}$, and the hourly wage rate is calculated by annual wages divided by the total number of working hours. The measurement error in this estimate will in general be correlated with our hours of work measure. Hence, it will be important to instrument for the wife's wage. The family consumption expenditure variable is endogenous to the familys problem and so must be treated as an endogenous right-hand-side variable in the econometric analysis. Consequently, both family consumption and the wife's wage are treated as endogenous, and the instrumental variables method is used to estimate these two variables as follows:

The hourly wage rate could be statistically endogenous since the wife's working hours are calculated by the summation of part-time weeks multiplied by $16{ }^{3}$ and full-time week multiplied by $40^{4}$ and the hourly wage rate is calculated by annual wages divided by the total number of working hour. The measurement error in this estimate will in general be correlated with our hours of work measure. Hence, it will be important to instrument for the wife's wage. Family consumption and the wife's wage are treated as endogenous, and the instrumental variables method is used to estimate these two variables as follows:

$$
\ln C_{t}=M_{t} \beta_{C}+\varepsilon_{C, t}
$$

\footnotetext{
${ }^{1}$ Our estimate of the average hours for a part-time worker.

${ }^{2}$ Our estimate of the average hours for a full-time worker.

${ }^{3}$ Our estimate of the average hours for a part-time worker.

${ }^{4}$ Our estimate of the average hours for a full-time worker.
} 


$$
\ln W_{W, t}=M_{t} \beta_{W}+\varepsilon_{W, t}
$$

where $M_{t}$ is a vector of exogenous characteristics that contains variables not included in $X_{3 t}, \beta_{C}$ and $\beta_{W}$ are vectors of parameter; $\varepsilon_{C, t}$ and $\varepsilon_{W, t}$ are error terms.

Substituting equations (2.19) and (2.20) into equation (2.16),

$$
\begin{aligned}
\ln L_{W, t} & =X_{3 t} \beta^{*}+\alpha_{C}^{*} M_{t} \beta_{C}+\alpha_{W}^{*} M_{t} \beta_{W}+\varepsilon_{t}^{*} \\
& \equiv Z_{t} \beta+\varepsilon_{t}^{*}
\end{aligned}
$$

where $Z_{t}$ contains variables not included in $X_{3 t}$, and $\varepsilon_{t}^{*}=\alpha_{C}^{*} \varepsilon_{C, t}+\alpha_{W}^{*} \varepsilon_{W, t}+\nu_{t}^{*}$.

Define a participation index to take account of selection:

$$
I_{t}^{*}=\ln \bar{T}-Z_{t} \beta-\varepsilon_{t}^{*}
$$

where

$$
I_{t}^{*} \begin{cases}\geq 0 & \text { if the wife works; } \\ <0 & \text { otherwise. }\end{cases}
$$

For the families with wives working, equation (2.19), (2.20) and (2.21) become:

$$
\begin{gathered}
\ln C_{t}=M_{t} \beta_{C}+E_{t}\left\{\varepsilon_{C, t} \mid \varepsilon_{t}^{*} \leq \ln \bar{T}-Z_{t} \beta\right\}+\xi_{C, t} \\
\ln W_{W, t}=M_{t} \beta_{W}+E_{t}\left\{\varepsilon_{W, t} \mid \varepsilon_{t}^{*} \leq \ln \bar{T}-Z_{t} \beta\right\}+\xi_{W, t} \\
\ln L_{W, t}=Z_{t} \beta+E_{t}\left\{\varepsilon_{t}^{*} \mid \varepsilon_{t}^{*} \leq \ln \bar{T}-Z_{t} \beta\right\}+\xi_{t}
\end{gathered}
$$

where $E_{t}\left\{\varepsilon_{C, t} \mid \varepsilon_{t}^{*} \leq \ln \bar{T}-Z_{t} \beta\right\}, E_{t}\left\{\varepsilon_{W, t} \mid \varepsilon_{t}^{*} \leq \ln \bar{T}-Z_{t} \beta\right\}$ and $E_{t}\left\{\varepsilon_{t}^{*} \mid \varepsilon_{t}^{*} \leq\right.$ $\left.\ln \bar{T}-Z_{t} \beta\right\}$ are the expectations of $\varepsilon_{C, t}, \varepsilon_{W, t}$ and $\varepsilon_{t}^{*}$ conditional on the wife's working. $\xi_{C, t}, \xi_{W, t}$ and $\xi_{t}$ are mean zero error terms over the sample of families with the wife working. 
Assume the following joint normal distribution for $\varepsilon_{C, t}, \varepsilon_{W, t}$, and $\varepsilon_{t}^{*}$, we have the following

$$
\left(\begin{array}{c}
\varepsilon_{C, t} \\
\varepsilon_{W, t} \\
\varepsilon_{t}^{*}
\end{array}\right) \sim N\left[\left(\begin{array}{l}
0 \\
0 \\
0
\end{array}\right),\left(\begin{array}{ccc}
\sigma_{C}^{2} & \sigma_{C W} & \sigma_{C L} \\
\sigma_{C W} & \sigma_{W}^{2} & \sigma_{W L} \\
\sigma_{C L} & \sigma_{W L} & \sigma_{L}^{2}
\end{array}\right)\right]
$$

where $\sigma_{C}^{2}, \sigma_{W}^{2}$ and $\sigma_{L}^{2}$ are variances for $\varepsilon_{C, t}, \varepsilon_{W, t}$, and $\varepsilon_{t}^{*}$, respectively. $\sigma_{C W}, \sigma_{C L}$ and $\sigma_{W L}$ are covariances between these error terms.

Equations (2.23), (2.24) and (2.25) can be rewritten as:

$$
\begin{gathered}
\ln C_{t}=M_{t} \beta_{C}+\frac{\sigma_{C L}}{\sigma_{C}} I M R_{t}+\xi_{C, t} \\
\ln W_{W, t}=M_{t} \beta_{W}+\frac{\sigma_{W L}}{\sigma_{W}} I M R_{t}+\xi_{W, t} \\
\ln L_{W, t}=Z_{t} \beta+\sigma_{L} I M R_{t}+\xi_{t}
\end{gathered}
$$

where $I M R_{t}=\phi\left(\ln \bar{T}-Z_{t} \beta\right) / \Phi\left(\ln \bar{T}-Z_{t} \beta\right)$ is the Inverse Mill's Ratio, and $\phi(\cdot), \Phi(\cdot)$ stand for the standard normal density function and distribution function.

\subsubsection{Heckman Selection Model}

The equation (2.28) describes the leisure (working hours) decision of the immigrant wife. Immigrant wife has to choose to work, and then her working hours can be observed. If this decision is made randomly, then it is okay to ignore that not all wages are observed and ordinary regression could be used to fit the working hours decision model. But the assumption is unlikely to be true; the immigrant wife who has low wages and several kids may be unlikely to choose to work because her earnings may not be able to cover the daycare fees, and thus the sample of observed is biased upward. The Heckman selection model is used to address this selection bias problem. 
Equation (2.28) can be estimated using Heckman's method. First, we use the Probit estimator to estimate the wife's participation decision, equation (2.22), over the entire sample. Next, we compute the Inverse Mill's ratio, $I M R_{t}$ that will be used in the estimation of equations (2.26), (2.27) and (2.28). These estimates are consistent but not asymptotically efficient. This method is widely used in empirical research in which a sample selection issues are present.

To derive the estimation equation of Euler equation for consumption, assume $r_{t}=r$, and rewrite equation (2.8) as:

$$
U_{C, t}=\frac{(1+r)}{(1+\rho)} E_{t} U_{C, t+1} e^{\Gamma_{t}}
$$

where

$$
\Gamma_{t} \begin{cases}>0 & \text { if the family is credit constrained; } \\ =0 & \text { otherwise. }\end{cases}
$$

Rational expectations imply:

$$
\frac{(1+r) U_{C, t+1}}{(1+\rho) U_{C, t}} e^{\Gamma_{t}}=1+v_{t+1}
$$

where $v_{t+1}$ is an expectation error.

Taking the natural logarithm of both sides of equation (2.30), substitute the partial derivative of the utility function with respect to consumption and rearrange:

$$
\ln C_{t+1}-\ln C_{t}=a_{t+1}+b^{*} \Gamma_{t}-\left(X_{3 t+1}-X_{3 t}\right) \theta^{*}+\zeta_{t+1}
$$

where $a_{t+1}=\frac{\ln (1+\rho)-\ln (1+r)+E_{t} \ln \left(1+v_{t+1}\right)}{\alpha_{C}-1}, \theta^{*}=\frac{\theta}{\alpha_{C}-1}, b^{*}=-\frac{1}{\alpha_{C}-1}, \zeta_{t+1}=\frac{\nu_{t}-\nu_{t+1}+\eta_{t+1}}{\alpha_{C}-1}$ and $\eta_{t+1}$ is an expectation error. 
We could assume that $a_{t+1}$ is same for immigrant and native families, i.e., the rate of time preference, $\rho$, and the distribution of the expectation errors are the same. However, this assumption is strong. Then the differences $a_{t+1}+b^{*} \Gamma_{t}$ can be considered as the differences in the effects of the credit constraints. The three parts in $a_{t+1}+b^{*} \Gamma_{t}$ are three sources which can not be distinguished by the model. All of them may lead to differences in $a_{t+1}+b^{*} \Gamma_{t}$. First, differences in $\rho$, the rate of time preference, between immigrant and non-immigrant families, which appears in $b_{t+1}$, could explain these differences. Second, differences in the distribution of the forecast error, $v_{t+1}$, between the two groups, could explain the differences in $a_{t+1}+b^{*} \Gamma_{t}$. Third, credit constraints, as represented by differences in $\Gamma(t)$, the credit constraint multiplier, between immigrant and non-immigrant families could explain these differences. It is possible to examine the effects of credit constraints by defining a household affected by a credit constraint, as done by Zeldes(1989). We assume that immigrant and nonimmigrant households have the same forecast error distribution, which implies that $E_{t}\left\{\ln \left(1+v_{t+1}\right)\right\}$ is the same for immigrant and non-immigrant families. ${ }^{5}$

Since differences in the rate of time preference, $\rho$ are assumed to be same, the differences in the credit constraint multiplier $\Gamma(t)$ between immigrant and non-immigrant families can be identified in the structural model. Immigrant families may have lower value of $\rho$ than Canadian-born families. They are more likely to save rather than consume because the expected future income is less than the current income. $\rho$ is likely to rise as the amount of savings rises. So families will limit their savings to the amount at which $\rho=r$. The variable of the net change in assets and liabilities provides us with the possibility to test the credit constraint effect on labour supply behaviour and consumption behaviour. Therefore, the difference in the values of the parameters $a_{t+1}+b^{*} \Gamma_{t}$ between immigrant and non-immigrant families can be used to

\footnotetext{
${ }^{5}$ Similar assumption can be seen in both the dynamic labor supply literature (MaCurdy (1983)) and in the dynamic consumption literature (Zeldes (1989) and Runkle (1991)).
} 
decide whether we can use the credit constraint to explain differences in the working hours between immigrant and non-immigrant wives. This procedure is an improvement over Worswick (1999), which was unable to test for credit constraint due to a lack of suitable information in the Canadian Census data.

\subsection{The data and Empirical Strategy}

The data employed for the estimation of labor supply functions are drawn from the public use files of the Family Expenditure Surveys (FAMEX) (1984, 1986, 1990 and 1992) of Statistics Canada. We do not include the other four years $(1969,1974,1978$ and 1982) of the FAMEX surveys because of a lack of the information about the immigrant wife's source country. The survey carried out in 1996 did not include the immigration information, so it is not useful for the current study. The survey was replaced by the Survey of Household Spending after 1996, which unfortunately does not contain questions related to the immigration status of the household members. FAMEX data is the best available data for our study because it contains information about consumption, education and labor supply. The Census data used by Worswick (1999) does not contain consumption information. He uses family level data on married couples from Canada's Census data, which contains hours information but not consumption data. Consequently, he could not analyze how credit constraints affect the family's consumption behavior. We use the FAMEX data in our analysis. The FAMEX data has detailed information about durable and non-durable consumption expenditures.

We do not include the families for which one of the spouses is Canadian-born. Because the Canadian-born spouse has Canadian education and connections, this kind of family may not face the same credit constraint as families where both spouses are 
immigrants. In each survey year, the sample is restricted to couples (married or common law) in economic families where the household reference person and the reference person's spouse are both immigrants and between the ages of 25 and 59 . The FAMEX sample contains economic families residing in the 10 provinces of Canada, and the FAMEX is restricted to households residing in the 14 largest cities (all with populations of more than 100,000 people). The sample contains 1518 immigrant families and 9765 Canadian-born families. All variables expressed in dollars were converted into 2007 equivalents using the Consumer Price Index for Canada.

The respondents are not asked their annual working hours in the FAMEX surveys. Consequently, we approximate annual working hours by multiplying the number of weeks worked and an estimate of the usual number of hours worked per week. The data include the numbers of part-time and full-time working weeks. We assume parttime work is 16 hours a week, and that full-time work is 40 hours a week. This calculation will introduce measurement error, but since the annual working hours on the left hand side of the regression, this measurement error will not affect the estimated coefficients of key variables. The hourly wage is calculated as the annual earnings divided by the annual working hours. This procedure introduces the possibility of statistical erogeneity for the hourly wage rate in equation (2.18). Because we can only observe the wife's working hours if she works, a potential sample selection bias exists. The Heckman regression command in STATA is used to address the sample selection issue. This procedure is done in two steps. First, we use probit estimation to estimate the wife's participation decision. The consumption level and wife's wage rate are modelled as a function of age, age squared, education, wife's mother tongue, a dummy variable for wife being foreign-born, year-since-migration and its square, arrival cohorts, residence region dummies and time dummies. The FAMEX has questions related to a list of family expenditure items. We add all of 
the annual expenditure data on food, housing, etc. to generate a measure of family consumption. ${ }^{6}$ To estimate the Euler equation (2.31), because FAMEX is not a panel data set, we use synthetic cohort means to derive panel-like data based on the wife's four arrival cohorts (before 1961, between 1961 and 1970, between 1971 and 1980, between 1981 and 1992), six birth cohorts (20's, 30's, 40's, 50's, 60's, 70's), three source country dummies (from UK, USA, North and West Europe; from South and East Europe; from all other countries) in the estimation, similar to the method used by Browning, Deaton and Irish (1985) and Worswick (1999). There are 256 subgroups with observations. ${ }^{7}$

We estimate the Euler equation in two ways. First, we use a dummy variable indicating that the family is likely to be credit constrained in equation (2.22) to estimate the Euler equation for consumption. The families are divided into two groups: constrained and not constrained. Zeldes (1989) defines the "liquidity-constraint" group of those with zero wealth or a wealth-income ratio less than two months' net income. We define a family as credit constrained if the net change in assets and liabilities of the family is less than two months' net income. If the credit constraint does not play a role, then the coefficient on credit dummy will not be significant. Second, we split the sample into two groups. Group I is for families likely to be credit constrained, and group II is for families unlikely to be credit constrained according to the former definition of credit constraint. Then we estimate the Euler equation by adding the family's disposable income into equation (2.22) for the two groups separatively, as

\footnotetext{
${ }^{6}$ Expenditures include: all food; shelter: rented, owned, other accommodation, water, fuel, electricity; property taxes; household operation: communication, child care, laundry, cleaning, pet care, household supplies; household furnishing, equipment, services related to furnishings and equipment; expenditure on clothing; auto and truck purchase and operation, rented vehicles, local, commuter, intercity transportation services; health care; personal care: expenditure on personal care supplies, equipment and services; recreation; reading materials and other printed matter; education: supplies, textbooks, tuition, services; tobacco products and alcoholic beverages; dues to unions and professional associations; retirement and pension fund payments; expenditures on persons outside spending unit and charitable organizations.

${ }^{7}$ Worswick (1999) used ninety subgroups.
} 
done by Zeldes (1989). If the credit constraint does not bind, then the estimation results should be similar for both groups, and the coefficient on income should be insignificant. If the credit constraint binds, then the coefficient on income should be significant for group I and insignificant for group II.

Table 2.1 contains sample means of the main variables. Immigrant married women work about 100 hours more than Canadian-born married women on average. The hourly wage rate for immigrant married women is $\$ 3.26$ lower than that of Canadianborn married women. Immigrant married women are less likely to work on average than Canadian-born married women. Immigrant husbands work 46 hours less than Canadian-born husbands and have about $\$ 3.26$ lower wage rate. Both the immigrant husband and wife are older than Canadian-born counterparts on average. Immigrant families have about $\$ 900$ lower overall consumption but spend $\$ 1,000$ more on food consumption than Canadian-born families. Immigrant families are more likely to have children above 6 years old than Canadian-born families.

Table 2.2 and Table 2.3 contain the sample means for selected variables by year. Immigrant married women are less likely to work each year except 1984, but they work more hours in 1984, 1986, 1990 and 1992 than Canadian-born married women. Immigrant married women are older than Canadian-born married women on average for each survey year. Immigrant husbands work fewer hours than Canadian-born husbands except in 1986. Both immigrant husbands and wives have lower hourly wage rates than Canadian-born husbands and wives. Immigrant families consume less each year except in 1986. Each year, immigrant families spend more on food consumption than Canadian-born families.

Table 2.4 contains the sample means by source-country groupings. Immigrant married women from UK, US, North and West Europe and other countries group are more likely to work than immigrant married women from South and East Europe. 
Immigrant married women from South and East Europe and the "other" countries work more than 100 hours longer than Canadian-born married women and those from UK, US, North and West Europe. Immigrant married women from South and East Europe and other countries have a wage rate that is $\$ 5.3$ lower than Canadian-born married women. Immigrant married women from the UK, US North Europe and West Europe earn the highest hourly wage rate. Immigrant families from the "other" countries are more likely to have children under 12 than Canadian-born families and families from the UK, US and Europe. Immigrant families with wives from the UK, US, North and West Europe have much higher durable and non-durable consumption expenditure than Canadian-born families and other immigrant families. Immigrant married women from the UK, US and Europe are older than Canadian-born married women and those from other countries. All immigrant families with wives from each country group spend more on food consumption than Canadian-born families

Tables 2.5, 2.6 and 2.7 contain the sample means for the 1971-80 arrival cohorts for immigrant married women from UK,US, North and West Europe, South and East Europe, other countries. Immigrant married women from UK, US, North and West Europe who arrive between 1971 and 1980 work more hours in 1984 than 1986. Their families consume more on food consumption in 1984 than other years, and they are more likely to have children between 7 and 9 in 1984. Immigrant married women from South and East Europe who arrive between 1971 and 1980 work more as they stay in Canada. They are more likely to have children between 10 and 12 in 1984 . Immigrant married women from other countries who arrive between 1971 and 1980 work less as they stay in Canada. Immigrant married women from South and East Europe work more hours than those from UK, US, North and West Europe and have the lowest wage rate each year. Immigrant married women's hourly wage rate is generally increasing by year except those from other countries. Immigrant married 
women from UK, US, North and West Europe are more likely to work than those from South and East Europe, and they have the highest wage rate each year.

\subsubsection{Choice of Instrumental Variable}

As noted above, The log of the family's consumption expenditure and the log of the wife's wage are treated as endogenous. The variables used as instruments are the husband's occupation, the wife's age, the wife's education, the wife's first language and the region of residence of the family. These variables are assumed to affect the overall lifetime wealth of the household and hence affect the level of consumption at each point in time through the lifetime budget constraint of the household (which can be derived by summing the asset accumulation constraint across time). The wifes education and language fluency variables determine in part the wifes wage (as indicated by human capital theory) and so these are valid instruments for the hourly wage variable in this model. The identifying assumption is that education and occupation do not affect the underlying preferences of the family and hence do not appear as taste shifters in the households first order conditions.

\subsection{Empirical Results}

The estimation results for equation (2.28) are presented in Table 2.8. The log of the family's consumption expenditure and the log of the wife's wage are treated as endogenous. ${ }^{8}$ The variables used as instruments are the husband's occupation, the wife's age, the wife's education, the wife's first language and the region of residence of the family. These variables will affect income but not the preference on working hours and consumption, so they are not showing in the utility function. The curvature

\footnotetext{
${ }^{8}$ The family consumption is a choice variable. The wage is not a choice variable, but is calculated by earnings divided by hours.
} 
parameter on the consumption, $\alpha_{C}$, is - 0.35 and the curvature parameter on the wife's leisure time, $\alpha_{W}$, is $-8.66 .{ }^{9}$ They are calculated from equation (2.17) and (2.18) based on the estimation of the coefficient on the log of the family consumption and the log of the wife's wage rate. ${ }^{10}$. The default group is the family whose wife arrived in Canada between 1981 and 1992. The coefficient on FB, a dummy variable identifying whether the family is immigrant, indicates that the wife in default group has significantly more leisure time than the Canadian-born wife. The coefficient on consumption is positive and significant at 5 percent level, indicating that the family consumption affects the wife's leisure time positively. The coefficient on the wife's wage rate indicates that an increase of the wife's wage rate reduces the wife's leisure time, thus leading to a significanct increase in the wife's working hours. The information about the immigrant wife's source country is included in the estimation. The default source country is from UK, US, North and West Europe. Immigrants from this group have more equivalent credentials compared to Canadians. Immigrant married women from South and East Europe and other countries have significantly 3.7 and 3.5 percent percent less leisure time, respectively, and thus work longer than the default group. The immigrant wife's arrival cohorts are also included in the estimation. The default arrival cohort is between 1981 and 1992, which is the recent arrival cohort. The immigrant married women who arrived between 1961 to 1980 have significantly 4 percent more leisure time than the recent arrival cohort, indicating that the recent arrival married women work longer than other arrival cohorts. An increase in the number of children under 6 will statistically reduce the wife's working hours. But for the foreign-born family, an increase in the number of children will decrease the wife's

\footnotetext{
${ }^{9}$ These coefficients show that the utility function is quasiconcave in terms of consumption and the wife's leisure time.

${ }^{10}$ The curvature of the husband's leisure time, $\alpha_{H}$, can not be estimated by this equation because we do not use information about the husband's leisure time in the derivation of the estimation equation
} 
working hours. The coefficient on year-since-migration indicates that the immigrant wife's working hour is increasing with the time they stay in Canada.

Predicted differences between immigrants and Canadian-born can be calculated as follow:

$$
\text { Difference }=\alpha_{1}+\alpha_{2} * Y S M+\alpha_{3} * Y S M^{2} \text {, }
$$

Predicted differences between each arrival cohort and Canadian-born can be calculated as follow:

$$
\text { Difference }=\alpha_{1}+\alpha_{2} * Y S M+\alpha_{3} * Y S M^{2}+\alpha_{4 i} \text {, }
$$

where $\alpha_{i}$ s are the estimated coefficients on immigrant dummy variable, year since migration, square of year since migration and arrival cohort in the regression of equation 2.28 .

The estimation results of the Euler equation (2.31) for total consumption, durable consumption, non-durable consumption and food consumption are shown in Table 2.9 through Table 2.12. The first two terms of equation (2.26), $a_{t+1}+b^{*} \Gamma_{t}$, are assumed to be a function of family's credit constraint status, the wife's age group, the immigrant wife's arrival cohorts and source country. The coefficients on credit constraint dummy variable are all positive and significant at at least the 5 percent level, implying that the credit constraints positively affect the family's consumption growth. The regression of Euler equation for total consumption (Table 2.9) shows that the family whose wife's age between 45 and 59 and have kids older than 6 are more likely to be credit constrained because the coefficients on these two variables are negative and significant at at least the 5 percent level. The regression results of Euler equation for durables consumption (Table 2.10) indicate that immigrant families whose wife arrived between 1961 and 1970, between 1971 and 1980, and have kids older than 6 are more likely to 
be credit constrained compared to other families since the coefficient on this term is negative and significant at at least the five percent level. The immigrant families from 'Other' category are less likely to be credit constrained compared to those from the UK, US, North and West Europe, since the coefficient is positive and significant at the 5 percent level. The regression results of Euler equation for non-durable consumption expenditure (Table 2.11) indicate that families whose wife is aged between 25 and 34 and between 45 and 59 are more likely to be credit constrained compared to those with wife's age between 35 and 44. The coefficients on arrival cohort 1981-92 are negative for all regressions of Euler equation, indicating that the immigrant families whose wife arrived into Canada between 1981 and 1992, which is relatively new, are more likely to be credit constrained, although this result is not significant.

Table 2.13 is the estimated coefficient on the family's disposable income of Euler equation for Group I (more likely to be credit constrained) and Group II (less likely to be credit constrained). The estimated coefficients on family's disposable income for the group I are all significant at 5 percent level. The coefficients on family's disposable income for Group II are significant at 5 percent level except for the regression of Euler equation for food equation.

The coefficients on the family's disposable income of the Euler regression for food consumption are as expected. For the group with the credit constraint, the family's disposable income will affect the family's food consumption choice. For the group without the credit constraint, the family's food consumption will not be affected by the family's disposable income. The coefficient on disposable income is significant at the 5 percent level for group I and insignificant for group II, implying that the credit constraint binds. We can conclude that the credit constraint does exist, and the inability to borrow against future income affects family's food consumption behavior. 


\subsection{Conclusions}

The Family Investment Hypothesis is tested by analyzing the immigrant wife's working hours decision. A dynamic labor supply model under credit constraints is developed. The regression results generally support the Family Investment Hypothesis. The empirical results show that recent immigrant married women work longer than Canadian-born married women in the first years of arrival in Canada, and the immigrant families are more likely to be credit constrained. This is not true after they have spent a longer time in Canada. The married immigrant women from South and East Europe and from other countries work more hours than those from North and West Europe. The number of working hours increases with the wife's wage rate and the duration of residence in Canada. The sample means also show that the longer the immigrant wife stays in Canada, the higher the wage rate and the more hours they work. The estimation results for the Euler equation for the groups with and without a credit constraint show that credit constraints are binding and are important for the family's food consumption behavior. Our findings suggest that credit

constraints affect the labor supply of the immigrant married women and the family's consumption behavior. The results show that credit constraints can possibly explain the differences in labour supply and family food consumption behaviour. The results support Family Investment Hypothesis but the evidence is not strong so far. The FAMEX is not perfect for the analysis since it is not a panel data set, and the two important variables for our analysis: - annual working hours and consumption - have to be constructed according to some assumptions. The further research is needed based ideally on a longitudinal data set.

The existing literature shows that male earns at higher wage rate than female. According to the results that female immigrants work longer in the first years after arrival during their husband investing on human capital, it is natural to raise the 
question that whether the wage difference will be still existing if female immigrants have a chance to get established because they do not need to work longer hours to support family consumption, but have the same opportunity to invest on their human capital. If government can provide a certain help for immigrant families to invest on their human capital, the assimilation process of immigrant families will be shorter. A financial program appropriate for immigrants like the current OSAP program in Ontario would be a possibility. The OSAP program is good for Canadian young people to go to university or college but not good for immigrant families because it is harder for new immigrant families to satisfy those conditions. A job-specific training program maybe another possibility. The current language program (like ESL) seems not very helpful for immigrants to find a job. If government can provide some co-op opportunities to new immigrants, then they can receive Canadian working experiences and references required by employers. 


\section{Chapter 3}

\section{Dwelling Ownership and Housing Equity of Immigrant Families in Canada}

\subsection{Introduction}

From the first chapter, we see that the recent immigrant families to Canada have lower income and lower consumption expenditure than Canadian-born families or than did immigrant families from earlier arrival cohorts. However, their saving behaviour is not significantly different from Canadian-born families or the earlier immigrant families. Research on immigrant family's housing decisions helps us understand immigrants saving behaviour. Home ownership can be a large investment for many households, as houses' value increasing as time goes by. Immigrant families will need to decide whether to rent a dwelling or try to purchase a dwelling given their assets, current incomes and access to credit. While thinking about the savings behaviour

of recent immigrants, it is important to keep in mind these housing decisions since 
the immigrant family's savings behaviour may be closely linked to the process of accumulating enough wealth in order to have a sufficiently large down-payment for an owned dwelling or to make mortgage payments on a dwelling that has already been purchased.

Green and White (1997) used a probit model to analyse data from the Panel Study of Income Dynamics (PSID), the Public Use Microsample of the 1980 Census of Population and Housing (PUMS), and High School and Beyond (HSB) and found that home ownership affects children's education and reduces the probability of having children as teenagers. Myers, Megbolugbe and Lee (1998) used logistic model to estimate the home ownership by analyzing the Public Use Microdata Sample (PUMSA), censuses of 1980 and 1990 of America and found that cohort membership, aging, and duration of U.S. residence are strong predictors of home ownership.

A small but growing literature exists in Canada on the relationship between the economic performance of immigrants and their housing decisions in Canada. Ray and Moore (1991) used 1986 Canadian census and a log-linear model to analyze the housing tenure among immigrants in Canada and found lower rates of home ownership for more recent immigrants, especially those from the developing countries. Balakrishnan and Wu (1992) used the 1986 Public Use census data to analyze house tenure in selected Canadian cities and found that home ownership is high for Italians and Chinese and low for blacks and native people. Laryea (1999) also used the logistic model to investigate house tenure in Toronto, Montreal and Vancouver by using the Public Use Sample Tapes of 1991 Canadian census. He found that immigrants have lower ownership and need six to eight years to catch up to the home ownership rates of the Canadian-born; immigrants of European/USA and Chinese origin have high ownership rate and those of African/Caribbean origin have very low ownership rate. Until recently, immigrant families in Canada's larger cities have had higher 
home ownership rates than have the Canadian born. However, Haan (2005), using data from the 1981 through 2001 Canadian Census confidential files, found that this advantage has reversed over the past 20 years. This is attributed to both a drop in immigrant rates of home ownership and an increase in the rates of home ownership among the Canadian born. Haan analyzed standard consumer demand models and used them to explain these changes in home ownership incidence by immigrants and native-born families in Canada. He found that the standard model is highly successful at explaining the immigrant home ownership advantage in 1981 and the increase in home-ownership since 1981 for the native born. However, the model explains only one third of the decline in home-ownership rates of immigrants since $1981 .{ }^{1}$

The focus of this paper is on the decision both to own a dwelling and the process of the accumulation of equity in that dwelling. A model of home ownership is estimated that allows for this decision to vary between the Canadian born and immigrants and by immigrant arrival cohort, years-since-migration to Canada and source country region or mother tongue. I focus on male household reference person as did Myers, Megbolugbe and Lee (1998). I estimate the model separately over the FAMEX and SFS data due to concerns about the possibility comparability of the two data sources. In addition, for immigrants who own their dwellings, I calculate the equity held in the dwelling (defined as perceived value of the dwelling minus the remaining principal on the mortgage). The housing equity variable is used as the dependent variable in reduced form regressions estimated separately over the FAMEX and the SFS samples to compare housing equity between immigrants and the Canadian-born families.

\footnotetext{
${ }^{1}$ See also Haan (2009).
} 


\subsection{Data and Empirical Strategy}

As in the previous chapter, data are employed from the public use files of the Family Expenditure Surveys (FAMEX) (1969, 1974, 1982, 1984, 1986, 1990 and 1992)2 and the confidential master files of the Surveys of Financial Security (SFS) of Statistics Canada (1999 and 2005). There are in total four years of the survey $(1983,1999$, 2005 and 2012) but only the data for 1999 and 2005 were available when I began this research. The SFS includes all major financial and non-financial assets of Canadians such as the money owing on mortgages, vehicles, credit cards, student loans and other debts. The newest data, which was conducted between September and November 2012, was released on February 25, 2014. Both the FAMEX and SFS surveys contain a set of weights that allow for analyses that can be generalized to the entire Canadian population in the survey year. I use these weights and define our samples and variables so as to make the analysis with the FAMEX data and the analysis with the SFS data as similar as possible. The purpose of the survey is to collect information from a sample of Canadian families on their assets, debts, employment, income and education. This helps in understanding how family finances change because of economic pressures.

In each survey year, the sample is restricted to couples (married or common law) where the household reference person and the reference person's spouse are each between the ages of 22 and 64. The FAMEX and SFS sample contain economic family of the 10 provinces of Canada and the FAMEX is restricted to households residing in the 14 largest cities (all with populations of more than 100,000 people. All variables

\footnotetext{
${ }^{2}$ For the 1978 FAMEX reference year, the information on immigrant year of arrival is highly aggregated and so this year was not used as part of the regression analysis. The survey was also carried out in 1996; however, the immigration questions were not asked in that survey so it is not useful for the current study. Unfortunately, the survey was discontinued after that year and replaced by the Survey of Household Spending which does not contain questions related to the immigration status of the household members.
} 
expressed in dollars were converted into 2007 equivalents using the Consumer Price Index.

Table 3.1 contains sample means of the main variables in the analysis broken down by the immigrant status of the reference person. I defined a household as being an immigrant household if the male reference person is an immigrant.

From the proportions of households by region of residence, it is clear that immigrant households are much more likely to reside in Ontario and British Columbia than are Canadian-born households and that this concentration is even greater in the more recent SFS data than in the earlier FAMEX data. Given the difference in house costs across the provinces, with both Toronto and Vancouver having especially high costs of house relative to other provinces in Canada, it is important to control for region of residence in the analysis, particularly for the analysis of housing equity.

Immigrant reference persons are older than their Canadian-born counterparts with the difference being two years across the two samples. The immigrant educational distribution is also more dispersed in the FAMEX with many more immigrant reference persons having both very low education and more having higher education relative to the Canadian-born educational distribution. In both datasets, immigrant reference persons are more likely to have university degree than are the Canadian-born reference persons.

Mean after tax income is very similar between immigrant and Canadian-born households with immigrant households having roughly $\$ 900$ and $\$ 400$ lower income, the FAMEX and SFS data, respectively.

The own dwelling indicator variable in the FAMEX data has a higher mean over the Canadian-born households sample indicting a owning rate of 71.7 percent compared with 66.4 percent for the immigrant households. In the SFS, immigrant households have lower home ownership rates $(73.6 \%)$ compared with Canadian-born house- 
holds $(81.1 \%)$. The housing equity variable is defined as the difference between the reference person's perceived valuation of the owned dwelling and the reported outstanding principal on the mortgage for the dwelling. This variable is equal to zero for households that do not own their dwelling. Housing equity is larger on average for immigrant households than for Canadian-born households with the difference being $\$ 49,000$ in the FAMEX data and $\$ 39,000$ in the SFS data. This indicates that immigrant households may rely more heavily on their owned homes as a saving vehicle than do Canadian-born households.

Figures 3.1(a) and 3.1(b) are the non-parametric Kernel density estimation for the housing equity variables in FAMEX and SFS respectively. The housing equity distributions are similar and highly skewed to the right. The housing equity distribution of immigrant households for FAMEX is less smooth than that for SFS. In both graphs we see thicker tail for immigrant households, indicating that there are more immigrant households holding housing equity between $\$ 200,000$ and $\$ 500,000$ than do Canadian-born households. There is no big difference for immigrant and Canadian-born households that hold housing equity more than $\$ 500,000$. Immigrant households are more likely to hold housing equity less than $\$ 200,000$ than do Canadian-born households.

\subsection{Estimation Approach}

\subsubsection{Theoretical Framework and Reduced From Estimation Approach}

While reduced form analysis is employed in this paper, it is important to be clear about the kind of underlying economic framework that is being used to motivate the analysis. We have in mind a dynamic utility maximization problem for the married 
couple in which consumption, labour supply and human capital investment decisions are being made in each period subject to a lifetime budget constraint and possibly also credit constraints. The married couple may have accumulated wealth that can be used to finance current consumption in excess of current income. In the absence of such wealth, consumption expenditure can only exceed current income if the family has access to credit.

\subsubsection{General Specification of the Estimating Equations}

I analyse the house decisions and housing equity of immigrant and Canadian-born households using a specification of the explanatory variables that is consistent with the literature on immigrant earnings. The general specification has the following basic form:

$$
\begin{aligned}
& \text { Equity }_{i t}=X_{i t} \alpha+\alpha_{1} A G E_{i t}+\alpha_{2} A G E_{i t}^{2}+E_{i} \alpha_{E}+\alpha_{3} Y_{i t}+\alpha_{4} Y_{i t}^{2}+\alpha_{5} M_{i t} \\
& \quad+\alpha_{6} M_{i t}^{2}+\delta F B_{i}+\Sigma_{c=1}^{C-1} \delta_{c i} d_{c i}+\Sigma_{b=1}^{B-1} \delta_{b i} d_{b i}+\delta_{1} Y S M_{i t}+\delta_{2} Y S M_{i t}^{2}+u_{i t}
\end{aligned}
$$

where $X_{i t}$ is a vector of household characteristics that includes six region of residence indicator variables (with Ontario as the default category) and a complete set of survey year indicator variables to allow for flexible period effects that are common to all households in the survey year (with the default year being 1986 for the FAMEX data and 1999 for the SFS data). The age of the reference person enters in a linear-quadratic form to allow for life cycle effects on savings patterns.

The variable $E_{i}$ represents the education of the reference person and appears as three indicator variables in the analysis. The variable $Y_{i t}$ represents household after tax income. A control for total number of household members, $M_{i t}$, is also included 
to allow for savings to vary according to the size of the household. In each stage of the analysis, I experiment with different versions of (1) so as to investigate the impact that after tax income and the 'total household members' variable has on the estimated immigrant/non-immigrant differences in savings.

The second row of the equation includes the foreign-born indicator variable, $F B_{i}$, which equals zero for the Canadian-born households. The $d_{c i}$ are immigrant arrival cohort variables in FAMEX where the cohorts identified are: 1) before 1946, 2) 1946$55,3)$ 1956-60, 4) 1971-65, 5) 1966-70, 6) 1971-75, 7) 1976-80, 8) 1981-85, 9) 1986-90. In the SFS, the arrival cohort variables are: 1) before 1960, 2) 1960-69, 3) 1970-79, 4) 1980-89, 5) 1990-99 and 6) 2000-03. I deleted data for 1991 and 1992 in FAMEX, 2004 and 2005 in SFS because these years are not good to test the effect of year-sincemigration. The $d_{b i}$ are the dummy variables for source region of birth in FAMEX and mother tongue in SFS. The year-since-migration variable (YSM) also equals zero for the Canadian-born households. It enters in a linear/quadratic form and allows for the differences in saving and wealth accumulation behaviour to vary according to the duration of residence of immigrant households independent of the life cycle effects modelled through the age variables.

Predicted differences between immigrants and Canadian-born are calculated as follow:

$$
\text { Difference }=\delta++\delta_{1} * Y S M++\delta_{2} * Y S M^{2},
$$

Predicted differences between each arrival cohort and Canadian-born are calculated as follow:

$$
\text { Difference }=+\delta_{1}++\delta_{2} * Y S M++\delta_{3} * Y S M^{2}++\delta_{c i},
$$

where $+\delta_{i}$ s are the same as that in equation 3.1. 
When analyzing the home ownership, I use a probit model,

$$
\operatorname{Pr}\left(O w n=1 \mid Z_{i t}\right)=\Phi\left(Z_{i t} \beta\right)
$$

where $\Phi$ is cumulative distribution function of the standard normal distribution, $Z_{i t}$ includes all explanatory variables on the right hand of equation (3.1) and $\beta$ includes all of the coefficients of these explanatory variables. The left hand of equation (3.2) represents the probability of own dwelling.

The marginal effect of a right hand variable is the effect of an unit change of this variable on the probability $P(O w n=1 \mid Z=z)$, given that all other right hand variables are constant:

$$
\frac{\partial \operatorname{Pr}\left(O w n=1 \mid Z_{i t}\right)}{\partial Z_{i t}}=\varphi\left(Z_{i t}\right) \beta
$$

\subsubsection{Family Income and Sources of Income Variation}

Paxson (1992) estimates a series of savings models over a sample of Thai rice farmers. She employs a savings model based on quadratic utility and a stream of transitory income shocks that are correlated with weather shocks. Current income is decomposed into transitory income; permanent income and a residual that contains both transitory and permanent income components (see also a similar study by Cameron and Worswick, 2003, for the case of rural households in Indonesia). These three components of current income are then included in the savings equation yielding coefficients on the marginal propensity to save out of: 1) permanent income, 2) transitory income and 3) the residual transitory/permanent income term.

In the current study, I do not have proxies for transitory income. However, I use the same approach to finding instruments for permanent income by using the 
education of the household reference person and spouse as being correlated with permanent income but not transitory income. Since the instrument set does not include variables that predict transitory income, the part of current income that is due to transitory income shocks falls into the error term and the resulting coefficient on the income variable can be interpreted as the marginal propensity to save out of permanent income.

\subsubsection{Decision to Own the Household Dwelling and Accumu- lation of Housing equity}

In our analysis of the incidence of owning the family dwelling, I carry out probit estimation of a binary choice model with the right hand side of the index having the same general form as the savings equation, (1). The specification allows us to estimate differences in the probability of a family owning their dwelling between Canadian-born families and immigrant families according to the arrival cohort, years-since-migration. In the analysis of the FAMEX data, I also control for the source country region. This information is not available in the SFS data but instead I have detailed information on the person's mother tongue. I control for this information for the case of immigrant households recognizing that it is not equivalent but in some cases will act as a good proxy for country of birth. In addition, I use this specification of the right-handside variables in our regression analysis where value of housing equity appears as the dependent variable.

\subsubsection{Choice of Instrumental Variable}

The family's income should be treated as endogenous because those random shocks that affect income likely also affect home ownership. The variables used as instruments are the husband and wife's education, the wife's age, the wife's year since 
migration, the wife's first language and the region of residence of the family. Our identifying assumption is that these variables affect income and thus the lifetime budget constraint of the household but not the households preferences on owning a house. So they are reliable to be instrumental variables.

\subsection{Empirical Results}

\subsubsection{Dwelling Ownership and the Accumulation of Housing equity}

There is a question on perceived value of the dwelling (if owned) and a question on the remaining principal of the mortgage held against the principal dwelling in FAMEX. The difference between the value of the dwelling and the remaining principal on the mortgage is used as a measure of the housing equity of the household. The principal housing equity variable appears in SFS. The definition is similar to that in FAMEX. I use this measure of housing equity as a component of the overall wealth of the household. However, I also first explore the determinants of home ownership since significant differences in the incidence of dwelling ownership between immigrants and Canadian-born households may mean significant differences in the extent to which household wealth is held in house as opposed to some other assets. In both the analysis of dwelling ownership incidence and in the analysis of housing equity, I employ the same sets of control variables as in the previous savings and change in net assets analysis.

In Table 3.2(a), results are presented from probit estimation over the household's decision over whether or not to own their dwelling for FAMEX. In column (2), indicator variables for source region of birth are included for the immigrant reference person. The default contains immigrants born in the United States, the United King- 
dom, Western Europe or Northern Europe. An indicator variable for immigrants who were born in Southern or Eastern Europe is included as an indicator variable for immigrants born in other regions of the world. In columns (3) and (4), controls for the household income level, the total number of household members and their squared terms are also included. In column (3), the income variables treated as exogenous. In column (4) and (5), estimation is carried out by two-step allowing for heteroskedasticity of unknown form and the household income variable is treated as endogenous. The estimates in column (4) of Table 3.2(a) are generated from two-step estimation of the ownership equation with the education variables of the reference person excluded and instead used as instruments for the family income variable. The estimate in column (5) of Table 3.2(a) are generated from two-step estimation of the ownership equation with the education variables of the reference person and spouse used as instruments for the family income variable.

Scanning across the five columns of the table, the coefficient on the immigrant indicator variable is negative and significant indicating that immigrant households are generally less likely to own their dwelling than are the Canadian-born households. Unlike what was found in the savings and change in net assets analyses in the first chapter, the years-since-migration variables are statistically significant indicating that immigrant households become relatively more likely to own their dwelling with more time in Canada and that this effects diminishes with time in Canada. Many of the coefficients on the immigrant arrival cohort controls are also significant and the overall pattern indicates that the earlier arrival cohorts (before 1960s, especially before 1946) and the most recent cohorts (1986-90) are less likely to own their dwelling (relative to the default category of the 1966-70 cohorts). The earliest immigrant households less likely to own their dwelling may because that the seniors prefer to living in apartments because of their age and health problem. The most recent immigrant households may 
have credit barriers which reduce the probability to own their dwellings. All the coefficients on education are statistically significant. The households with reference person holding university degree are more likely to own their dwelling. The coefficients on the age variables are statistically significant, indicating that the probability of owning dwelling is increasing with age.

Figure 3.2(a) contains the difference in the predicted value of the Standard Normal Distribution function between an immigrant household and an otherwise similar Canadian-born household for the case of high school education and the household reference person being age 25 in FAMEX. In order to avoid predicting behavior far outside of the calendar years spanned by our data, each profile is plotted over the years-since-migration range for which I observe at least some of the immigrants in each arrival cohort in at least one of the survey years. The immigrant households in the 1961-65 cohorts have higher probabilities of owning their homes than do the Canadian-born households and this difference grows with years stayed in Canada. For the other arrival cohorts, they all have lower probabilities of owning a dwelling over at least part of the years-since-migration range observed in the data with each cohort starting at arrival in Canada with relatively low probabilities of owning a dwelling, but with enough time in Canada, many of the arrival cohorts have higher probabilities of owning a dwelling than do the Canadian-born households. The exceptions are the three post 1975 cohorts. The immigrants in these cohorts enter Canada with probabilities of owning a dwelling that are 10 to 25 percentage points lower than is the case for the Canadian-born households. In the case of the 1976-80 cohorts, the probability grows quickly with years-since-migration but by 15 years in Canada the difference had not yet completely declined to zero.

The fact that the post 1975 cohort controls have such large coefficients in absolute means that the effect of age on their index has a relatively small impact on the 
probability of owning a dwelling (since the value of the index is in a tail of the distribution of the error term) relative to the effect of age for the Canadian-born comparison household where the impact on the probability is much larger (since the value of the index is closer to the middle of the distribution of the error term). This effect dominates the year-since-migration effect for low value of years-since-migration.

Based on the controls for immigrant source region, immigrants from Southern and Eastern Europe have higher rates of dwelling ownership than do immigrants from the UK, the US, Northern Europe and Western Europe based on the estimates in columns (2) through (5). The coefficient on the income variable in columns (3) through (5) is positive and significant and the fact that an IV method is used in column (4) and (5) does not have a large impact on the coefficient on income. Finally, the coefficients on the control for number of members in the household are positive and significant in columns (3) through (5) indicating that larger families, ceteris paribus, are more likely to own their dwellings than smaller families. The estimates for immigrant, year-since-migration, arrival cohorts, age and education are very similar to what we have found in column (1).

In Table 3.2(b), results are presented from probit estimation over the household's decision over whether or not to own their dwelling for the SFS data. Scanning across the columns of the table, the coefficient on the immigrant indicator variable is negative and significant indicating that immigrant households are generally less likely to own their dwelling than are the Canadian-born households. The years-since-migration variables are statistically significant indicating that immigrant households become relatively more likely to own their dwelling with more time in Canada and that this effect diminishes with time in Canada. These results are similar to the results in the analysis of FAMEX. The coefficients on the immigrant arrival cohort control are not statistically significant with the exception of 1960-69 arrival cohorts in first two 
columns. All the coefficients on education are statistically significant, indicating that the households with reference person holding higher education have higher probability to own their dwellings.

Immigrants with mother tongue of Arabic or in the 'Other Asian' group are less likely to own their dwelling than are immigrants whose mother tongue is English and/or French. These mother tongue relationships are robust to the inclusion of income and number of household members (as shown in column (3)).

Figure 3.2(b) contains the difference in the predicted value of the Standard Normal Distribution function between an immigrant household and an otherwise similar Canadian-born household for the case of high school education and the household reference person being age 25 in SFS. We cannot see a similar pattern as in the analysis of FAMEX when the year-since-migration is more than 30 years. In order to avoid predicting behavior far outside of the calendar years spanned by our data, each profile is plotted over the years-since-migration range for which I observe at least some of the immigrants in each arrival cohort in at least one of the survey years. The immigrant households arrived before 1960 have higher probabilities of owning their homes than do the Canadian-born households and this difference decreases with years stayed in Canada. The immigrant households arrived between 1960 and 1969 has almost same probabilities of owning their homes. The other arrival cohorts are similar to the analysis in FAMEX. They all have lower probabilities of owning a dwelling over at least part of the years-since-migration range observed in the data with each cohort starting at arrival in Canada with relatively low probabilities of owning a dwelling, but with enough time in Canada, many of the arrival cohorts have higher probabilities of owning a dwelling than do the Canadian-born households. The exceptions are the two post 1990 cohorts. The immigrants in these cohorts enter Canada with probabilities of owning a dwelling that are 10 to 35 percentage points lower than is the case for the 
Canadian-born households. In the case of the 1990-99 cohorts, the probability grows quickly with years-since-migration but by 17 years in Canada the difference had not yet completely declined to zero.

The final stage of the analysis of this paper involves the estimation of a regression model with the dependent variable being the housing equity of the household.

In Table 3.3(a), the estimates of housing equity for households that own dwelling in FAMEX data are presented using the same five specifications of the explanatory variables as was used in Tables 3.2(a). As was the case in the dwelling ownership analysis, there is a clear pattern of differences between the immigrant and non-immigrant households in terms of their house outcomes. Across all five specifications, we see negative coefficients on the immigrant indicator variable indicating lower housing equity at the time of arrival in Canada (YSM=0) than Canadian-born households, ceteris paribus, in the range of $\$ 44,200$ to $\$ 50,400$ lower equity. However, a strong relationship between housing equity is found with duration of residence in Canada. For example, after just one year of residence in Canada, the initial disadvantage of an immigrant family at arrival is reduced by approximately $\$ 5,500$. From the column (1) through (3), we can see that households whose reference person holds university degree have much higher housing equity than the default group.

Large differences across immigrant arrival cohorts are also found with the earlier cohorts having much lower housing equity and these effects being significant for the earliest three arrival cohorts (relative to the default cohort, 1966-70) and significantly higher housing equity for the 1986-90 arrival cohorts. This latter result is surprising given the low savings and change in net assets found for these cohorts in the Tables 2 and 3 from the former analysis about savings and wealth accumulating and the fact that these cohorts are generally found to have relatively low incomes relative to the earlier arrival cohorts. Once household income is introduced in columns (3) through 
(5), the coefficients on the 1986-90 dummy variables increase (with the larger effect being for the 1986-90 cohorts). This is consistent with these cohorts having relatively low income and the regression model with income included needing to adjust the coefficients on the arrival cohort intercept shift in order to explain the relatively high housing equity for these cohorts of immigrant households.

In Figure 3.3(a), differences in housing equity between immigrant households and Canadian-born households are plotted by arrival cohort and years-since-migration. The parameter estimates are taken from column (1) of Table 3.3(a). The strong positive cohort effects are apparent as the curves for more recent arrival cohorts lie above and to the left of the curves for the earlier arrival cohorts. This pattern is in stark contrast to what was found in Figure 3.2(a) where more recent arrival cohorts are less likely to own their dwellings relative to earlier arrival cohorts for the same number of years-since-migration.

Based on the results presented in columns (2) through (5), significant differences in housing equity are present by the source country region of the immigrant reference person. Households with a reference person from a country in Southern and Eastern Europe have housing equity that ranges from $\$ 17,700$ to $\$ 28,900$ higher than the housing equity of households with a reference person from the default group (US, UK, northern Europe and Western Europe). For households where the immigrant reference person is from a source country that falls in the 'Other' category, the coefficients on the indicator variable are either statistically insignificant or small in absolute value.

The number of household member variable is positive and significant at the 5 percent level in column (3) through (5) indicating $\$ 12,900$ to $\$ 13,800$ higher housing equity for each additional household member.

Table 3.3(b) contains the estimates from the housing equity model for households that own their dwellings using the SFS data. The immigrant and year-since-migration 
variables are not statistically significant. Similar to the results of the FAMEX analysis, all the education variables are statistically significant and households whose reference person holds a university degree have much higher housing equity. The immigrant households with mother tongue of Chinese have much higher housing equity than those with mother tongue of English and/or French. The immigrant households with mother tongue of European also have higher housing equity than those with mother tongue of English and/or French. Only the coefficient of 2000-03 arrival cohorts is statistically significant, indicating that the most recent immigrant households have much lower housing equity than those arrived before 1960. This is consistent with the results of the former analysis of the lower savings and lower home ownership for the most recent immigrant households. The estimate for income is very similar to what we found in the analysis of FAMEX data.

From Figure 3.5 we can see that in the period of 1986-90, the new housing price indexes, 5-year mortgage rate and bank rate were increasing. The bank rate of this period was relatively higher than the period of 2000-05. If we control for the new housing price index and bank rate, we may have different results with Table 3.3(a) and 3.3(b).

In Figure 3.3(b), differences in housing equity between immigrant households and Canadian-born households are plotted by arrival cohort and years-since-migration. The parameter estimates are taken from column (1) of Table 3.3(b). The strong negative cohort effect is apparent as the curve for the most recent arrival cohorts lie below of the curves for the earlier arrival cohorts. This is consistent to the result from the ownership analysis that more recent arrival cohorts are less likely to own their dwellings relative to earlier arrival cohorts for the same number of years-sincemigration. The difference in housing equity for earlier arrival cohorts are decreasing with year since migration, probably because as they getting older, they prefer to not 
taking care of house and living in apartments.

In order to understand how the low rates of dwelling ownership and high levels of home equity for dwelling owners for the recent arrival cohorts of immigrants in the FAMEX analysis, the home equity analysis is extended to incorporate the households in our overall sample who rent their dwelling. The analysis of Table 3.3(a) and 3.3(b) are repeated but with these households included in the sample and a value of zero assigned to their observations for the housing equity variable. The resulting model of housing equity can be thought of as the unconditional model of housing equity in contrast to the model used in the analysis of Table 3.4(a) and 3.4(b) which can be thought of as the conditional housing equity model (in the sense that the sample if conditioned on owning the household's dwelling).

Table 3.4(a) and 3.4(b) contain the regression estimates for FAMEX and SFS, respectively from this analysis. The estimates for FAMEX in Table 3.4(a) are generally very similar of those of Table 3.3(a) with the exception of the coefficient on the 198690 arrival cohorts. Instead of estimates in the range of 60 to 90 in Table 3.3(a), the equivalent Table 3.4(a) coefficient estimates are much smaller in magnitude and not statistically significant after controlling for income. The estimates for SFS in Table 3.4(b) are generally very similar of those of Table 3.3(b) with the exception of the coefficients on the 2000-03 cohort variables. The equivalent Table 3.4(b) coefficient estimates are much smaller in absolute magnitude and not statistically significant after controlling for income. It is also worth noting that the standard errors in 4(a) and $4(\mathrm{~b})$ have in fact declined relative to the equivalent standard errors for these coefficients in Table 3.3(a) and 3.3(b). This is likely due to the fact that we are now adding in many more observations (the renters) and these observations have values of zero for the dependent variable.

In Figure 3.4(a) and 3.4(b), I present predicted difference in housing equity be- 
tween immigrant households and Canadian-born households which are equivalent to those of Figure 3.3(a) and 3.3(b); however, they are based on the estimates from Table 3.4(a) and 3.4(b). It is clear that the profiles for the two 1980s cohorts in Figure 3.4(a) now lie close to those for the post 1960 cohorts - unlike in Figure 3.3(a) where these two cohort profiles lay above and to the left of all of the other arrival cohort profiles. Figure 3.4(b) shows that the differences in housing equity for the recent and the earliest arrival cohorts are decreasing as they stay longer in Canada.

The change in the coefficients on the 1980s in FAMEX and 2000s in SFS cohort variables that results from the inclusion of the households that rent their dwelling is consistent with the idea that the households in these arrival cohorts face significant barriers to credit in terms of buying their first home. If we condition on households who own their dwelling, we see very large levels of equity for the immigrant households that are members of these arrival cohorts. It is possible that these immigrant households find it very difficult to gain credit unless they have accumulated a significant down-payment which would of course show up as a relatively high level of housing equity. It is also surprising that this general pattern holds in the column (3) through column (5) results of each table once income is introduced into the model. This means that even after controlling for the fact that the most recent immigrant households had relatively low income after arrival, compared with earlier arrival cohorts, we still see evidence of a barrier to home ownership.

In summary, important differences by immigrant status are found in terms of propensity to own the dwelling and housing equity. Immigrant cohorts generally arrive in Canada with a lower propensity to own a house and if they do own a house have lower housing equity in the first year in Canada. However, strong assimilation effects are found indicating that both the propensity to own a house and the amount of housing equity both grow with time in Canada even after controlling for overall 
age effects (which are significant in both cases).

\subsection{Concluding Remarks}

The home ownership and housing equity outcomes of immigrants in Canada have been studied using seven cross-sections of the Survey of Family Expenditures of Statistics Canada spanning the years 1969 to 1992 and the Financial Security Survey (SFS) for the years 1999 and 2005.

Models of dwelling ownership and equity are estimated. Recently-arrived immigrant households are less likely to own their dwelling and if they do own their dwelling hold $\$ 44,000$ to $\$ 51,000$ for FAMEX and $\$ 42,000$ to $\$ 59,000$ for SFS less equity in it. Strong assimilation is found through the analysis of FAMEX in the sense that the probability of owning a dwelling and the equity held in the dwelling grow quickly with years-since-migration even after controlling for overall life cycle effects through controls based on the age of the reference person in the household. Immigrant families are less likely to own their dwellings in the first years after arrival. But after 6 to 10 years staying in Canada, they have higher probability of owing dwellings than Canadian-born families. The result from the analysis of SFS is different. The difference in probability of owning dwelling between immigrant and Canadian-born families is deceasing after 40 years of arrival. The more recent arrival cohorts are much less likely to own their dwelling and this is consistent with the findings of very low incomes for these cohorts in the immigrant earnings literature. In the analysis of housing equity for home owners, I find that immigrant families have lower housing equity than Canadian-born families in the first years after arrival. After several years, immigrant families have higher housing equity than Canadian-born families and the difference is increasing with the year-since-migration. This is not true for the analysis of SFS where we see the difference in housing equity between immigrant and Canadian-born 
families does not change with the year-since-migration. However, among immigrant households who own their dwellings, housing equity is in fact higher for the more recent arrival cohorts in the analysis of FAMEX. In order to investigate this further, I re-estimated the housing equity equation adding in households that did not own their dwelling and assigning a value of zero for their housing equity. We see that the more recent immigrant families have lower housing equity than Canadian-born families in the analysis of FAMEX and SFS. The results for all households are different with the case of home-owning households in the analysis of SFS. The immigrant families have lower housing equity than Canadian-born households in the first years after arrival. After several years, they have higher housing equity than Canadian-born households but the difference is decreasing after 40 years of arrival. The parameter estimates were largely unaffected once the model was re-estimated over the expanded sample although the positive and significant cohort effects for the most recent arrival cohorts were replaced by statistically insignificant coefficients that were near zero with relatively small standard errors. I interpret this result as being consistent with a barrier to credit for recent immigrant arrival cohorts. The incidence of ownership analysis indicates that these groups of immigrant households had very low ownership rates.

The housing equity analyses indicate that only households able to support a relatively high level of housing equity are appearing in the data as homeowners. Some banks or other financial institutions have mortgage programs for new-comers to Canada which allow new immigrants without jobs to be approved by paying 30 percent to 35 percent down payment. For example, The Canadian Imperial Bank of Commerce's new resident and non-resident home ownership programs ${ }^{3}$ provide "flexible down payment options as a new resident, where you pay a minimum down payment of 35 percent for conventional mortgages and as little as 5 percent down

$\begin{array}{cccccc}{ }^{3} \mathrm{CIBC} & \text { Newcomer } & \text { Banking - } & \text { Own your } 1 \text { st } \\ \text { https://www.cibc.com/ca/mortgages/new-nonres-homeowner-pgrms.html }\end{array}$


payment for high ratio insured mortgages." Bank of Montreal and Royal Bank of Canada has similar mortgage program for new-comers to Canada within three years. ${ }^{4}$. These programs are helpful for those new immigrants who have enough savings in their home country to own their dwellings. The current affordable housing program for low income households needs several years to wait. So it is not helpful for new immigrants who qualify for it. For those new immigrants who do not have enough savings and stable income, Government Canada could provide relevant policy to help them during their assimilation in Canada.

The results that new immigrants are less likely to own dwellings and have lower housing equity compared to earlier immigrants and Canadian-born provide some implications for immigration selection and settlement policy. Many new immigrants are doing low-earning jobs in the first years after arrival because of their language deficiency and their education credentials are not accepted by employers. Since 2008, Canada Immigration and Citizenship Department has changed the selection process for the Federal Skilled Worker Program which needs all applicants to submit thirdparty language testing results and foreign educational credential assessments. These changes will help those immigrants with better English and or French and proper education comparable to Canadians to find professional jobs that will lead to a better income and expenditure outcomes. As long as they have relatively high-income jobs, many immigrants will be able to buy dwellings with the help of mortgage. The proposed Expression of Interest (EOI) application program - developed by New Zealand and also being used in Australia is helpful for employers since it allows them to find candidates for skilled employment from the pool of skilled workers created by EOI. This system will be more efficient than the current system because the immigrant applications are directly selected in part by the applicants having job offers. It will

\footnotetext{
${ }^{4}$ https://www.cibc.com/ca/mortgages/new-nonres-homeowner-pgrms.html
} 
speed up the selection process for skilled immigrants. With employers participation in the selection of immigrants, the new immigrants will better fit Canadas labour market needs because employers know more about what kind of skills they need than immigration officers. The EOI system will also help new immigrants to improve their incomes after arrival in Canada, which will likely lead to improved consumption expenditure and home ownership rates because they can come to Canada with a job offer under this system. 


\section{Bibliography}

[1] Abbott, M.G. and C.M. Beach (1993) 'Immigrant Earnings Differentials and Birth-year Effects for men in Canada: postwar-1972.' Canadian Journal of Economics $26,505-524$.

[2] , Aydemir A. and M. Skuterud (2005) Explaining the Deteriorating Entry Earnings of Canadas Immigrant Cohorts, 1966-2000, Canadian Journal of Economics, 38(2):641-7.

[3] Akbari, Ather and Yigit Aydede (2009) Effects of Immigration on Housing Prices in Canada, Working paper \#24, Atlantic Metropolis Centre.

[4] Amuedo-Dorantes, Catalina and Susan Pozo (2002), Precautionary Saving by Young Immigrants and Young Natives, Southern Economic Journal, 69(1), 4871.

[5] Andersson, Lina (2011) 'The Female Immigrant Labor Supply: The Effect of an In-Work Benefit,' Labor 25. 2 (Jun 2011): 198-227.

[6] Altonji, J. (1986) 'Intertemporal Substitution in Labour Supply: Evidence from Micro Data,' Journal of Political Economy 94, S176-S215.

[7] Aydemir, Abdurrahman and Mikal Skuterud (2005) Explaining the Deteriorating Entry Earnings of Canadas Immigrants Cohorts, 1966-2000, Canadian Journal of Economics, 38(2): 641-71. 
[8] Baker, M. and D. Benjamin (1994a) 'The Performance of Immigrants in the Canadian Labor Market,' Journal of Labor Economics 12, 369-405.

[9] Baker, M. and D. Benjamin (1997) 'The Role of Family in Immigrants' Labor Market Activity: An Evaluation of Alternative Explanations,' American Economic Review, 87(4), 705-727.

[10] Balakrishnan, T.R. and Zheng Wu. 1992. Home Ownership Patterns and Ethnicity in Selected Canadian Cities. Canadian Journal of Sociology/Cahiers Canadiens de Sociologie, 17: 389-403.

[11] Basilio, L., Bauer, T. K., and Sinning, M. (2009). 'Analyzing the labor market activity of immigrant families in Germany. 'Labor Economics, 16(5), 510-520.

[12] Beach, C. and C. Worswick (1993) 'Is There a Double-Negative Effect on the Earnings of Immigrant Women?" Canadian Public Policy 19, 36-53.

[13] Beaudry, P. and D. Green. 2000. Cohort patterns in Canadian earnings: Assessing the role of skill premia in Inequality trends. Canadian Journal of Economics, 33(4): 987-1005.

[14] Bernhardt, D. and D. Backus (1990) 'Borrowing Constraints, Occupational Choice, and Labor Supply,' Journal of labor Economics 8, 145-173.

[15] Blau, Francine D., Lawrence M. Kahn, Joan Y. Moriarty, and Andre Portela Souza (2003) 'The Role of the Family in Immigrants' Labor-Market Activity: An Evaluation of Alternative Explanations: Comment,' American Economic Review, 93(1): 429447.

[16] Blau, Francine D., Lawrence M. Kahn, Papps Kerry L. (2011) 'Gender, Source Country Characteristics, and Labor Market Assimilation among Immigrants,' Review of Economics and Statistics 93(1), 43-58. 
[17] Bloom, D., G. Grenier and M. Gunderson. 1995. The changing labour market position of Canadian immigrants. Canadian Journal of Economics, 28(4b): 9871005.

[18] Blundell, R. and Walker, I. (1986) 'A Life-Cycle Consistent Empirical Model of Family Labor Supply Using Cross-Section Data,' Review of Economic Studies, vol. $53(4), 539-58$.

[19] Borjas, G.J. (1985)'Assimilation, Change in Cohort Quality, and the Earnings of Immigrants,' Journal of labor Economics 3, 463-89.

[20] Borjas, G.J. and S. Bronars (1991) 'Immigration and the Family,' Journal of Labor Economics 9, 123-149.

[21] Browning, M., A. Deaton, and M. Irish (1985) 'A Profitable Approach to Labor Supply and Commodity Demands over the Life-Cycle,'Econometrica 53, 503-543.

[22] Burbidge, J. and A. L. Robb (1985) Evidence on wealth-age profiles in Canadian cross section data. Canadian Journal of Economics, 18: 854-875.

[23] Cameron, L.A. and C. Worswick (2003) Labour Supply Responses to Crop Loss in Indonesia, Review of Development Economics, 7(2): 327-41.

[24] Campbell, M. (1994) 'Too Many Immigrants, Many Say,' Globe and Mail, March 10.

[25] Carroll, Christopher D., Byung-Kun Rhee, and Changyong Rhee (1994) Are There Cultural Effects on Saving? Some Cross-Sectional Evidence, Quarterly Journal of Economics, 109(3), August, pp. 685 - 699. 
[26] Carroll, Christopher D., Byung-Kun Rhee, and Changyong Rhee (1999) Does Cultural Origin Affect Saving Behavior? Evidence from Immigrants, Economic Development and Cultural Change, 48(1): 33-50.

[27] Chiswick, B.R. (1978) 'The Effect of Americanization on the Earnings of ForeignBorn Men,' Journal of Political Economy 86, 897-921.

[28] Cobb-Clark, D. (1993) 'Immigrant Selectivity and Wages: The Evidence for Women,' American Economics Review 986-993.

[29] Cobb-Clark, Deborah A. and Thomas F. Crossley (2004) Revisiting the Family Investment Hypothesis, Labour Economics, 11(3): 373-93.

[30] Cobb-Clark, Deborah A. and Vincent Hildebrand (2002) The Wealth and Asset Holdings of U.S.-Born and Foreign-Born Households: Evidence from SIPP Data, Forschungsinstitut zur Zukunft der Arbeit (IZA), Discussion Paper, no. 674.

[31] Cobb-Clark, D., Connolly, M.D. and Worswick, C. (2005) 'Post-migration investments in education and job search: a family perspective,' Journal of Population Economics 18(4), 663-690.

[32] Cobb-Clark, D. and Crossley, T. F. (2004) 'Revisiting the Family Investment Hypothesis,' Labor Economics, 11(3), 373-393.

[33] Cogan, J. (1981) 'Fixed Costs and Labor Supply,' Econometrica 49, 945-963.

[34] Cohen-Goldner, Sarit, Chemi Gottlibovski and Nava Kahana (2009) The role of marriage in immigrants human capital, Journal of Population Economics, 22: 983-1003. 
[35] Crossley, T.F., McDonald, J.T. and C. Worswick (2001) Immigrant Benefit Receipt Revisited: Sensitivity to the Choice of Survey Years and Model Specification, Journal of Human Resources, 36(2): 379-397.

[36] Duleep, H. and S. Sanders (1993) 'The Decision to work by Married Immigrant Women,' ilrr 46, 64-80.

[37] Faruqui1, U. and Torchani S. (2012) 'How Important Are Liquidity Constraints for Canadian Households? Evidence from Micro-Data', Bank of Canada Discussion Paper 2012-9.

[38] Fortin, N. (1993) 'Borrowing Constraints and Female Labor Supply: Nonparametric and Parametric Evidence of the Impact of Mortgage Lending Rules,' Universite de Montreal, 9309.

[39] J. D. Gilbson, The Communications Handbook, CRC Press, 2010.

[40] Green, D. A., and Worswick, C. (2012): Immigrant earnings profiles in the presence of human capital investment: measuring cohort and macro effects, Labour Economics, 19 (2): 241-259.

[41] Green, R. K., and M. J. White (1997): Measuring the Benefits of Homeowning: Effects on Children, Journal of Urban Economics, 41: 441-461.

[42] Green, D. A. and Worswick, C. (2012) 'Immigrant earnings profiles in the presence of human capital investment: Measuring cohort and macro effects,' Labour Economics, Elsevier, vol. 19(2), 241-259.

[43] Haan, Michael (2009) Are Immigrants Buying to Get In: The Role of Ethnic Clustering on the Homeownership Propensities of 12 Toronto Immigrant Groups, 1996- 2001. Research Paper, Business and Labour Market Analysis Division, Statistics Canada. 
[44] Haan, Michael (2008) The Place of Place: Location and Immigrant Economic Wellbeing in Canada. Population Research and Policy Review, 27(6 ): 751-771.

[45] Haan, Michael (2005) The Decline of the Immigrant Homeownership Advantage: Life-Cycle, Declining Fortunes and Changing House Careers in Montreal, Toronto and Vancouver, 1981-2001. Urban Studies (November).

[46] Heckman, J. (1979) 'Sample Selection Bias as a Specification Error,' Econometrica $47,153-61$.

[47] Heckman J. and T.E. MaCurdy (1980) 'A Life Cycle Model of Female Labor Supply,' res 47, 47-74.

[48] Jakubson,G. (1988). 'The Sensitivity of Labor-Supply Parameter Estimates to Unobserved Individual Effects: Fixed- and Random-Effects Estimates in a Nonlinear Model Using Panel Data,' Journal of Labor Economics, vol. 6(3), 302-29.

[49] Kim, S., and Varanasi, N. (2010). 'Testing the family investment hypothesis: Theory and evidence', University of Washington, Department of Economics, Working Papers: UWEC-2010-01.

[50] LaLonde, R. and R. Topel (1992) 'Immigrants in the American Labor Market: Quality, Assimilation, and Distributional Effects,' it AEA Papers and Proceedings $\mathrm{rm}, 297-302$.

[51] Laryea, Samuel A. 1999. Homeownership Patterns of Immigrants in Canada. Vancouver Centre of Excellence, Vancouver.

[52] Long, J. (1980) 'The Effect of Americanization on Earnings: Some Evidence for Women,' Journal of Political Economy 88,620-629. 
[53] MaCurdy, T.E. (1981) 'An Empirical Model of Labor Supply in a Life-Cycle Setting,' Journal of Political Economy 89, 1059-1085.

[54] MaCurdy, T.E. (1983) 'A Simple Scheme for Estimating an Intertemporal Model of Labor Supply and Consumption in the Presence of Taxes and Uncertainty,' ier 24, 265-289.

[55] McDonald, J. and C. Worswick (2012), Retirement Incomes and Labour Supply of Older Immigrants in Canada: 1991-2006, 2012 Canadian Economics Association Meetings, Calgary.

[56] McDonald, J. and C. Worswick (1998), The Earnings of Immigrant Men in Canada: Job Tenure, Cohort and Macroeconomic Conditions, Industrial and Labor Relations Review, 51(3), 465-482.

[57] Moffitt, R. (1982) 'The Tobit Model, Hours of Work and Institutional Constraints,' The Review of Economics and Statistics, Vol. 64(3), 510-515.

[58] Mroz, T. (1987) 'The Sensitivity of an Empirical Model of Married Women's Hours of Work to Economic and Statistical Assumptions.' Econometrica 59, 76599.

[59] Myers, D., I. Megbolugbe, and S. W. Lee (1998). Cohort Estimation of Homeownership Attainment among Native-Born and Immigrant Populations, Journal of House Research, 9(2): 237-269.

[60] Paxson, Christina H. (1993) Using Weather Variability to Predict the Response of Savings to Transitory Income in Thailand, American Economic Review, 82(1): $15-33$.

[61] Picot, G. and Piraino P.(2013) Immigrant earnings growth: selection bias or real progress? Canadian Journal of Economics, 46(4): 1510-36. 
[62] Ray, Brian K. and Eric Moore (1991). Access to homeownership among immigrant groups in Canada, Canadian Review of Sociology, 28(1): 129.

[63] Reilly, K.T. (1994) 'Annual Hours and Weeks in a Life-Cycle Labor Supply Model: Canadian Evidence on Male Behavior,' Journal of Labor Economics 12, $460-477$.

[64] Runkle, D. (1991) 'Liquidity Constraints and the Permanent Income Hypothesis,' Journal of Monetary Economics 27, 73-98.

[65] Saiz, Albert (2003) Room in the Kitchen for the Melting Pot: Immigration and Rental Prices. Review of Economics and Statistics, 85(3):502521.

[66] Shamsuddin, A. (1998). 'Labor supply of immigrant women in australia.' Australian Journal of Labor Economics, 2(2):105-133.

[67] Shamsuddin, A. F. M., and D. J. DeVoretz (1998) Wealth accumulation of Canadian and foreign-born households in Canada. Review of Income and Wealth, 44: 515-533.

[68] Wooden, M., VandenHeuvel, A. (1997). 'Family composition and the labor supply choices of married immigrant women.' Australian Journal of Labor Economics, $1(2), 121-142$.

[69] Worswick, C. (1996) 'Immigrant Families in the Canadian Labour Market, ' Canadian Public Policy, University of Toronto Press, vol. 22(4), pages 378-396, December.

[70] Worswick, C. (1999) 'Credit Constraints and the Labour Supply of Immigrant Families in Canada,' Canadian Journal of Economics, 32(1): 152-170. 
[71] Zabel, J. (1993) 'The Relationship between Hours of Work and Labor Force Participation in Four Models of Labor Supply Behavior,' Journal of Labor Economics $11,387-416$.

[72] Zeldes, S. (1989) 'Consumption and Liquidity Constraints: An Empirical Investigation,' Journal of Political Economy 97, 305-346.

[73] Zhang, Xuelin (2003) The wealth position of immigrant families in Canada, Research Paper No. 197, catalogue number 11F0019MIE, Analytical Studies Branch, Statistics Canada. 
Appendix A

\section{Tables for Chapter 1}


Table 1.1: Sample Means of Key Variables

\begin{tabular}{|c|c|c|}
\hline Variable & Immigrant Households & Canadian-born Households \\
\hline \multirow{2}{*}{ Total Income } & 78.3 & 81.1 \\
\hline & -41 & -42 \\
\hline \multirow{2}{*}{ After Tax Income } & 63.8 & 64.7 \\
\hline & -29 & -30 \\
\hline \multirow{2}{*}{ Wages \& Salaries } & 63.2 & 68.1 \\
\hline & -39 & -41 \\
\hline \multirow{2}{*}{ Self-employment Income } & 7.33 & 5.57 \\
\hline & -25 & -22 \\
\hline \multirow{2}{*}{ Consumption expenditure } & 54.6 & 55.3 \\
\hline & -23 & -24 \\
\hline \multirow{2}{*}{ Savings } & 9.19 & 9.41 \\
\hline & -21 & -19 \\
\hline \multirow{2}{*}{ Change in Net Assets } & 4.62 & 4.86 \\
\hline & -18 & -19 \\
\hline \multicolumn{3}{|l|}{ Region of Residence } \\
\hline \multirow{2}{*}{ Atlantic Provinces } & 0.01 & 0.06 \\
\hline & -0.1 & -0.24 \\
\hline \multirow{2}{*}{ Quebec } & 0.192 & 0.347 \\
\hline & -0.39 & -0.48 \\
\hline \multirow{2}{*}{ Ontario } & 0.508 & 0.29 \\
\hline & -0.5 & -0.45 \\
\hline \multirow{2}{*}{ Prairie Provinces } & 0.139 & 0.191 \\
\hline & -0.35 & -0.39 \\
\hline \multirow{2}{*}{ British Columbia } & 0.151 & 0.112 \\
\hline & -0.36 & -0.32 \\
\hline \multicolumn{3}{|l|}{ Reference Person } \\
\hline \multirow{2}{*}{ Age } & 43.4 & 40.6 \\
\hline & -11 & -11 \\
\hline \multirow{2}{*}{0 to 9 Years of Education } & 0.22 & 0.119 \\
\hline & -0.41 & -0.32 \\
\hline \multirow{2}{*}{ High School } & 0.359 & 0.454 \\
\hline & -0.48 & -0.5 \\
\hline \multirow{2}{*}{ Post-Secondary } & 0.239 & 0.265 \\
\hline & -0.43 & -0.44 \\
\hline \multirow{2}{*}{ University Degree } & 0.183 & 0.162 \\
\hline & -0.39 & -0.37 \\
\hline Sample Size & 4,773 & 16,292 \\
\hline
\end{tabular}

Note: 1. Income, savings, changes in assets and housing equity are all presented in thousands of 2007 Canadian dollars.

2. Standard deviations are in parentheses.

3. All household reference persons were male. 
Table 1.2: FAMEX Regression Estimates from Income Analysis

\begin{tabular}{|c|c|c|c|c|c|c|c|c|}
\hline \multirow[t]{2}{*}{ Variable } & \multicolumn{2}{|c|}{ Total Income } & \multicolumn{2}{|c|}{ After-Tax Income } & \multicolumn{2}{|c|}{ Wage-Salary } & \multicolumn{2}{|c|}{ Self-employment Income } \\
\hline & (1) & $(2)$ & $(3)$ & $(4)$ & $(5)$ & $(6)$ & (7) & $(8)$ \\
\hline \multirow{2}{*}{ Immigrant } & $-9.64^{* *}$ & $-4.60^{* *}$ & $-6.49^{* *}$ & -2.67 & $-8.33^{* *}$ & -3.48 & $-3.22 * *$ & -2.8 \\
\hline & 2.1 & 2.3 & 1.6 & 1.7 & 2.2 & 2.4 & 1.5 & 1.7 \\
\hline \multirow{2}{*}{ YSM } & 0.337 & 0.35 & 0.244 & 0.267 & 0.0384 & 0.0496 & $0.524^{* *}$ & $0.522 * *$ \\
\hline & 0.24 & 0.26 & 0.17 & 0.18 & 0.24 & 0.26 & 0.17 & 0.18 \\
\hline \multirow{2}{*}{ YSM2 } & -0.0025 & -0.0012 & -0.0010 & -0.00026 & 0.00247 & 0.0035 & $-0.0115 * *$ & $-0.0112 * *$ \\
\hline & 0.0056 & 0.0059 & 0.004 & 0.0042 & 0.0056 & 0.0059 & 0.0037 & 0.0039 \\
\hline \multirow{2}{*}{ Before 1946} & $7.79^{*}$ & 0.389 & 3.94 & 0.876 & $8.54^{* *}$ & 4.71 & 2.56 & 2.44 \\
\hline & 4.3 & 4.7 & 3.2 & 3.4 & 4.2 & 4.6 & 3.82 & 4.2 \\
\hline \multirow{2}{*}{$1946-55$} & -0.711 & -4.3 & -1.7 & $-4.57 * *$ & -0.16 & -4.09 & 0.265 & 0.188 \\
\hline & 2.6 & 2.8 & 1.8 & 2.0 & 2.6 & 2.8 & 2.1 & 2.3 \\
\hline \multirow{2}{*}{$1956-60$} & 2.7 & -0.903 & 1.28 & -1.54 & $3.85^{*}$ & 0.981 & -1.14 & -1.78 \\
\hline & 2.2 & 2.4 & 1.6 & 1.8 & 2.3 & 2.5 & 1.6 & 1.8 \\
\hline \multirow{2}{*}{$1961-65$} & 2.09 & -0.105 & 1.17 & -0.517 & $4.51^{*}$ & 2.2 & -1 & -0.981 \\
\hline & 2.3 & 2.6 & 1.7 & 1.9 & 2.5 & 2.8 & 1.7 & 1.9 \\
\hline \multirow{2}{*}{$1971-75$} & $-3.81 *$ & -3.34 & $-2.60^{*}$ & -2.36 & -2.64 & -2.44 & -0.082 & 0.552 \\
\hline & 2.2 & 2.5 & 1.6 & 1.8 & 2.3 & 2.5 & 1.7 & 2.0 \\
\hline \multirow{2}{*}{$1976-80$} & $-8.10^{* *}$ & -4.48 & $-6.30^{* *}$ & $-3.87 * *$ & $-4.95 *$ & -1.06 & -1.68 & -1.8 \\
\hline & 2.5 & 2.8 & 1.8 & 2.0 & 2.6 & 2.8 & 1.7 & 1.8 \\
\hline \multirow{2}{*}{$1981-85$} & $-17.0^{* *}$ & $-13.9 * *$ & $-10.8 * *$ & $-8.62 * *$ & $-15.1^{* *}$ & $-12.3^{* *}$ & -1.58 & -1.34 \\
\hline & 4.4 & 4.6 & 3.3 & 3.4 & 4.3 & 4.4 & 1.7 & 1.8 \\
\hline \multirow{2}{*}{$1986-90$} & $-26.6^{* *}$ & $-22.7 * *$ & $-17.7 * *$ & $-14.8^{* *}$ & $-26.1^{* *}$ & $-22.4^{* *}$ & 0.426 & 0.847 \\
\hline & 3.3 & 3.4 & 2.4 & 2.5 & 3.3 & 3.4 & 2.2 & 2.3 \\
\hline Huchond A 10 & $2.76^{* *}$ & $2.99 * *$ & $1.75^{* *}$ & $1.92 * *$ & $2.26 * *$ & $2.47 * *$ & $0.909 * *$ & $0.925 * *$ \\
\hline Husband Age & 0.36 & 0.37 & 0.26 & 0.26 & 0.38 & 0.391 & 0.23 & 0.24 \\
\hline & $-.0290 * *$ & $-.0315^{* *}$ & $-0.0180^{* *}$ & $-0.0198^{* *}$ & $-0.0263^{* *}$ & $-0.0287^{* *}$ & $-0.0092 * *$ & $-0.00936^{* *}$ \\
\hline Husband Age2 & 0.0042 & 0.0043 & 0.003 & 0.0031 & 0.0045 & 0.0046 & 0.0025 & 0.0026 \\
\hline & $2.68^{* *}$ & $2.51 * *$ & $1.95 * *$ & $1.83^{* *}$ & $3.71 * *$ & $3.56^{* *}$ & -0.108 & -0.102 \\
\hline Wife Age & 0.36 & 0.37 & 0.26 & 0.26 & 0.38 & 0.39 & 0.23 & 0.24 \\
\hline Wife A Ao? & $-0.0262^{* *}$ & $-0.0243^{* *}$ & $-0.0194 * *$ & $-0.0181 * *$ & $-0.0397 * *$ & $-0.0381 * *$ & 0.0008 & 0.0007 \\
\hline Wife Age2 & 0.0043 & 0.0045 & 0.0031 & 0.0032 & 0.0046 & 0.0048 & 0.0026 & 0.0027 \\
\hline High School(Husband) & $-8.80 * *$ & $-9.21 * *$ & $-6.01 * *$ & $-6.26 * *$ & $-8.88 * *$ & $-9.38^{* *}$ & -0.472 & -0.374 \\
\hline Hign Scnoor(Husband) & 0.84 & 0.87 & 0.65 & 0.66 & 0.93 & 0.96 & 0.5 & 0.52 \\
\hline Post Secondaru(Hushand) & $8.54^{* *}$ & $8.49^{* *}$ & $5.48^{* *}$ & $5.43^{* *}$ & $7.33^{* *}$ & $7.46^{* *}$ & 0.764 & 0.629 \\
\hline Post Secondary(Husband) & 0.79 & 0.82 & 0.57 & 0.58 & 0.83 & 0.85 & 0.5 & 0.51 \\
\hline University(Husband) & $27.4^{* *}$ & $27.3^{* *}$ & $17.5^{* *}$ & $17.4^{* *}$ & $20.2^{* *}$ & $20.2^{* *}$ & $6.80 * *$ & $6.82^{* *}$ \\
\hline University(Husband) & 1.3 & 1.3 & 0.89 & 0.91 & 1.3 & 1.3 & 1.0 & 1.1 \\
\hline 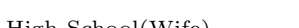 & $-11.0^{* *}$ & $-11.1^{* *}$ & $-7.97 * *$ & $-8.05^{* *}$ & $-8.82^{* *}$ & $-8.96^{* *}$ & $-1.63^{* *}$ & $-1.63^{* *}$ \\
\hline High Schoor(Wife) & 0.88 & 0.9 & 0.66 & 0.67 & 0.96 & 0.99 & 0.51 & 0.53 \\
\hline Post Secondary(Wife) & $7.94^{* *}$ & $7.83^{* *}$ & $5.74^{* *}$ & $5.63 * *$ & $7.36^{* *}$ & $7.18^{* *}$ & 0.503 & 0.565 \\
\hline & 0.8 & 0.82 & 0.57 & 0.58 & 0.83 & 0.85 & 0.57 & 0.58 \\
\hline University(Wife) & $17.6^{* *}$ & $17.7 * *$ & $12.6^{* *}$ & $12.7 * *$ & $18.0 * *$ & $18.0^{* *}$ & -1.19 & -1.02 \\
\hline University(Wife) & 1.5 & 1.6 & 1.1 & 1.1 & 1.6 & 1.6 & 1.1 & 1.1 \\
\hline Fomilu Sim & $2.21 * *$ & $2.10^{* *}$ & $1.71^{* *}$ & $1.62^{* *}$ & 0.605 & 0.446 & 0.727 & 0.779 \\
\hline Family size & 0.97 & 0.99 & 0.72 & 0.74 & 1.1 & 1.1 & 0.61 & 0.62 \\
\hline Fomilu Sinor & 0.133 & 0.149 & $0.177^{* *}$ & $0.190^{* *}$ & -0.0464 & 0.0752 & 0.0233 & 0.0128 \\
\hline Family size2 & 0.11 & 0.12 & 0.088 & 0.089 & 0.13 & 0.13 & 0.077 & 0.077 \\
\hline South and Fast Furone & & $-4.23 * *$ & & $-3.37 * *$ & & $-4.10 * *$ & & -0.368 \\
\hline South and East Europe & & 1.6 & & 1.1 & & 1.7 & & 1.2 \\
\hline Other Region & & $-10.9 * *$ & & $-8.08 * *$ & & $-10.5 * *$ & & -0.96 \\
\hline & & 2.0 & & 1.4 & & 2.0 & & 1.4 \\
\hline Intercent & $-47.0 * *$ & $-47.8^{* *}$ & $-24.2^{* *}$ & $-24.8^{* *}$ & $-54.7 * *$ & $-55.4^{* *}$ & $-16.4^{* *}$ & $-16.9^{* *}$ \\
\hline Intercept & 4.9 & 5.0 & 3.5 & 3.6 & 5 & 5.1 & 2.9 & 3.0 \\
\hline F-value & $11.1^{* *}$ & $7.05^{* *}$ & $9.39 * *$ & $6.10^{* *}$ & $10.4^{* *}$ & $7.46^{* *}$ & 0.49 & 0.65 \\
\hline $\mathrm{R} 2$ & 0.287 & 0.291 & 0.274 & 0.278 & 0.210 & 0.214 & 0.0273 & 0.0276 \\
\hline Sample Size & 21,065 & 20,255 & 21,065 & 20,255 & 21,065 & 20,255 & 21,065 & 20,255 \\
\hline
\end{tabular}

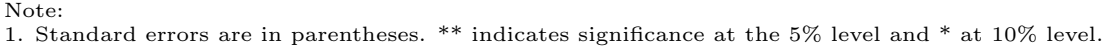

2. Controls included for three educational levels, four regions of residence, six survey year dummies.

3. The sample used in the results presented in columns $(2),(4),(6)$ and (8) does not contain observations from 1982 since source country information was not available.

4. The default immigrant arrival cohort is 1966-70. The default source country region is US, UK, northern Europe and Western Europe. 
Table 1.3: FAMEX Regression Estimates

\begin{tabular}{|c|c|c|c|c|c|c|c|c|}
\hline & \multicolumn{2}{|c|}{ Consumption } & \multicolumn{2}{|c|}{ Asset Change } & \multicolumn{2}{|c|}{ Saving Rate } & \multicolumn{2}{|c|}{ Savings } \\
\hline Variable & (1) & $(2)$ & (3) & $(4)$ & $(5)$ & (6) & $(7)$ & $(8)$ \\
\hline Immigrant & $-7.18^{* *}$ & -3.21 & $-2.02^{*}$ & -1.03 & -0.11 & -0.0567 & $-3.12^{* *}$ & -1.61 \\
\hline & 2.0 & 2.2 & 1.1 & 1.2 & 0.1 & 0.078 & 1.2 & 1.3 \\
\hline & 0.264 & 0.3 & 0.0107 & 0.0075 & 0.0109 & 0.0119 & 0.067 & 0.0452 \\
\hline YSM & 0.21 & 0.23 & 0.12 & 0.12 & 0.012 & 0.013 & 0.13 & 0.14 \\
\hline YSM2 & -0.00361 & -0.00314 & -0.0008 & 0.00118 & -0.0002 & -0.0002 & 0.00196 & 0.00295 \\
\hline YSML2 & 0.0047 & 0.0049 & 0.0028 & 0.003 & 0.0002 & 0.0002 & 0.0031 & 0.0033 \\
\hline Arrived & & & & & & & & \\
\hline Before 1946 & $7.36^{* *}$ & 3.9 & 1.3 & 0.61 & 0.00176 & -0.0533 & 0.727 & 0.0186 \\
\hline & 3.7 & 4.0 & 1.9 & 2.1 & 0.047 & 0.079 & 2.2 & 2.3 \\
\hline $1946-55$ & -0.33 & -3.35 & 0.802 & 0.122 & -0.0251 & -0.073 & -0.748 & -1.64 \\
\hline & 2.3 & 2.5 & 1.2 & 1.3 & 0.049 & 0.082 & 1.4 & 1.4 \\
\hline $1956-60$ & 0.613 & -2.9 & $2.62^{* *}$ & $2.27^{*}$ & 0.0117 & -0.0334 & $2.15^{*}$ & 1.82 \\
\hline & 0.849 & -0.906 & $213^{*}$ & 1.61 & 0.0155 & $\begin{array}{r}0.079 \\
-0.028\end{array}$ & 1.55 & $\begin{array}{r}1.4 \\
0.922\end{array}$ \\
\hline $1961-65$ & 2.1 & 2.4 & 1.1 & 1.3 & 0.035 & 0.055 & 1.3 & 1.5 \\
\hline & $-4.50^{* *}$ & $-4.50^{* *}$ & 0.763 & 1.07 & 0.0139 & 0.0309 & 0.267 & 0.647 \\
\hline $1971-75$ & 2.0 & 2.3 & 1.2 & 1.4 & 0.021 & 0.026 & 1.2 & 1.4 \\
\hline $1976-80$ & $-8.60 * *$ & $-6.37 * *$ & -0.371 & 0.501 & 0.0282 & $0.0751 *$ & -0.315 & 1.31 \\
\hline $1976-80$ & 2.4 & 2.7 & 1.1 & 1.3 & 0.028 & 0.039 & 1.2 & 1.4 \\
\hline & $-12.6^{* *}$ & $-10.3^{* *}$ & $-4.43^{* *}$ & $-3.95^{*}$ & -0.92 & -0.894 & $-5.96 * *$ & $-5.14^{* *}$ \\
\hline $1981-85$ & 3.9 & 4.1 & 2.2 & 2.2 & 0.82 & 0.81 & 2.5 & 2.5 \\
\hline & $-21.9^{* *}$ & $-18.8^{* *}$ & $-6.01 * *$ & $-5.31 * *$ & -0.511 & -0.449 & $-7.09 * *$ & $-6.04 * *$ \\
\hline $1986-90$ & 2.9 & 3.0 & 1.7 & 1.7 & 0.41 & 0.4 & 1.9 & 1.9 \\
\hline Husband A ge & $2.55^{* *}$ & $2.72 * *$ & 0.141 & 0.197 & 0.00798 & 0.0104 & $0.569 * *$ & $0.653^{* *}$ \\
\hline Husband Age & 0.33 & 0.34 & 0.17 & 0.18 & 0.0094 & 0.01 & 0.18 & 0.19 \\
\hline Husband Ame? & $-.0268 * *$ & $-0.0287^{* *}$ & -0.00105 & -0.00167 & -0.0002 & -0.0002 & $-0.00594 * *$ & $-0.00691 * *$ \\
\hline Husband Age2 & 0.0038 & 0.004 & 0.002 & 0.0021 & 0.0001 & 0.0001 & 0.0021 & 0.0022 \\
\hline Wife Are & $2.17^{* *}$ & $2.02 * *$ & $0.539 * *$ & $0.518 * *$ & -0.00505 & -0.00666 & $0.591 * *$ & $0.560 * *$ \\
\hline Wife Age & 0.33 & 0.34 & 0.19 & 0.2 & 0.01 & 0.011 & 0.19 & 0.19 \\
\hline & $-0.0226^{* *}$ & $-0.0209 * *$ & $-0.00464^{* *}$ & $-0.00445^{*}$ & 0.0002 & 0.0002 & $-.00377^{*}$ & -0.00343 \\
\hline Wite Age2 & 0.004 & 0.0041 & 0.0023 & 0.0024 & 0.0001 & 0.0002 & 0.0023 & 0.0023 \\
\hline Himb Schol(Huboud) & $-7.93^{* *}$ & $-8.22^{* *}$ & -0.566 & -0.669 & 0.0132 & 0.00822 & $-1.78^{* *}$ & $-1.92 * *$ \\
\hline High School(Husband) & 0.77 & 0.79 & 0.41 & 0.42 & 0.039 & 0.039 & 0.46 & 0.47 \\
\hline Post Secondary(Husband) & $7.72 * *$ & $7.63^{* *}$ & $1.29^{* *}$ & $1.38^{* *}$ & -0.00695 & -0.0067 & $1.69^{* *}$ & $1.75^{* *}$ \\
\hline Fost secondary (nusband) & 0.75 & 0.77 & 0.42 & 0.44 & 0.032 & 0.033 & 0.41 & 0.42 \\
\hline University (Husband) & $22.5^{* *}$ & $22.4^{* *}$ & $5.57 * *$ & $5.59^{* *}$ & -0.0205 & -0.0211 & $7.64^{* *}$ & $7.58^{* *}$ \\
\hline University(Husband) & 1.1 & 1.2 & 0.67 & 0.69 & 0.087 & 0.088 & 0.66 & 0.67 \\
\hline High School(Wife) & $-9.83^{* *}$ & $-9.96 * *$ & $-1.62 * *$ & $-1.50 * *$ & -0.0687 & -0.0733 & $-2.27^{* *}$ & $-2.26 * *$ \\
\hline High School(Wife) & 0.81 & 0.84 & 0.43 & 0.44 & 0.062 & 0.066 & 0.48 & 0.49 \\
\hline Post Secondary (Wife) & $6.95 * *$ & $6.91 * *$ & $1.23 * *$ & $1.12^{* *}$ & $.0754^{*}$ & $.0743^{*}$ & $1.84^{* *}$ & $1.74^{* *}$ \\
\hline Post secondary(Wife) & 0.74 & 0.76 & 0.43 & 0.44 & 0.042 & 0.042 & 0.43 & 0.43 \\
\hline & $13.7^{* *}$ & $13.8^{* *}$ & $3.53^{* *}$ & $3.58^{* *}$ & $.138^{*}$ & $.140 *$ & $5.62 * *$ & $5.68^{* *}$ \\
\hline University(Wife) & 1.3 & 1.4 & 0.78 & 0.79 & 0.081 & 0.082 & 0.82 & 0.83 \\
\hline Family Size & $4.58^{* *}$ & $4.46^{* *}$ & $-2.02 * *$ & $-2.00 * *$ & -0.024 & -0.0237 & $-2.75^{* *}$ & $-2.73^{* *}$ \\
\hline Family Size & 0.84 & 0.86 & 0.5 & 0.51 & 0.03 & 0.031 & 0.51 & 0.52 \\
\hline Family Size? & -0.0799 & -0.061 & $0.172^{* *}$ & $0.172^{* *}$ & 0.00313 & 0.00325 & $0.253^{* *}$ & $0.251 * *$ \\
\hline Family size2 & 0.1 & 0.1 & 0.059 & 0.06 & 0.003 & 0.003 & 0.061 & 0.062 \\
\hline Sout t & & $-3.51 * *$ & & -0.877 & & -0.0114 & & -1.33 \\
\hline south and East Europe & & 1.4 & & 0.81 & & 0.028 & & 0.88 \\
\hline Other Begion & & $-8.58^{* *}$ & & $-2.03^{* *}$ & & $-0.151^{\wedge}$ & & $-2.96 * *$ \\
\hline Uther Kegion & & 1.8 & & 0.99 & & 0.087 & & 1.1 \\
\hline Intercent & $-35.8^{* *}$ & $-35.7^{* *}$ & $-8.79^{* *}$ & $-9.50 * *$ & -0.0881 & -0.104 & $-15.6^{* *}$ & $-16.6^{* *}$ \\
\hline Intercept & 4.3 & 4.4 & 2.4 & 2.5 & 0.1 & 0.11 & 2.5 & 2.6 \\
\hline F-value & $9.15^{* *}$ & $6.01 * *$ & $3.29 * *$ & $2.63 * *$ & 1.14 & 1.11 & $3.64 * *$ & $3.24^{* *}$ \\
\hline $\mathrm{R} 2$ & 0.264 & 0.267 & 0.057 & 0.0572 & 0.0091 & 0.0095 & 0.109 & 0.111 \\
\hline Sample Size & 21,065 & 20,255 & 21,065 & 20,255 & 21,064 & 20,254 & 21,065 & 20,255 \\
\hline
\end{tabular}

Note:

1. Standard errors are in parentheses. * indicates significance at the $5 \%$ level and * at $10 \%$ level.

2. Controls included for three educations, four region of residence, six survey year dummies.

3 . The sample used in the analysis of columns (2), (4) and (6) does not contain observations from 1982 since source country information was not available.

4. The default immigrant arrival cohort is 1966-70. The default source country region is US, UK, northern Europe and Western Europe. 


\section{Appendix B}

\section{Tables for Chapter 2}

Definitions of Variables and Tables

1) Whour: Annual working hours of wife $(=16 *$ Part-timeweeks $+40 *$ Full timeweeks)

2) Wwage: Wife's wage rate

3) Wage: Wife's age

4) Wwork: Dummy variable for wife working (=1 if wife works)

5) Hhour: Annual working hours of husband (=16* Part - timeweeks $+40 *$ Full-timeweeks)

6) Hwage: Husband wage rate

7) Hage: Husband age

8) Total Consumption: Family annual expenditure

9) Durable: Family durable consumption

10) Non-durable: Family non-durable consumption

11) Food: Family food consumption

12) Ch03: Number of children between 0 and 3 years old

13) Ch46: Number of children between 4 and 6 years old

14) Ch79: Number of children between 7 and 9 years old 
15) Ch1012: Number of children between 10 and 12 years old

16) Ch1315: Number of children between 13 and 15 years old

17) kids06: Number of children between 0 and 6 years old

18) kids6plus: Number of children above 6 years old

19) FB: Dummy variable for immigrant status (=1 if immigrant)

20) S.,E.Europe: Immigrant wife from South and East Europe

21) Other FB: Immigrant wife from other countries

22) scb61: Immigrant wife arrives in Canada before 1961

23) sc7180: Immigrant wife arrives in Canada between 1971 and 1980

24) YSM: Year since migration to Canada

25) YSM2: Square of YSM

26) Credit: Dummy variable for credit constraint status (= 1 if the family is credit constraint)

27) age2534: Age between 25 and 34

28) age4559: Age between 45 and 59

29) Lamda: Inverse Mill's Ratio for wife's work decision

30) Income: Family after-tax income 
Table 2.1: Sample Means of Variables

\begin{tabular}{l|rr|rrr}
\hline & \multicolumn{2}{|c}{ Canadian Family } & \multicolumn{2}{c}{ Immigrant Family } \\
Variables & mean & std.dev & mean & std.dev \\
\hline Credit & 0.744 & 0.44 & 0.733 & 0.44 \\
Whether wife works & 0.747 & 0.43 & 0.698 & 0.46 \\
Wife's hours & 1424 & 724 & 1522 & 693 \\
Wife's wages & 20.3 & 25 & 17.1 & 13 \\
Wife's age & 38.1 & 8.8 & 40.9 & 8.6 \\
Husband's hours & 1802 & 595 & 1754 & 641 \\
Husband's wages & 27.2 & 18 & 24.0 & 17 \\
Husband's age & 40.1 & 9.1 & 43.9 & 8.7 \\
Total Consumption & 57.1 & 24 & 56.2 & 25 \\
On Durables & 19.2 & 12 & 19.1 & 13 \\
On Non-Durables & 37.9 & 16 & 37.1 & 18 \\
On Food & 10.4 & 4.2 & 11.4 & 5.0 \\
Ch03 & 0.243 & 0.50 & 0.217 & 0.47 \\
Ch46 & 0.208 & 0.46 & 0.209 & 0.46 \\
Ch79 & 0.206 & 0.45 & 0.257 & 0.50 \\
Ch1012 & 0.198 & 0.45 & 0.230 & 0.48 \\
Ch1315 & 0.178 & 0.43 & 0.242 & 0.50 \\
\hline Sample Size & 6316 & & 1335 & \\
\hline
\end{tabular}

Note:

1) The wife's hour and wage are defined over the sample of women with positive hours of work;

2) Consumption expenditure is expressed in thousands of dollars. 


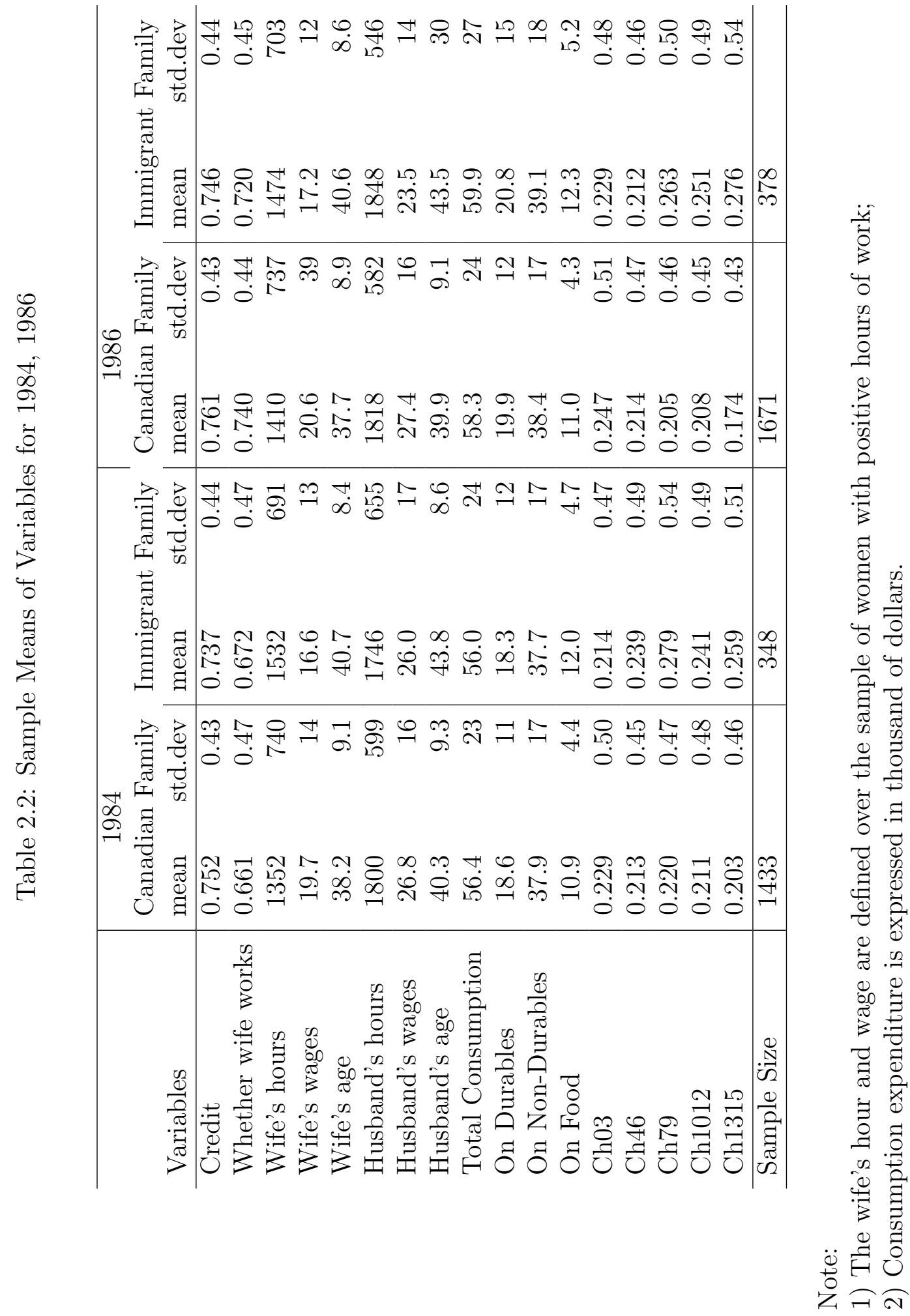




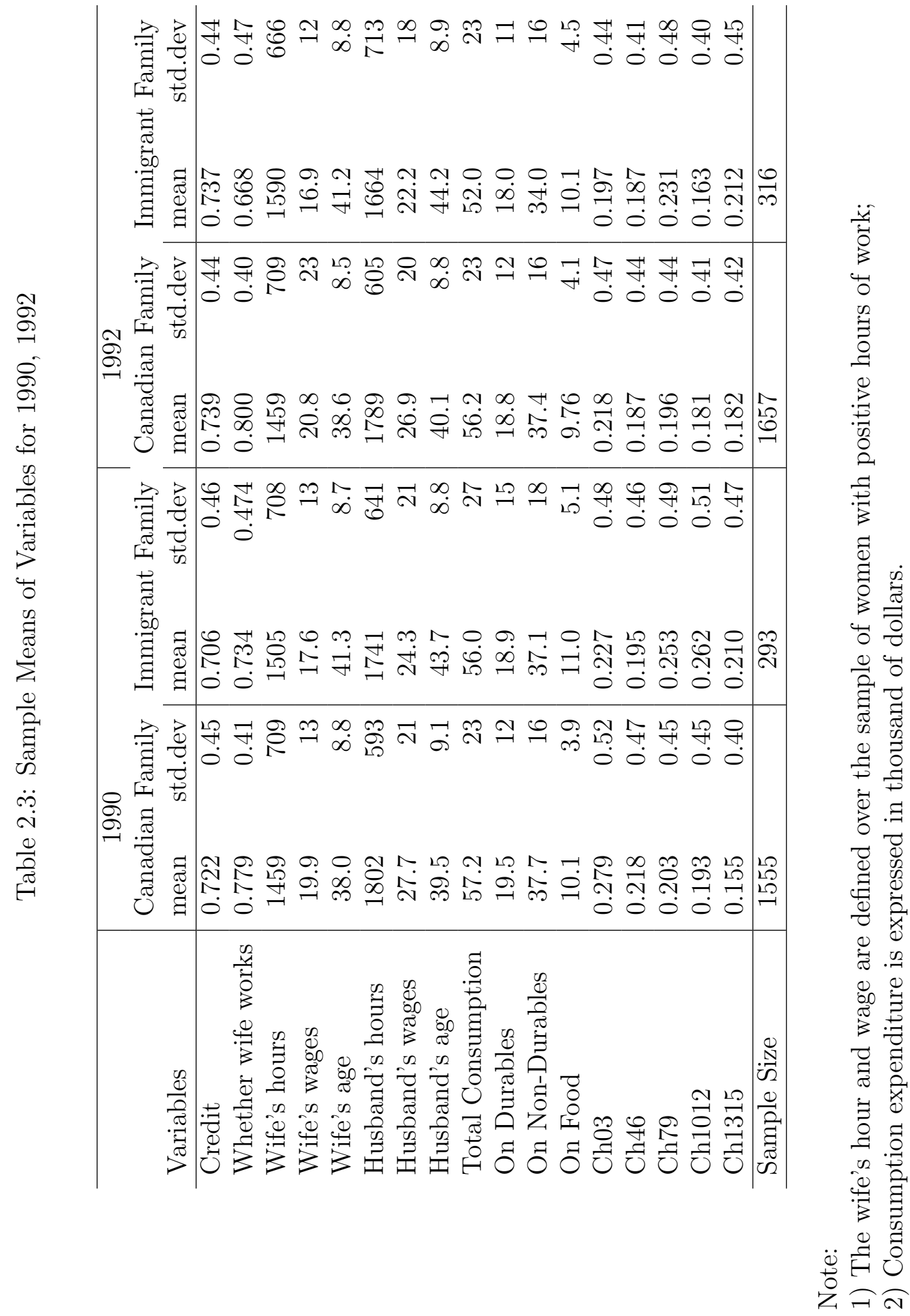




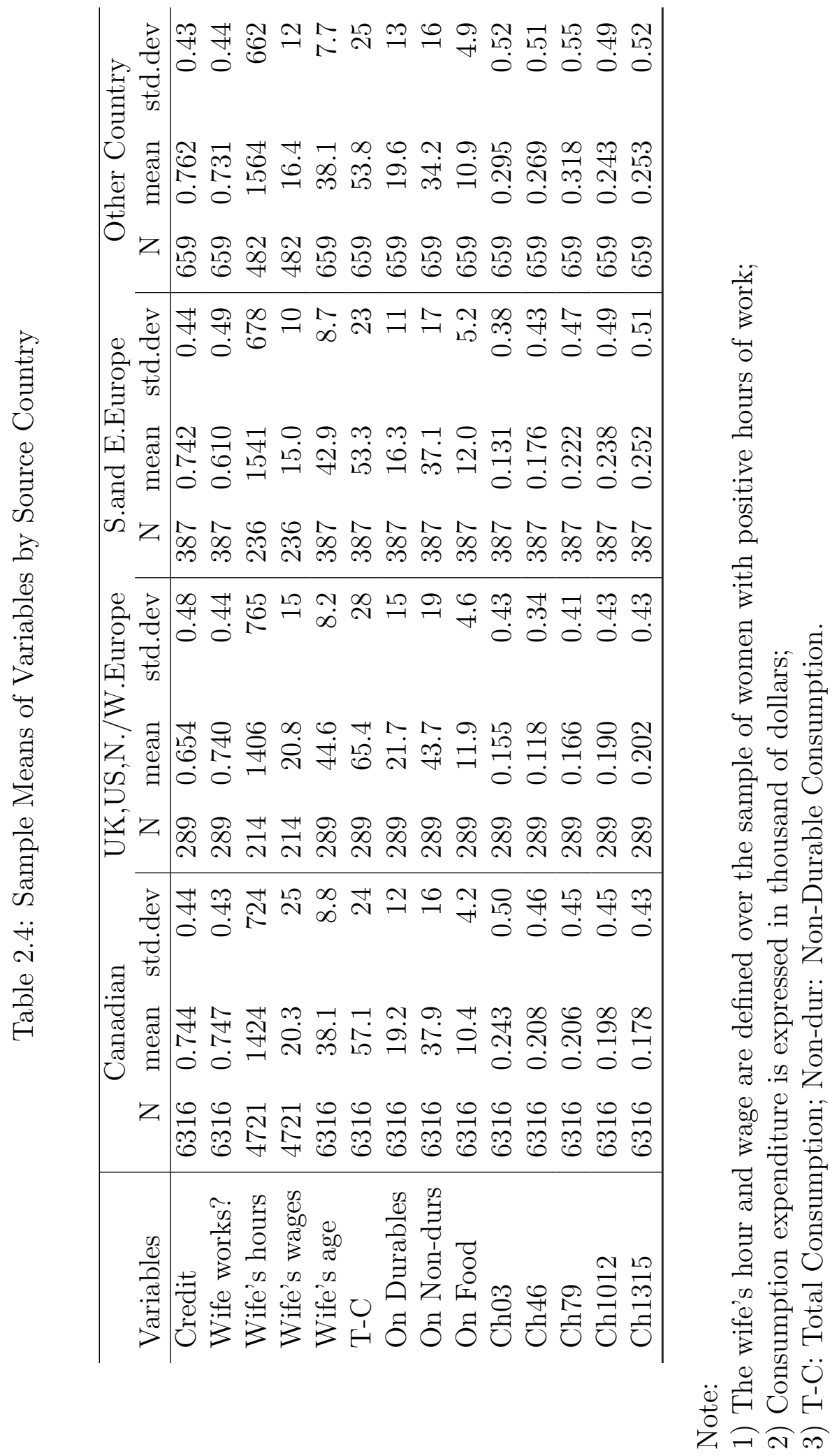


Table 2.5: Sample Means of Variables for 1971-80 arrival cohort: UK, US, North \& West Europe

\begin{tabular}{l|rr|rr|rr|rr}
\hline & \multicolumn{3}{|c}{1984} & \multicolumn{2}{c}{1986} & \multicolumn{2}{c}{1990} & \multicolumn{2}{c}{1992} \\
Variables & mean & std.dev & mean & std.dev & mean & std.dev & mean & std.dev \\
\hline Credit & 0.792 & 0.42 & 0.929 & 0.27 & 0.615 & 0.51 & 0.750 & 0.45 \\
Wife's hours & 1315 & 843 & 1252 & 750 & 1676 & 743 & 1571 & 797 \\
Wife's wages & 19.9 & 14 & 21.5 & 14 & 14.7 & 12 & 21.1 & 14 \\
Wife's age & 38.4 & 7.1 & 41.6 & 8.2 & 43.2 & 5.2 & 44.1 & 5.6 \\
Whether wife works & 0.708 & 0.46 & 0.929 & 0.27 & 0.692 & 0.48 & 0.875 & 0.34 \\
T-C & 72.7 & 32 & 74.2 & 29 & 64.6 & 21 & 77.4 & 34 \\
On Durables & 28.1 & 17 & 25.3 & 12 & 18.9 & 9.2 & 24.5 & 12 \\
On Non-durs & 44.6 & 18 & 49.0 & 20 & 45.8 & 15 & 52.9 & 24 \\
On Food & 13.7 & 5.3 & 13.0 & 2.2 & 12.3 & 4.6 & 12.8 & 6.1 \\
Ch03 & 0.167 & 0.38 & 0.214 & 0.43 & 0 & 0 & 0.109 & 0.44 \\
Ch46 & 0.250 & 0.53 & 0.143 & 0.36 & 0.231 & 0.60 & 0.125 & 0.34 \\
Ch79 & 0.500 & 0.66 & 0.214 & 0.43 & 0.308 & 0.63 & 0.188 & 0.54 \\
Ch1012 & 0.250 & 0.44 & 0.214 & 0.43 & 0.154 & 0.38 & 0.188 & 0.40 \\
Ch1315 & 0.208 & 0.51 & 0.523 & 0.55 & 0.154 & 0.38 & 0.250 & 0.45 \\
\hline Sample Size & 24 & & 14 & & 13 & & 16 & \\
\hline
\end{tabular}

Note:

1) The wife's hour and wage are defined over the sample of women with positive hours of work;

2) Consumption expenditure is expressed in thousand of dollars;

3) T-C: Total Consumption; Non-dur: Non-Durable Consumption. 
Table 2.6: Sample Means of Variables for 1971-80 arrival cohort: South \& East Europe

\begin{tabular}{l|rr|rr|rr|rr}
\hline & \multicolumn{3}{|c}{1984} & \multicolumn{2}{c}{1986} & \multicolumn{2}{c}{1990} & \multicolumn{2}{c}{1992} \\
Variables & mean & std.dev & mean & std.dev & mean & std.dev & mean & std.dev \\
\hline Credit & 0.750 & 0.44 & 0.765 & 0.43 & 0.688 & 0.48 & 0.739 & 0.45 \\
Wife's hours & 1480 & 737 & 1503 & 675 & 1769 & 538 & 1871 & 496 \\
Wife's wages & 13.3 & 14 & 14.0 & 8.6 & 19.2 & 8.3 & 12.0 & 5.9 \\
Wife's age & 36.0 & 7.4 & 38.4 & 7.0 & 44.4 & 8.6 & 41.6 & 8.3 \\
Whether wife works & 0.714 & 0.46 & 0.588 & 0.50 & 0.750 & 0.45 & 0.478 & 0.51 \\
T-C & 47.6 & 25 & 50.5 & 19 & 64.9 & 27 & 46.8 & 14 \\
On Durables & 16.1 & 13 & 15.7 & 9.1 & 16.9 & 12 & 14.7 & 8.5 \\
On Non-durs & 31.4 & 15 & 34.8 & 15 & 48.1 & 19 & 32.1 & 11 \\
On Food & 11.7 & 4.4 & 12.0 & 4.4 & 13.7 & 6.6 & 10.3 & 2.6 \\
Ch03 & 0.312 & 0.59 & 0.289 & 0.52 & 0.0625 & 0.25 & 0 & 0 \\
Ch46 & 0.393 & 0.63 & 0.265 & 0.51 & 0.313 & 0.48 & 0.217 & 0.42 \\
Ch79 & 0.464 & 0.64 & 0.353 & 0.49 & 0.313 & 0.60 & 0.174 & 0.39 \\
Ch1012 & 0.536 & 0.79 & 0.176 & 0.46 & 0.250 & 0.45 & 0.261 & 0.45 \\
Ch1315 & 0.214 & 0.50 & 0.353 & 0.60 & 0.313 & 0.48 & 0.304 & 0.47 \\
\hline Sample Size & 28 & & 34 & & 16 & & 23 & \\
\hline
\end{tabular}

Note:

1) The wife's hour and wage are defined over the sample of women with positive hours of work;

2) Consumption expenditure is expressed in thousand of dollars;

3) T-C: Total Consumption; Non-dur: Non-Durable Consumption. 
Table 2.7: Sample Means of Variables for 1971-80 arrival cohort: Other Country

\begin{tabular}{l|rr|rr|rr|rr}
\hline & \multicolumn{3}{|c}{1984} & \multicolumn{2}{c}{1986} & \multicolumn{2}{c}{1990} & \multicolumn{2}{c}{1992} \\
Variables & mean & std.dev & mean & std.dev & mean & std.dev & mean & std.dev \\
\hline Credit & 0.827 & 0.38 & 0.772 & 0.42 & 0.689 & 0.47 & 0.643 & 0.48 \\
Wife's hours & 1638 & 605 & 1566 & 679 & 1551 & 668 & 1585 & 631 \\
Wife's wages & 15.0 & 8.9 & 15.4 & 10 & 19.0 & 15 & 20.6 & 19 \\
Wife's age & 36.4 & 7.9 & 36.5 & 6.7 & 39.4 & 7.7 & 40.9 & 7.3 \\
Whether wife works & 0.667 & 0.47 & 0.792 & 0.41 & 0.757 & 0.43 & 0.804 & 0.40 \\
T-C & 52.0 & 20 & 53.4 & 22 & 55.7 & 19 & 54.9 & 21 \\
On Durables & 18.7 & 9.9 & 20.3 & 15 & 18.9 & 11 & 19.3 & 12 \\
On Non-durs & 33.3 & 15 & 33.1 & 13 & 36.8 & 15 & 35.6 & 14 \\
On Food & 11.0 & 4.1 & 11.3 & 4.4 & 11.7 & 4.5 & 10.7 & 3.8 \\
Ch03 & 0.446 & 0.61 & 0.284 & 0.51 & 0.298 & 0.53 & 0.130 & 0.35 \\
Ch46 & 0.333 & 0.57 & 0.426 & 0.61 & 0.243 & 0.49 & 0.196 & 0.40 \\
Ch79 & 0.297 & 0.53 & 0.412 & 0.60 & 0.378 & 0.57 & 0.268 & 0.52 \\
Ch1012 & 0.123 & 0.33 & 0.347 & 0.57 & 0.412 & 0.64 & 0.268 & 0.49 \\
Ch1315 & 0.247 & 0.51 & 0.238 & 0.59 & 0.270 & 0.53 & 0.357 & 0.52 \\
\hline Sample Size & 81 & & 101 & & 74 & & 56 & \\
\hline
\end{tabular}

Note:

1) The wife's hour and wage are defined over the sample of women with positive hours of work;

2) Consumption expenditure is expressed in thousand of dollars;

3) T-C: Total Consumption; Non-dur: Non-Durable Consumption. 
Table 2.8: Estimation Results for within Period Marginal Rate of Substitution Function: Wife's leisure time

\begin{tabular}{rrr|rrr}
\hline & & & & & \\
Variables & coefficient & std.error & Variables & coefficient & std.error \\
\hline Consumption & $0.140^{* *}$ & 0.019 & kids06 & $0.0257^{* *}$ & 0.0036 \\
Wife's wage & $-0.103^{* *}$ & 0.024 & kids6plus & $0.0142^{* *}$ & 0.0038 \\
S.,E.Europe & $-0.0374^{* *}$ & 0.010 & fbkids06 & $-0.0176^{* *}$ & 0.0082 \\
Other FB & $-0.0351^{* *}$ & 0.0094 & fbkids6plus & -0.0110 & 0.0071 \\
scb61 & 0.0433 & 0.028 & sc6170 & $0.0394^{*}$ & 0.022 \\
sc7180 & 0.0217 & 0.016 & YSM & $-0.00638^{* *}$ & 0.0019 \\
FB & $0.0434^{* *}$ & 0.014 & YSM2 & $0.000121^{* *}$ & 0.00004 \\
Intercept & $8.65^{* *}$ & 0.069 & Lamda & 0.0336 & 0.039 \\
\hline Wald chi2 & 323 & & $\mathrm{~N}$ & 7,476 & \\
Millls Lambda: & 0.0336 & 0.039 & & & \\
Rho & 0.349 & & Sigma & 0.0964 & \\
\hline
\end{tabular}

Note: ${ }^{* *}$ stands for $5 \%$ significance level; ${ }^{*}$ stands for $10 \%$ significance level. 
Table 2.9: Estimation Results of Euler Equation for Total Consumption

\begin{tabular}{rrr|rrr}
\hline With C.C. & & & Without C.C. & & \\
Variables & coefficient & std.error & Variables & coefficient & std.error \\
\hline Credit Constraint & $0.147^{* *}$ & 0.051 & - & & \\
age2534 & -0.0398 & 0.048 & age2534 & -0.0310 & 0.048 \\
age4559 & $-0.106^{* *}$ & 0.042 & age4559 & $-0.122^{* *}$ & 0.042 \\
d.kids06 & -0.0628 & 0.049 & d.kids06 & -0.0699 & 0.049 \\
d.kids6plus & $-0.102^{* *}$ & 0.040 & d.kids6plus & $-0.0916^{* *}$ & 0.040 \\
S..E.Europe & -0.0190 & 0.073 & S.,E.Europe & -0.00754 & 0.075 \\
other FB & 0.128 & 0.083 & other FB & 0.125 & 0.085 \\
scb6170 & -0.0837 & 0.076 & scb6170 & -0.101 & 0.078 \\
sc7180 & -0.134 & 0.083 & sc7180 & $-0.146^{*}$ & 0.084 \\
sc8192 & $-0.177^{*}$ & 0.096 & sc8192 & $-0.181^{*}$ & 0.098 \\
Intercept & 0.151 & 0.058 & Intercept & $0.283^{* *}$ & 0.034 \\
\hline Wald chi2 & 28.5 & & Wald chi2 & 19.9 & \\
N & 574 & & N & 574 & \\
R-Square: & Within: 0.0279 & & Within: 0.0242 & & \\
R-Square: & Between: 0.0820 & & Between: 0.0469 & & \\
R-Square: & Overall: 0.0485 & & Overall: 0.0345 & & \\
\hline
\end{tabular}

Note:

1) ** stands for $5 \%$ significance level;

2) * stands for $10 \%$ significance level;

3) We define a family with a credit constraint if the net change in assets and liabilities of the family is less than two months' net income;

4) C.C.: credit constraint. 
Table 2.10: Estimation Results of Euler Equation for Durable Consumption

\begin{tabular}{rrr|rrr}
\hline With C.C. & & & Without C.C. & & \\
Variables & coefficient & std.error & Variables & coefficient & std.error \\
\hline Credit Constraint & $0.232^{* *}$ & 0.071 & - & & \\
age2534 & 0.0392 & 0.066 & age2534 & 0.0526 & 0.066 \\
age4559 & -0.0658 & 0.058 & age4559 & -0.0913 & 0.058 \\
d.kids06 & -0.0247 & 0.068 & d.kids06 & -0.0344 & 0.068 \\
d.kids6plus & $-0.105^{*}$ & 0.056 & d.kids6plus & -0.0905 & 0.056 \\
S.,E.Europe & 0.0135 & 0.10 & S.,E.Europe & 0.313 & 0.10 \\
other FB & $0.212^{*}$ & 0.11 & other FB & $0.207^{*}$ & 0.12 \\
scb6170 & $-0.208^{* *}$ & 0.11 & scb6170 & $-0.234^{* *}$ & 0.11 \\
sc7180 & $-0.227^{* *}$ & 0.11 & sc7180 & $-0.245^{* *}$ & 0.12 \\
sc8192 & -0.101 & 0.13 & sc8192 & -0.107 & 0.13 \\
Intercept & 0.0461 & 0.080 & Intercept & 0.257 & 0.049 \\
\hline Wald chi2 & 29.2 & & Wald chi2 & 18.1 & \\
N & 572 & & Within: 0.0112 & 572 & \\
R-Square: & Within: 0.0281 & & Between: 0.0682 & & \\
R-Square: & Between: 0.0948 & & Overall: 0.0309 & & \\
R-Square: & Overall: 0.0481 & & & & \\
\hline
\end{tabular}

Note:

1) ** stands for $5 \%$ significance level;

2) * stands for $10 \%$ significance level;

3) We define a family with a credit constraint if the net change in assets and liabilities of the family is less than two months' net income;

4) C.C.: credit constraint. 
Table 2.11: Estimation Results of Euler Equation for Non-Durable Consumption

\begin{tabular}{rrr|rrr}
\hline With C.C. & & & Without C.C. & & \\
Variables & coefficient & std.error & Variables & coefficient & std.error \\
\hline Credit Constraint & $0.114^{* *}$ & 0.054 & - & & \\
age2534 & -0.0652 & 0.050 & age2534 & -0.0583 & 0.051 \\
age4559 & $-0.116^{* *}$ & 0.045 & age4559 & $-0.128^{* *}$ & 0.045 \\
d.kids06 & -0.0647 & 0.051 & d.kids06 & -0.0701 & 0.052 \\
d.kids6plus & $-0.104^{* *}$ & 0.042 & d.kids6plus & $-0.0965^{* *}$ & 0.042 \\
S.,E.Europe & -0.0478 & 0.078 & S.,E.Europe & -0.0391 & 0.079 \\
other FB & 0.0759 & 0.089 & other FB & 0.0732 & 0.090 \\
scb6170 & -0.00637 & 0.081 & scb6170 & -0.0192 & 0.082 \\
sc7180 & -0.0659 & 0.088 & sc7180 & -0.0746 & 0.089 \\
sc8192 & $-0.213^{* *}$ & 0.10 & sc8192 & $-0.216^{* *}$ & 0.10 \\
Intercept & $0.180^{* *}$ & 0.062 & Intercept & $0.283^{* *}$ & 0.038 \\
\hline Wald chi2 & 25.0 & & Wald chi2 & 20.3 & \\
N & 574 & & Within: 0.0243 & 574 & \\
R-Square: & Within: 0.0254 & & Between: 0.0436 & & \\
R-Square: & Between: 0.0645 & & Overall: 0.0368 & & \\
R-Square: & Overall: 0.0442 & & & & \\
\hline
\end{tabular}

Note:

1) ** stands for $5 \%$ significance level;

2) * stands for $10 \%$ significance level;

3) We define a family with a credit constraint if the net change in assets and liabilities of the family is less than two months' net income;

4) C.C.: credit constraint. 
Table 2.12: Estimation Results of Euler Equation for Food Consumption

\begin{tabular}{rrr|rrr}
\hline With C.C. & & & Without C.C. & & \\
Variables & coefficient & std.error & Variables & coefficient & std.error \\
\hline Credit Constraint & $0.0776^{* *}$ & 0.049 & - & & \\
age2534 & 0.00743 & 0.046 & age2534 & 0.0128 & 0.046 \\
age4559 & $-0.0732^{*}$ & 0.041 & age4559 & $-0.0810^{* *}$ & 0.041 \\
d.kids06 & 0.0473 & 0.047 & d.kids06 & 0.0440 & 0.047 \\
d.kids6plus & -0.0215 & 0.038 & d.kids6plus & -0.0165 & 0.038 \\
S..E.Europe & -0.0600 & 0.071 & S.,E.Europe & -0.0540 & 0.072 \\
other FB & 0.0578 & 0.081 & other FB & 0.0605 & 0.082 \\
scb6170 & 0.0363 & 0.074 & scb6170 & 0.0274 & 0.075 \\
sc7180 & -0.00667 & 0.080 & sc7180 & -0.0129 & 0.081 \\
sc8192 & -0.0504 & 0.094 & sc8192 & -0.0518 & 0.095 \\
Intercept & $0.153^{* *}$ & 0.056 & Intercept & $0.223^{* *}$ & 0.035 \\
\hline Wald chi2 & 11.2 & & Wald chi2 & 8.63 & \\
N & 574 & & N & 574 & \\
R-Square: & Within: 0.0005 & & Within: 0.0007 & & \\
R-Square: & Between: 0.0613 & & Between: 0.0402 & & \\
R-Square: & Overall: 0.0219 & & Overall: 0.0171 & & \\
\hline
\end{tabular}

Note:

1) ** stands for $5 \%$ significance level;

2) * stands for $10 \%$ significance level;

3) We define a family with a credit constraint if the net change in assets and liabilities of the family is less than two months' net income;

4) C.C.: credit constraint. 
Table 2.13: Coefficient on Log of Disposable Income from Estimation of Euler Equation for Group I and Group II Separately

\begin{tabular}{rrr|rrr}
\hline Consumption & Group I & Group II & & \\
\hline & coefficient & std.error & & coefficient & std.error \\
\hline Whole Consumption & $0.349^{* *}$ & 0.48 & & $0.761^{* *}$ & 0.15 \\
Durable Consumption & $0.180^{* *}$ & 0.070 & $0.870^{* *}$ & 0.18 \\
Non-Durable Consumption & $0.361^{* *}$ & 0.065 & $0.377^{*}$ & 0.20 \\
Food Consumption & $0.351^{* *}$ & 0.046 & 0.134 & 0.16 \\
\hline
\end{tabular}

Note: ${ }^{* *}$ stands for $5 \%$ significance level; ${ }^{*}$ stands for $10 \%$ significance level. 


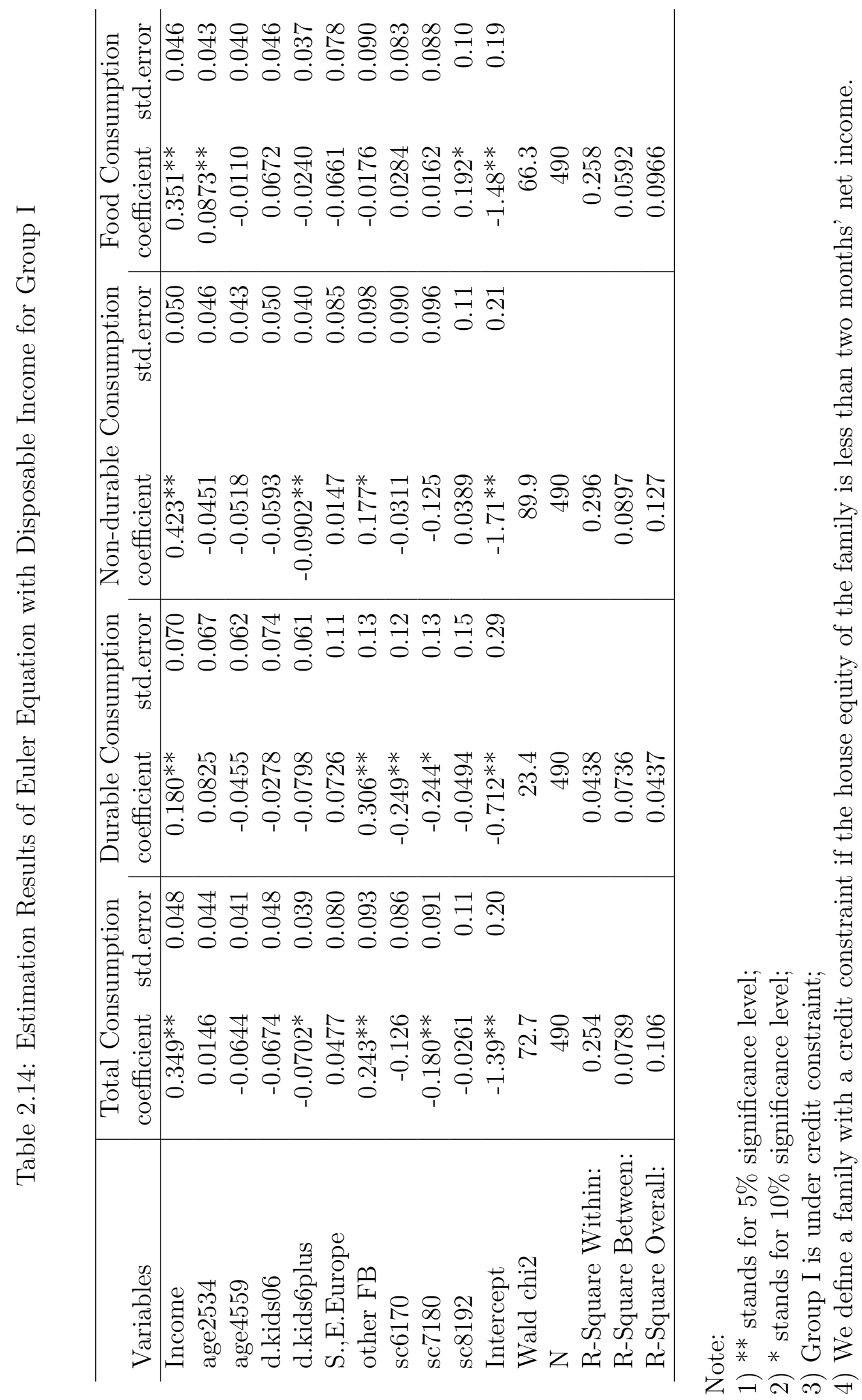




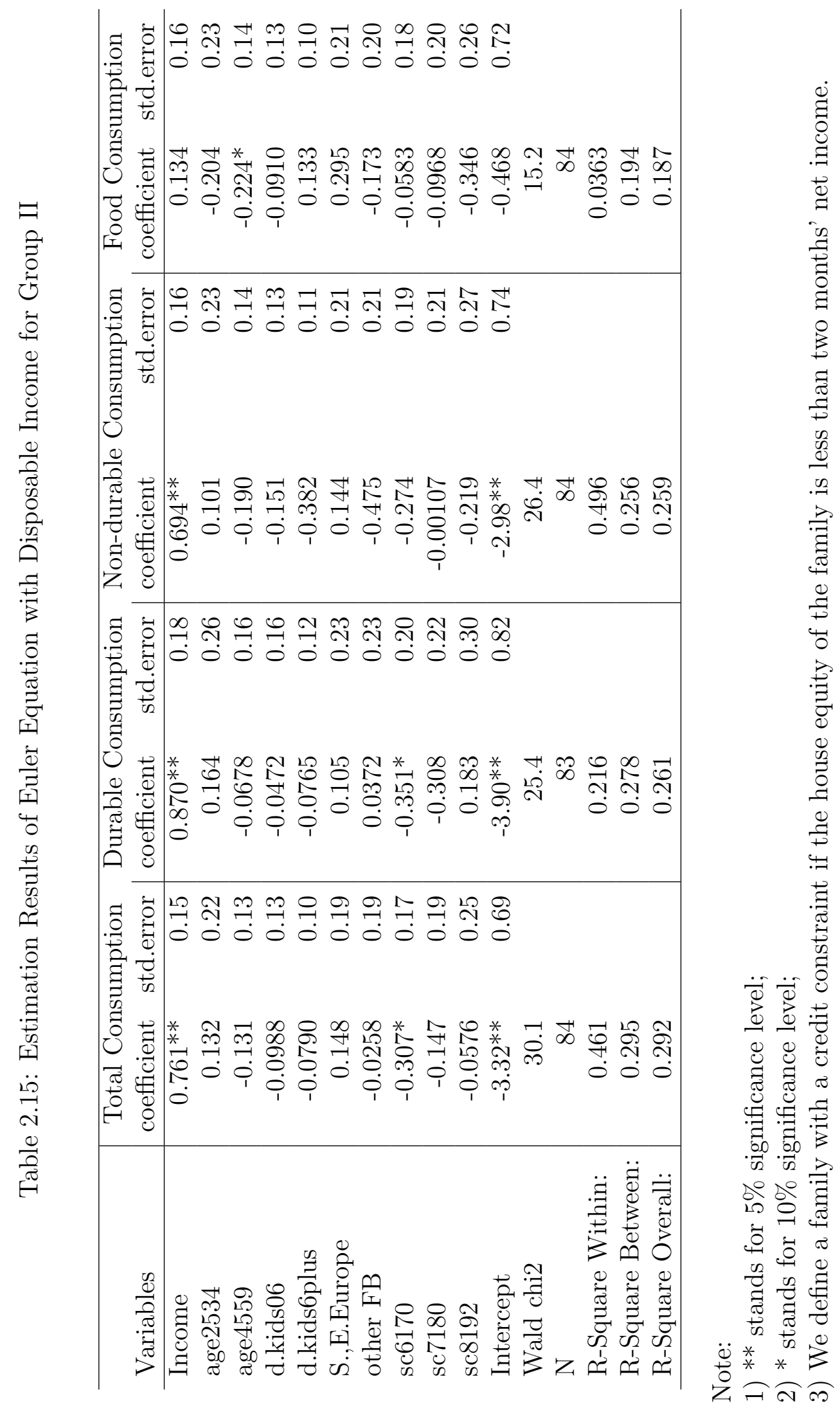


Appendix C

\section{Tables for Chapter 3}


Table 3.1: Sample Means of Variables

\begin{tabular}{l|rr|rr}
\hline \multirow{2}{*}{ Variable } & \multicolumn{2}{|c}{ Immigrant } & Households & \multicolumn{2}{c}{ Canadian-born Households } \\
& FAMEX & SFS & FAMEX & SFS \\
\hline After Tax Income & $63.8(29)$ & $68.8(56)$ & $64.7(30)$ & $69.2(47)$ \\
\hline Own Dwelling & $.717(.45)$ & $.736(.44)$ & $.664(.47)$ & $.811(.39)$ \\
\hline Housing equity & $188(142)$ & $152(186)$ & $139(112)$ & $113(173)$ \\
\hline Region of Residence & & & & \\
\hline Atlantic Provinces & $.010(.10)$ & $.0116(.11)$ & $.060(.24)$ & $.100(.30)$ \\
\hline Quebec & $.192(.39)$ & $.133(.34)$ & $.347(.48)$ & $.264(.44)$ \\
\hline Ontario & $.508(.50)$ & $.571(.50)$ & $.290(.45)$ & $.340(.47)$ \\
\hline Prairie Provinces & $.139(.35)$ & $.117(.32)$ & $.191(.39)$ & $.178(.38)$ \\
\hline British Columbia & $.151(.36)$ & $.166(.37)$ & $.112(.32)$ & $.118(.32)$ \\
\hline Reference Person Characteristics & & & & \\
\hline Age & $43.4(11)$ & $46.4(9.7)$ & $40.6(11)$ & $43.8(10)$ \\
\hline 0 to 9 Years of Education & $.220(.41)$ & $.150(.37)$ & $.119(.32)$ & $.193(.39)$ \\
\hline High School & $.359(.48)$ & $.218(.41)$ & $.454(.50)$ & $.259(.44)$ \\
\hline Post-Secondary & $.239(.43)$ & $.272(.45)$ & $.265(.44)$ & $.324(.47)$ \\
\hline University Degree & $.183(.39)$ & $.360(.48)$ & $.162(.37)$ & $.224(.42)$ \\
\hline Sample Size & 4,773 & 1,841 & 16,292 & 8,368 \\
\hline
\end{tabular}

Note:

1) Income and housing equity are all presented in thousands of Canadian dollars.

2) Standard deviations are in parentheses.

3) Housing equity is defined as the difference between the respondent's perception of the market value of the owned dwelling and the reported outstanding principal on the mortgage. Households renting their dwelling are not assigned a value of housing equity. Therefore the sample sizes for the housing equity variable above are 16,292 (FAMEX) and 8,368 (SFS) for the Canadian-born sample and 4,773 (FAMEX) and 1,841 (SFS) for the immigrant sample.

4) All household reference persons were male. 


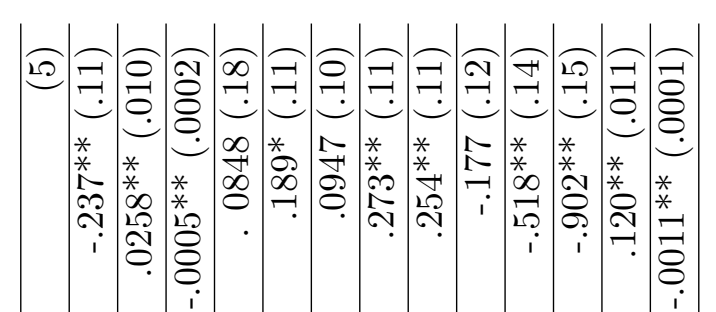

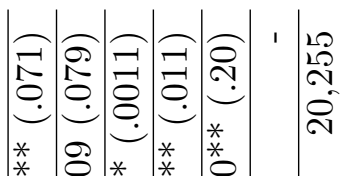

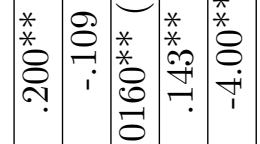

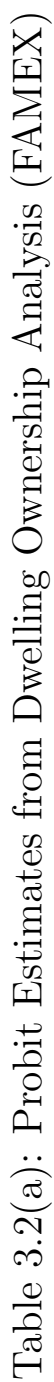

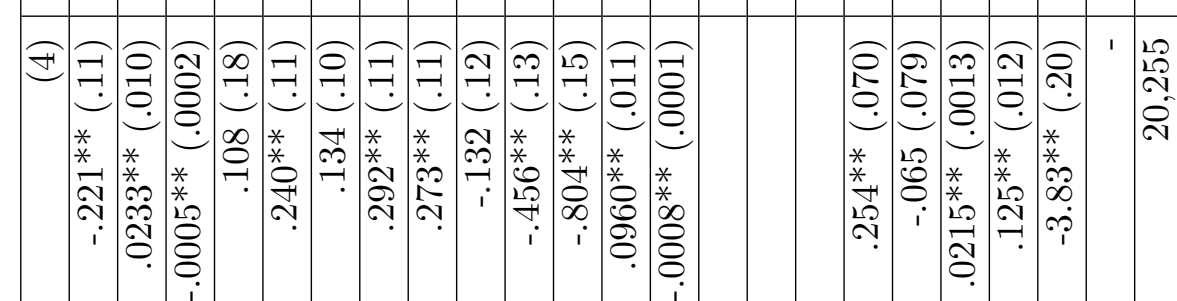

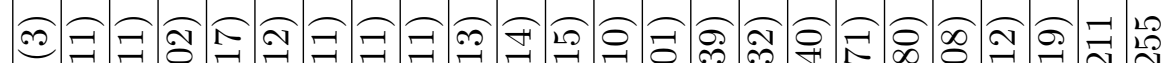
ت *

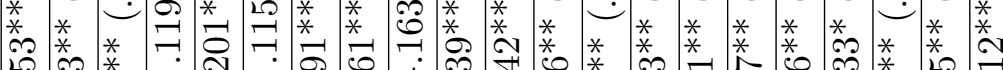
 i $\stackrel{\stackrel{0}{0}}{0 .}$

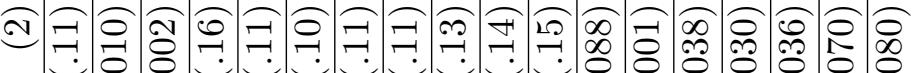
-

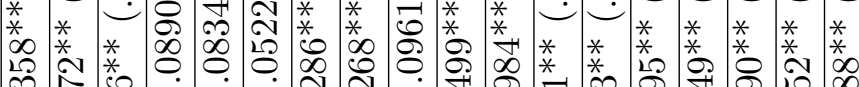
m. .

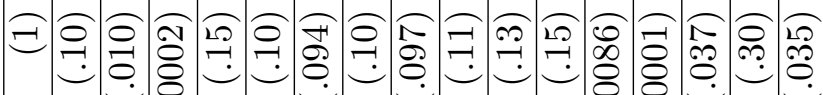

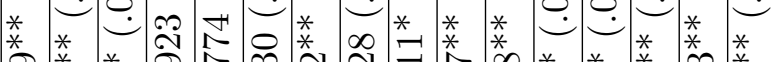

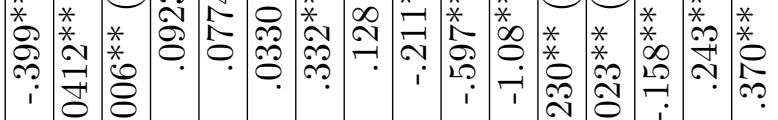
$\underset{1}{\rightarrow-1}$ ㅇ.

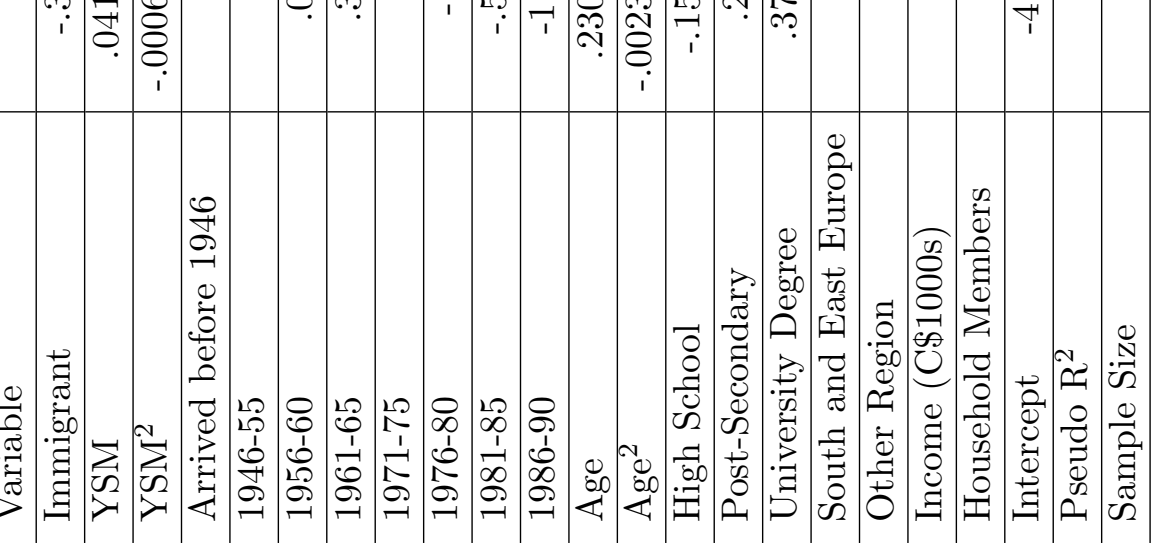

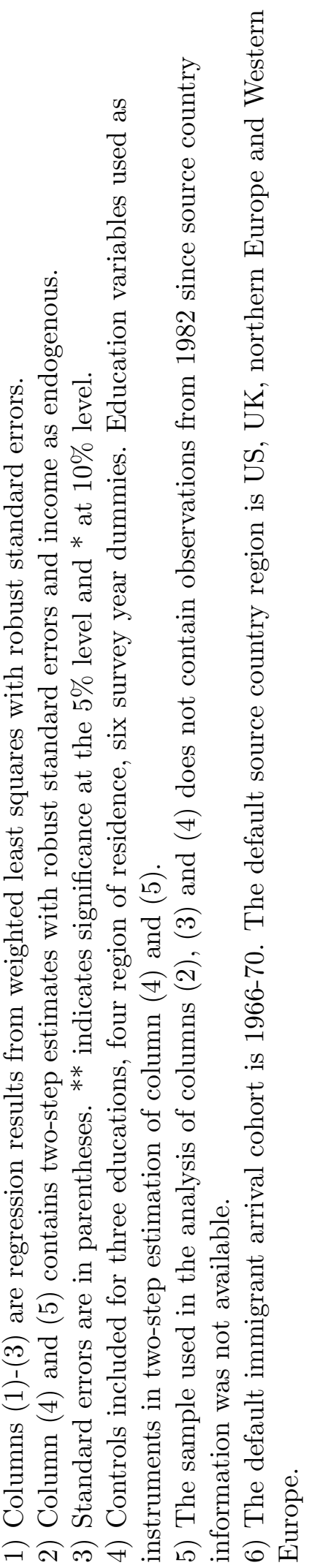


Table 3.2(b): Probit Estimates from Dwelling Ownership Analysis (SFS)

\begin{tabular}{|c|c|c|c|}
\hline Variable & (1) & $(2)$ & $(3)$ \\
\hline Immigrant & $-.127^{* *}(.31)$ & $-.122^{* *}(.34)$ & $-.114^{* *}(.34)$ \\
\hline Years-Since-Migration (YSM) & $.102^{* *}(.022)$ & $.107^{* *}(.022)$ & $.0804^{* *}(.024)$ \\
\hline $\mathrm{YSM}^{2}$ & $-.0014^{* *}(.0004)$ & $-.0015^{* *}(.0004)$ & $-.0010^{* *}(.0005)$ \\
\hline \multicolumn{4}{|l|}{ Arrived between } \\
\hline $1960-69$ & $-.593^{*}(.32)$ & $-.635^{*}(.33)$ & $-.530(.34)$ \\
\hline 1970-79 & $-.470(.36)$ & $-.396(.37)$ & $-.201(.39)$ \\
\hline $1980-89$ & $-.288(.34)$ & $-.145(.36)$ & $.015(.38)$ \\
\hline 1990-99 & $-.235(.32)$ & $-.0977(.34)$ & $-.0277(.35)$ \\
\hline $2000-03$ & $-.213(.36)$ & $-.0423(.38)$ & $.146(.39)$ \\
\hline Age & $.184^{* *}(.017)$ & $.186^{* *}(.017)$ & $.0846^{* *}(.019)$ \\
\hline $\mathrm{Age}^{2}$ & $-.0017^{* *}(.0002)$ & $-.0017^{* *}(.0002)$ & $-.00051^{* *}(.0002)$ \\
\hline High School & $.266^{* *}(.068)$ & $.256^{* *}(.069)$ & $.121^{*}(.069)$ \\
\hline Post-Secondary & $.482^{* *}(.065)$ & $.473^{* *}(.065)$ & $.307^{* *}(.066)$ \\
\hline University Degree & $.618^{* *}(.067)$ & $.616^{* *}(.067)$ & $.262^{* *}(.073)$ \\
\hline \multicolumn{4}{|l|}{ First language (Immigrants only) } \\
\hline Arabic & & $-.491^{* *}(.14)$ & $-.372^{* *}(.14)$ \\
\hline European & & $-.0085(.099)$ & $.0112(.10)$ \\
\hline Other Asian & & $-.516^{* *}(.19)$ & $-.495^{* *}(.18)$ \\
\hline Chinese & & $-.0626(.16)$ & $.137(.17)$ \\
\hline Other & & $-.464^{*}(.26)$ & $-.444(.30)$ \\
\hline Income $(\mathrm{C} \$ 1000 \mathrm{~s})$ & & & $.0134^{* *}(.002)$ \\
\hline Income $^{2}$ & & & $.00003(.00002)$ \\
\hline Household Members & & & $.460^{* *}(.070)$ \\
\hline Household Members $^{2}$ & & & $-.0393^{* *}(.009)$ \\
\hline Intercept & $-4.11^{* *}(.36)$ & $-4.13^{* *}(.36)$ & $-3.90 * *(.38)$ \\
\hline Pseudo $\mathrm{R}^{2}$ & .138 & .144 & .237 \\
\hline Sample Size & 10,209 & 10,209 & 10,209 \\
\hline
\end{tabular}

Note:

1) Columns (1)-(3) are regression results from weighted least squares with robust standard errors.

2) Standard errors are in parentheses. ${ }^{* *}$ indicates significance at the $5 \%$ level and * at $10 \%$ level.

3) Controls included for three educations, four region of residence, and one survey year dummy.

4) The default immigrant arrival cohort is before 1960. The default first language is English and/or French. 


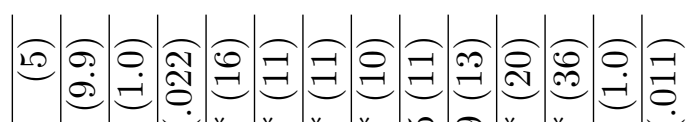

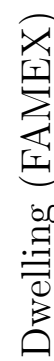

列

音

童

咅

羊

章

용

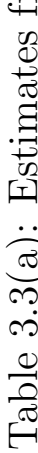

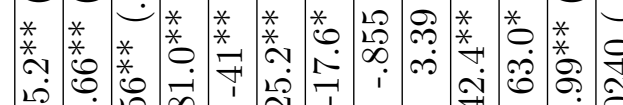

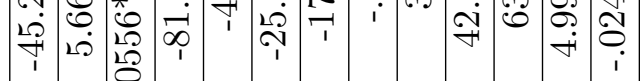

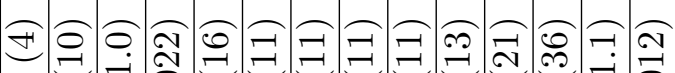

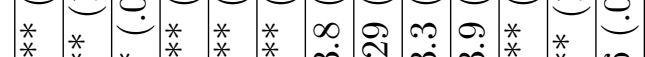

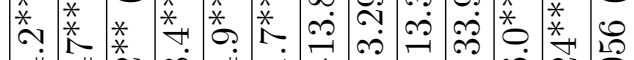

\section{舟官完}

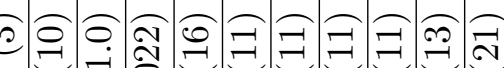

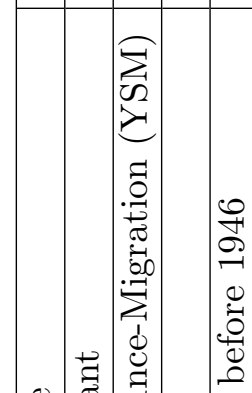

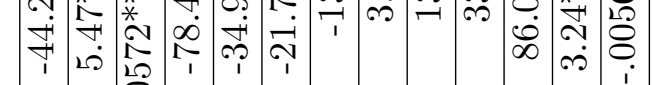

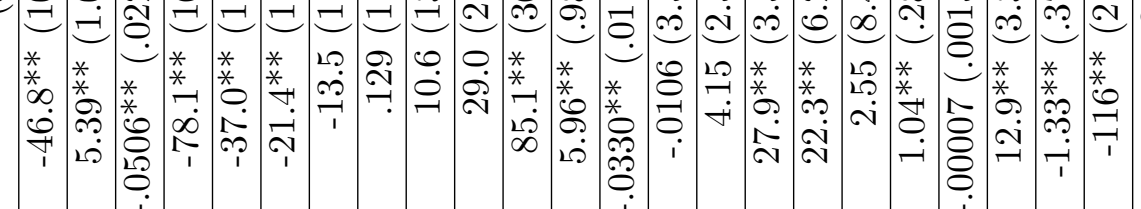

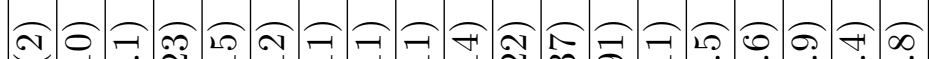

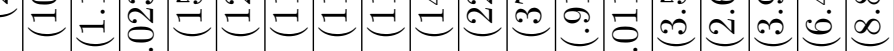

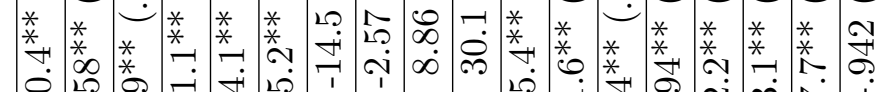

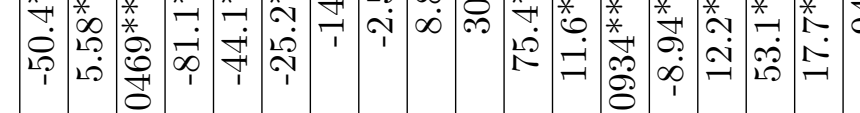

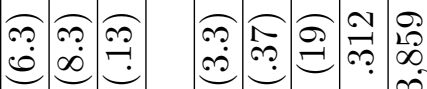

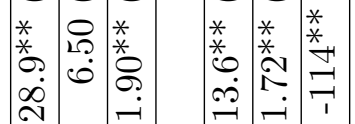

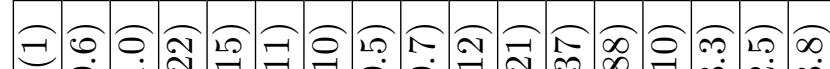

क ت

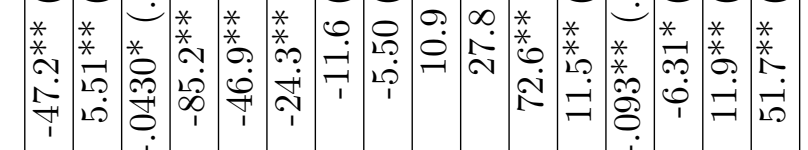

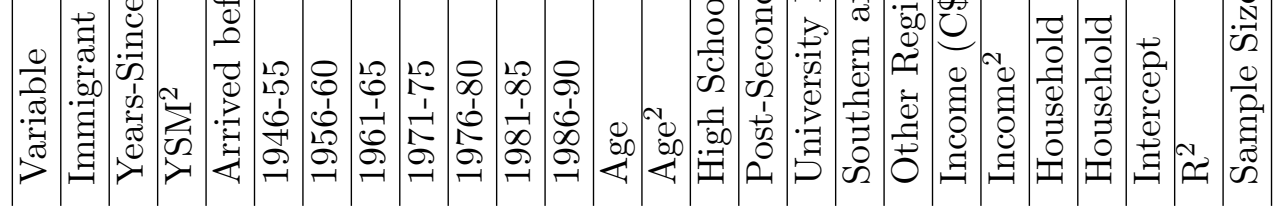

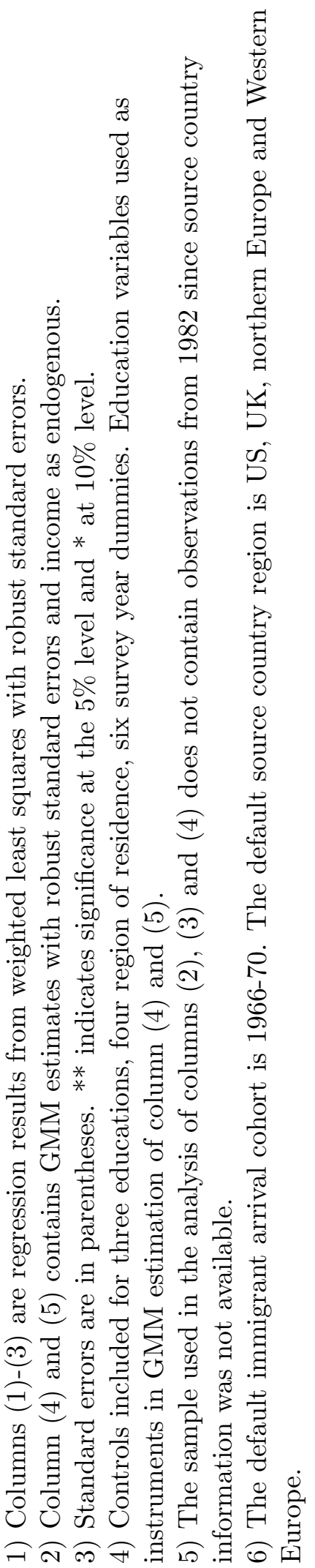




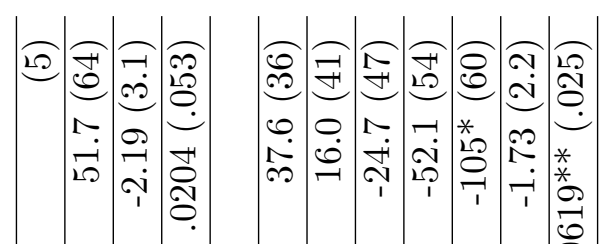

중

每

党

$\frac{0}{\frac{0}{9}}$

$\frac{3}{3}$

:

.

:

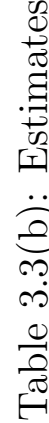

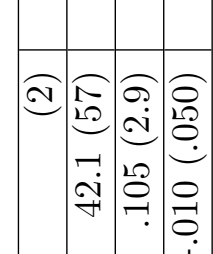

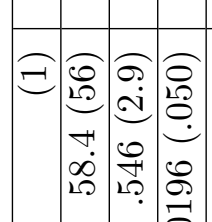

$\overrightarrow{0}$

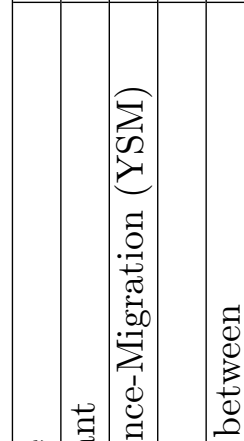

至

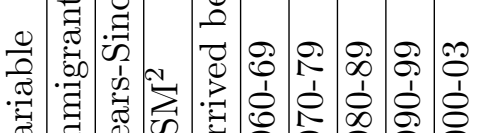

:

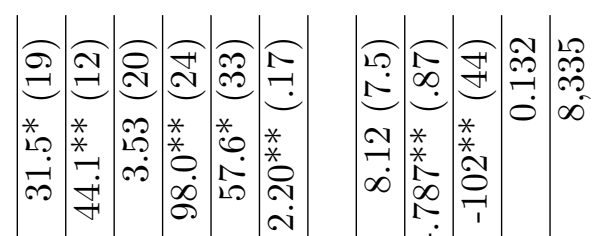

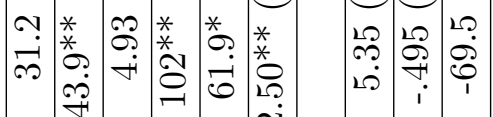

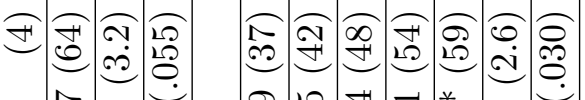

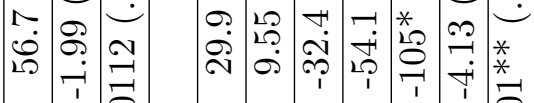

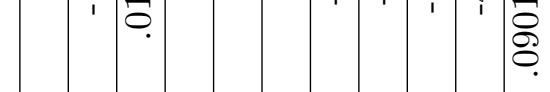

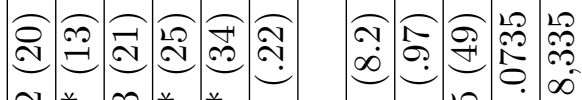

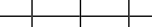

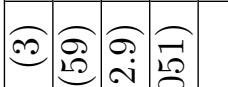

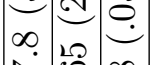

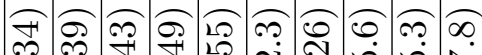

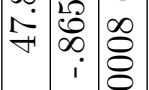

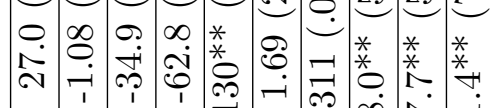

:

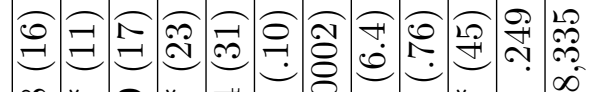

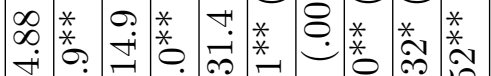

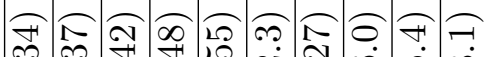

बִ

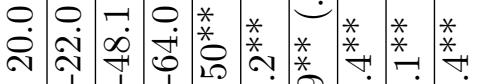

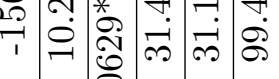

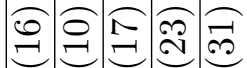

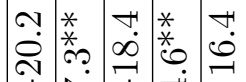 \\ 1}

童

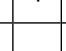

(

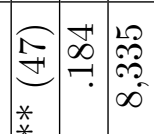

*

จิ

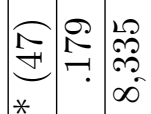

*

๙ิ

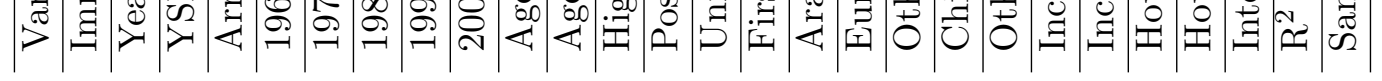

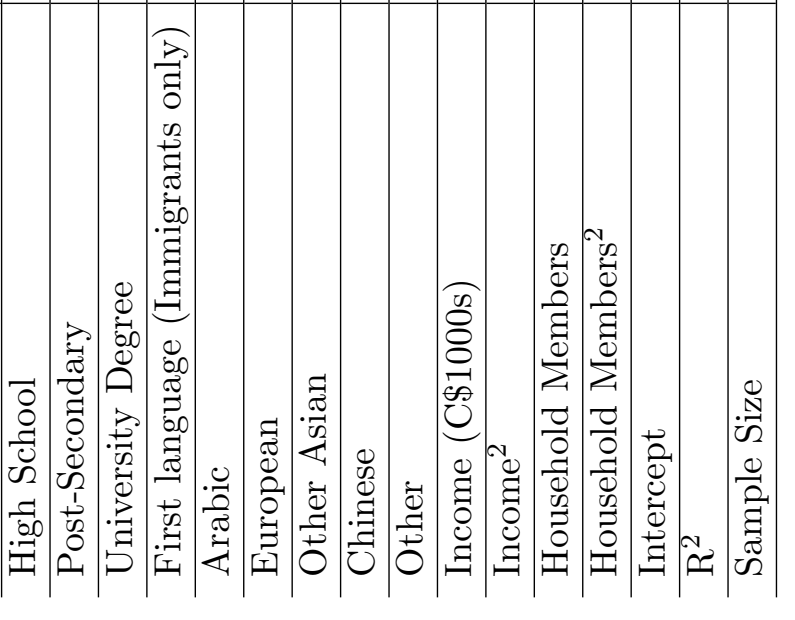

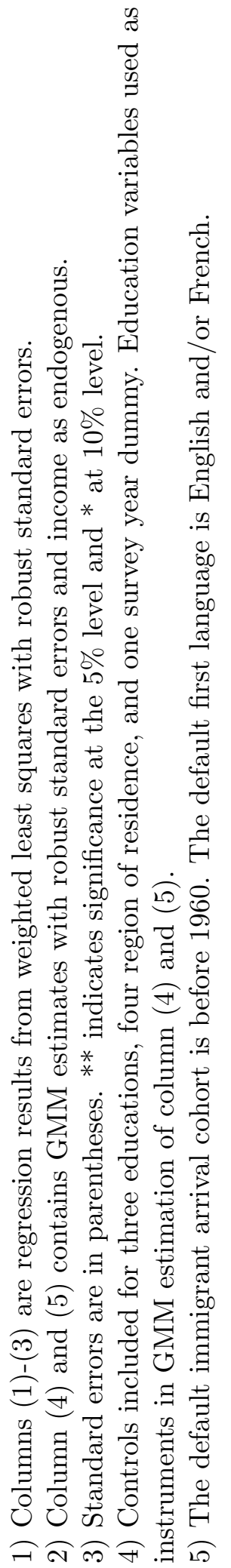




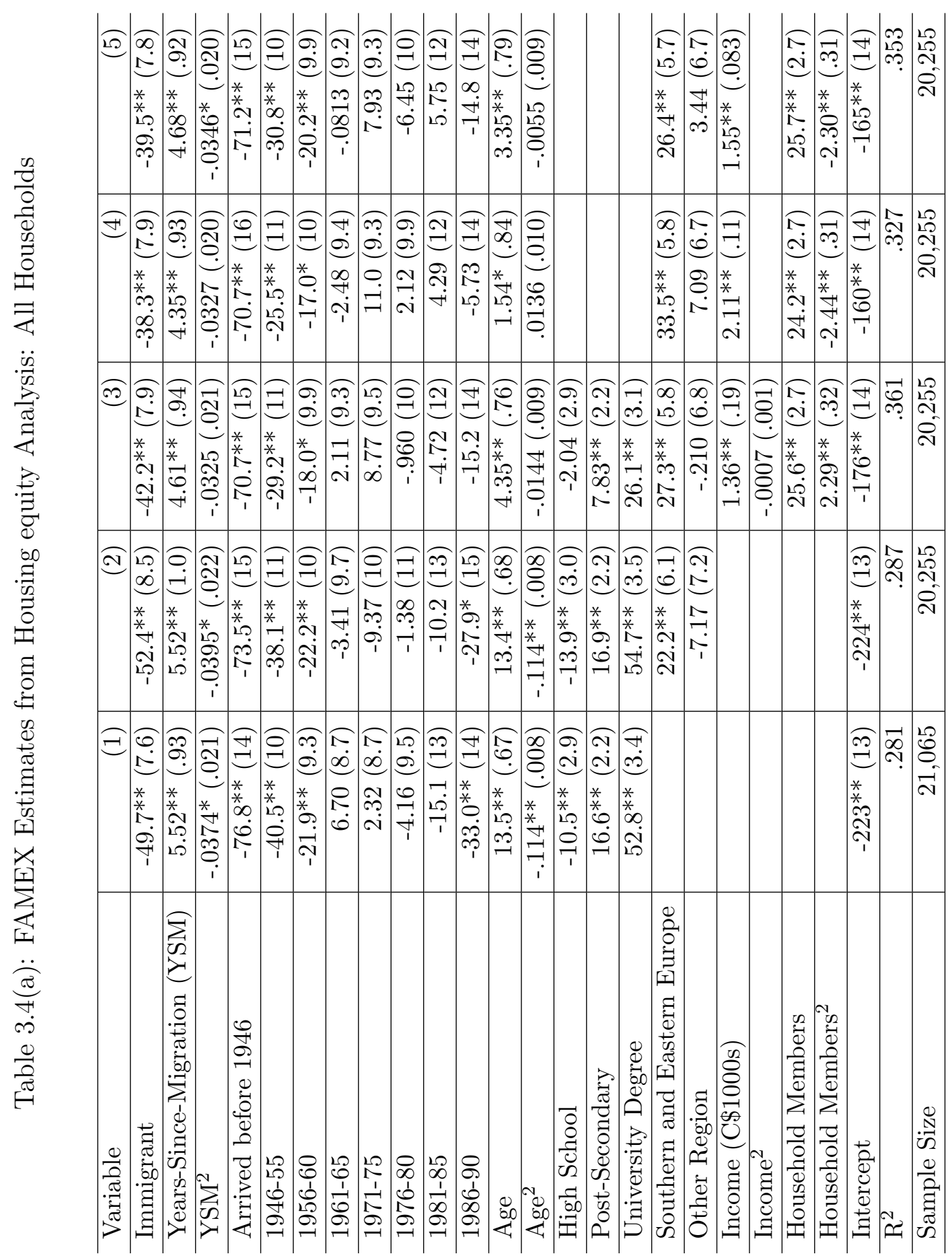




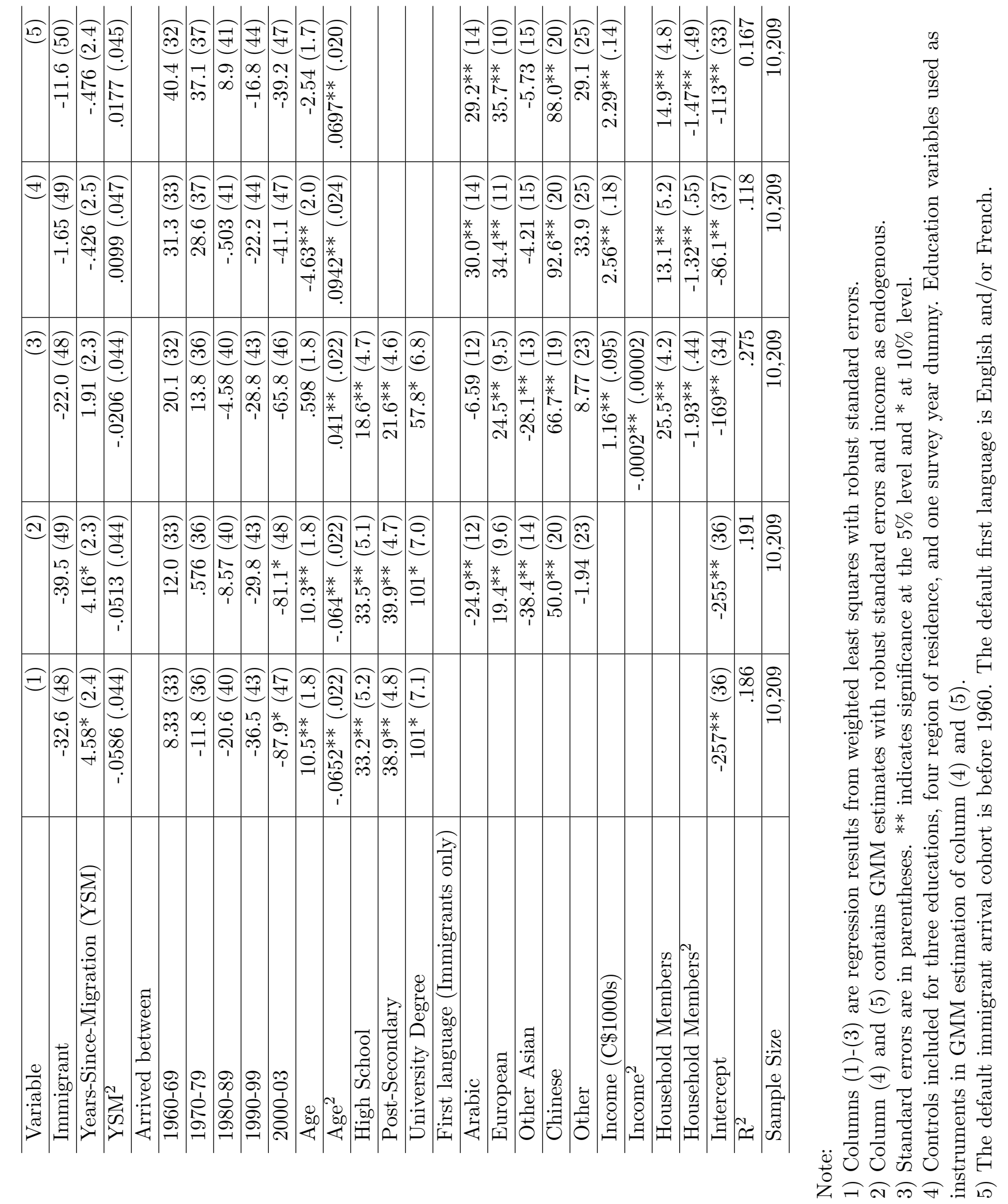




\section{Appendix D}

\section{Figures for Chapter 1}

Figure 1.1 Kernel Density Estimation for After-Tax Income (FAMEX, 1969-92)

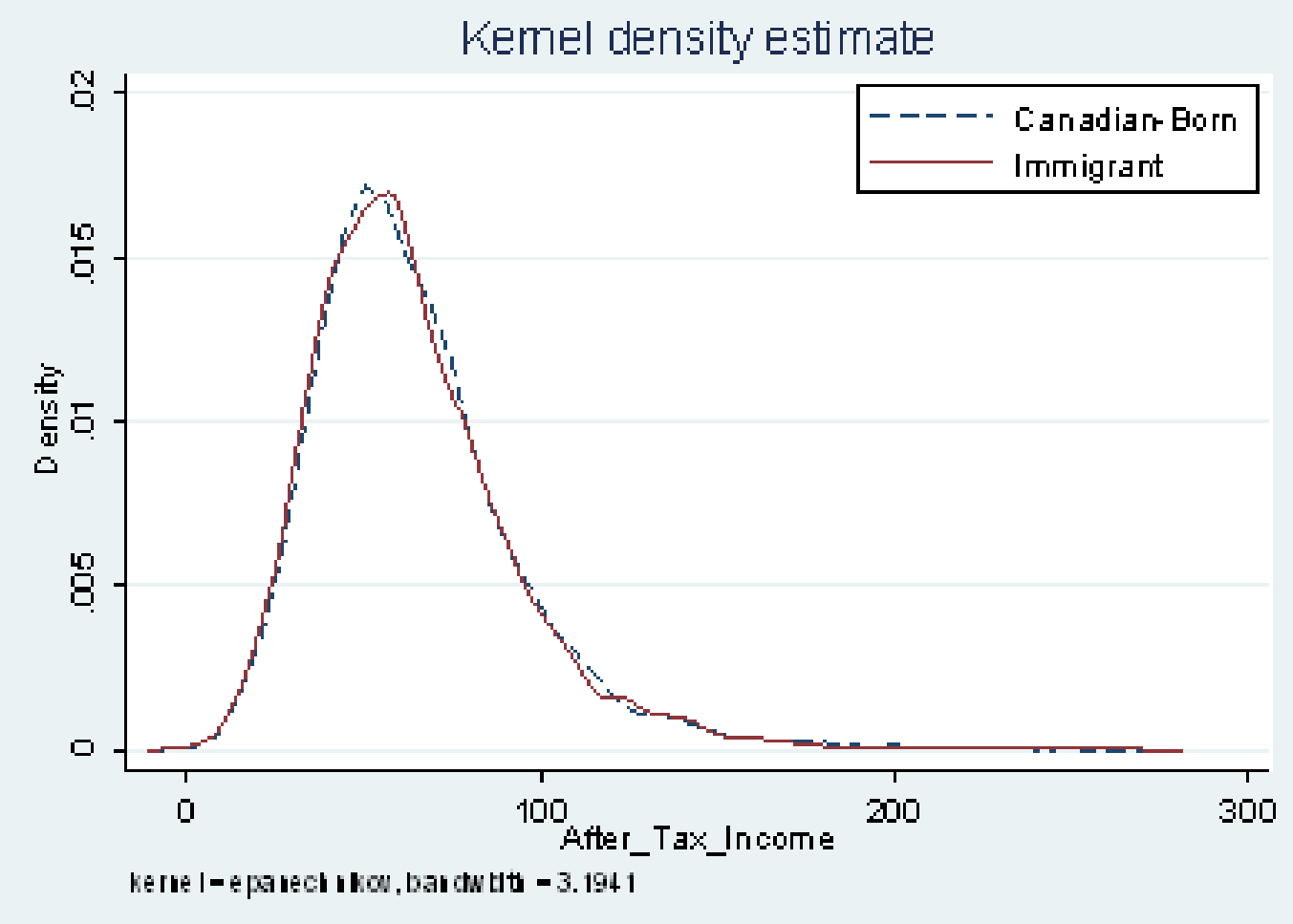


Figure 1.2 Kernel Density Estimation for Savings (FAMEX, 1969-92)

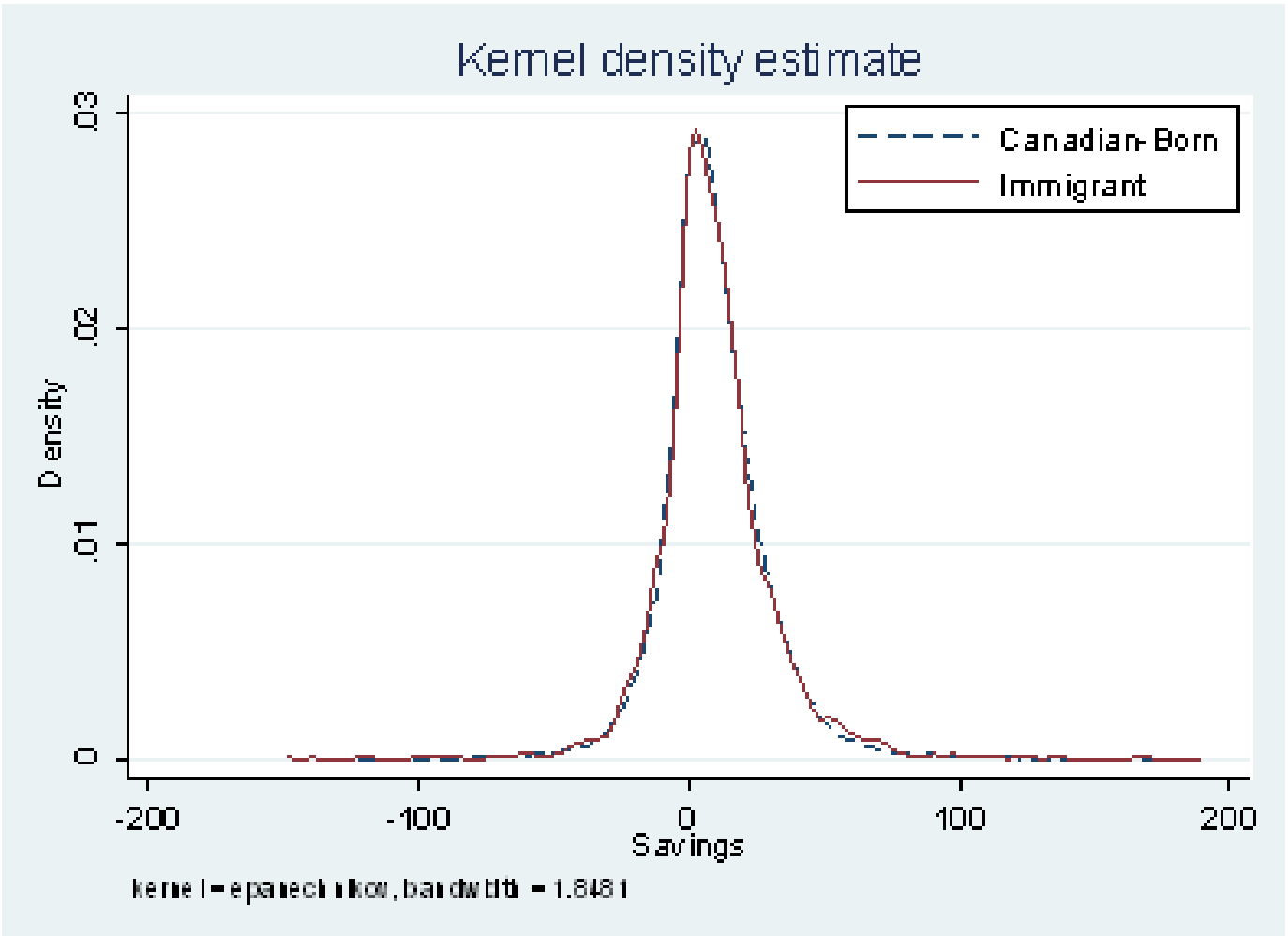


Figure 1.3 Kernel Density Estimation for Change in Assets (FAMEX, 1969-92)

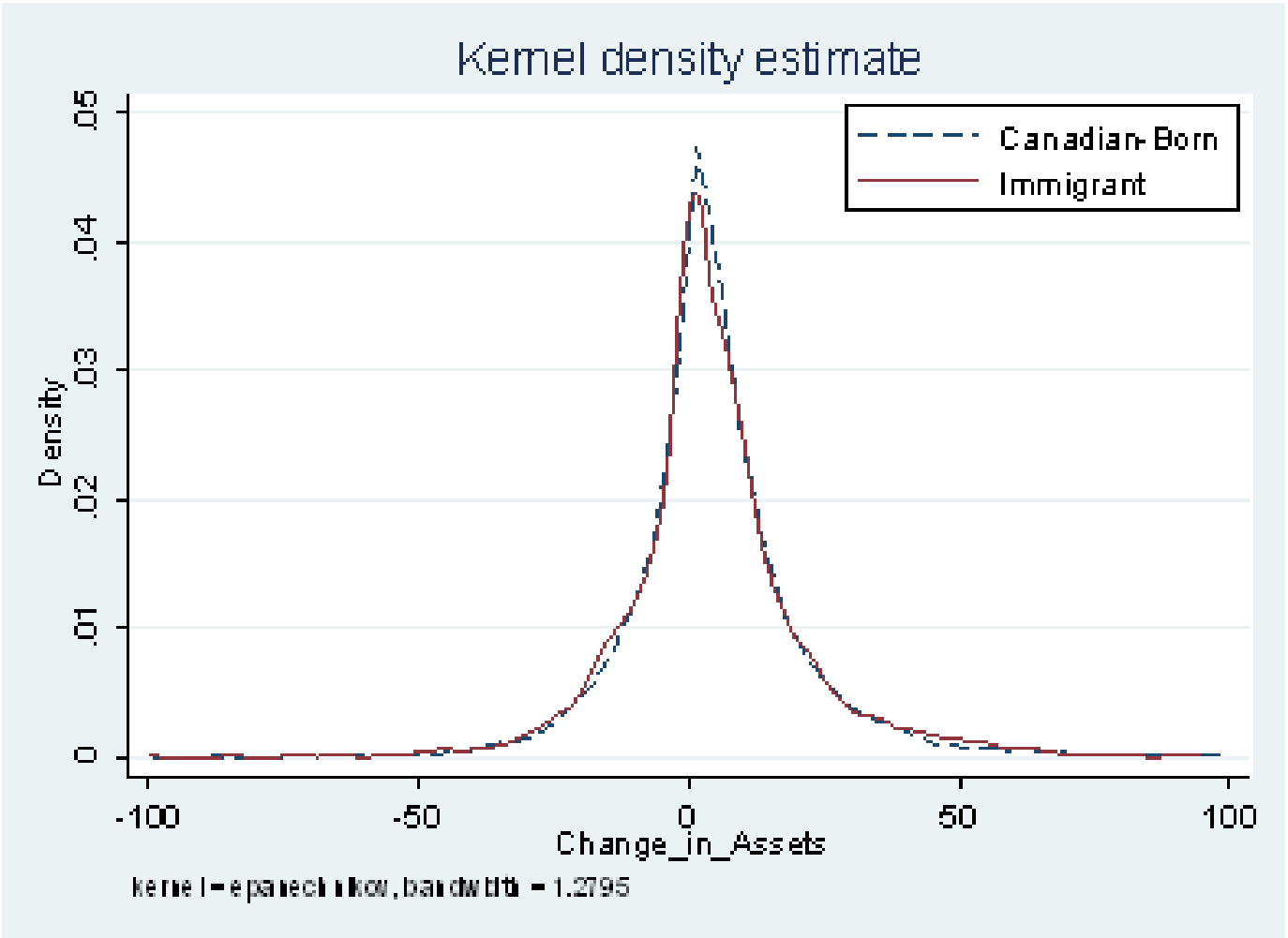


Figure 1.4

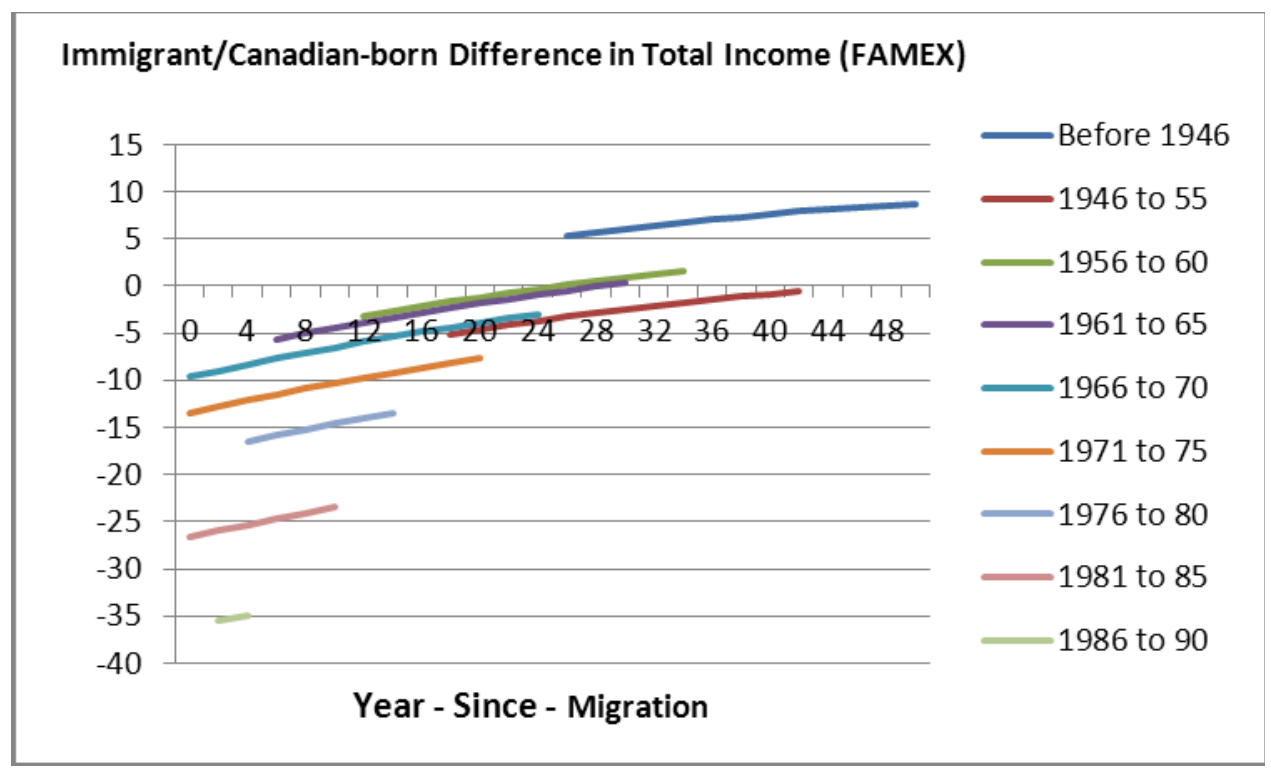


Figure 1.5

Immigrant/Canadian-born Difference in After-Tax Income (FAMEX)

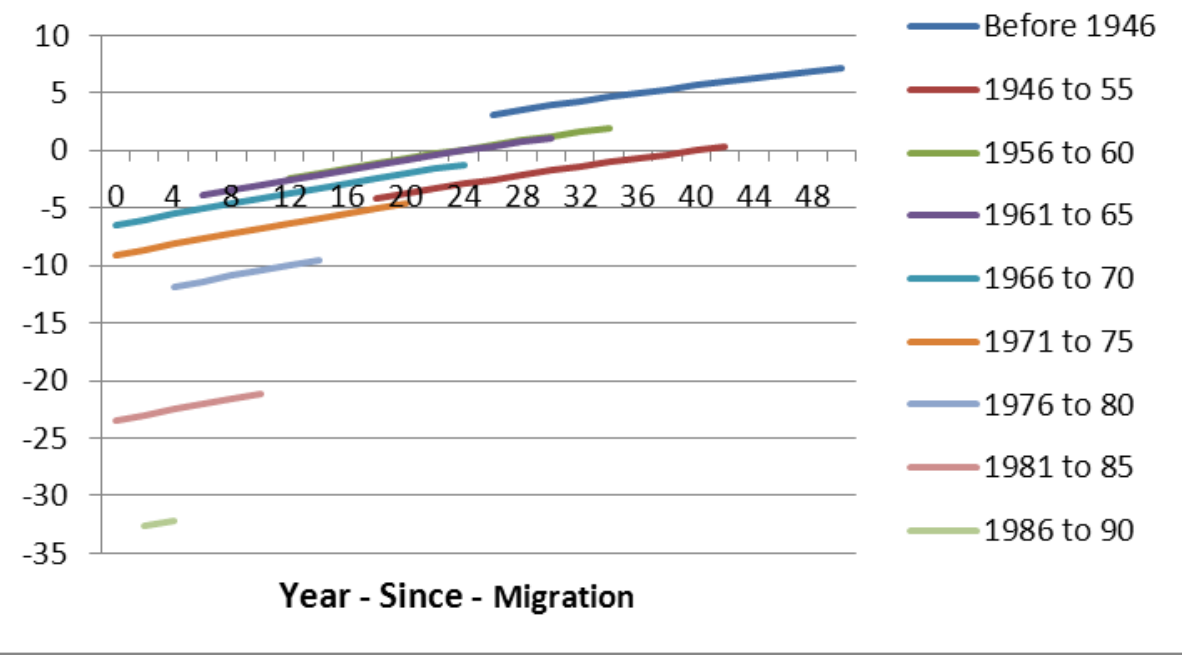


Figure 1.6

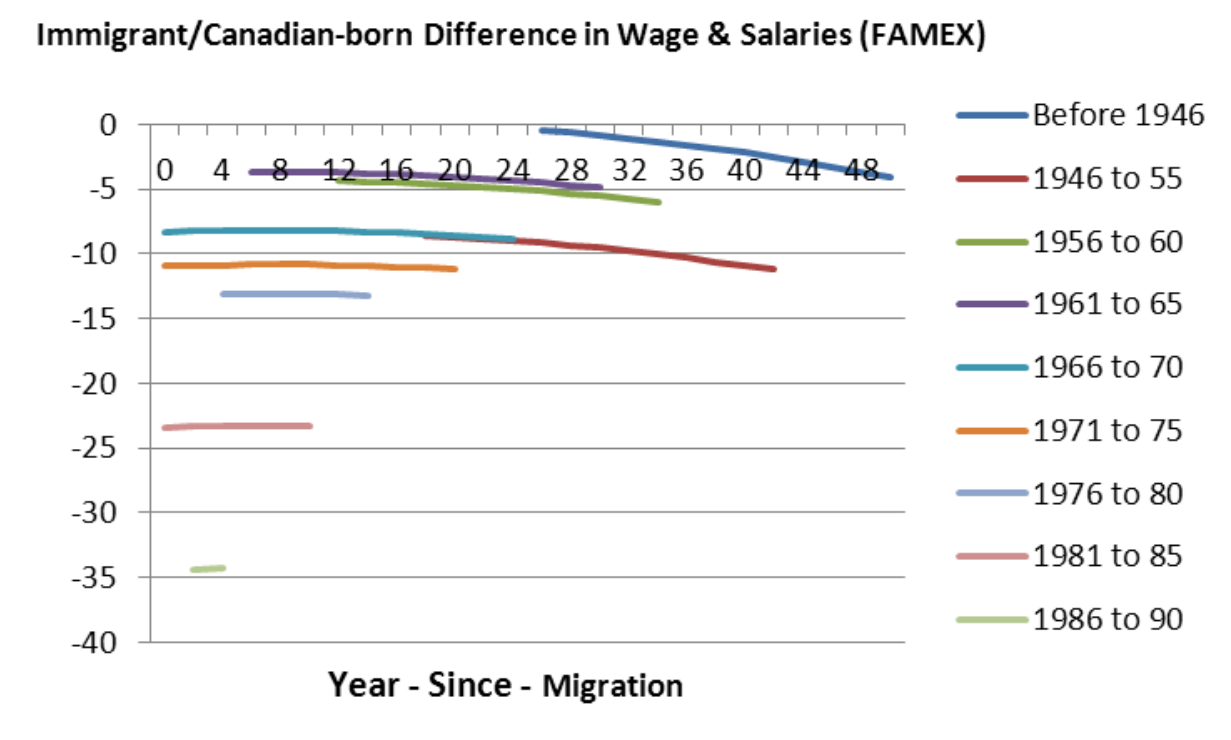


Figure 1.7

\section{Immigrant/Canadian-born Difference in Consumption (FAMEX)}

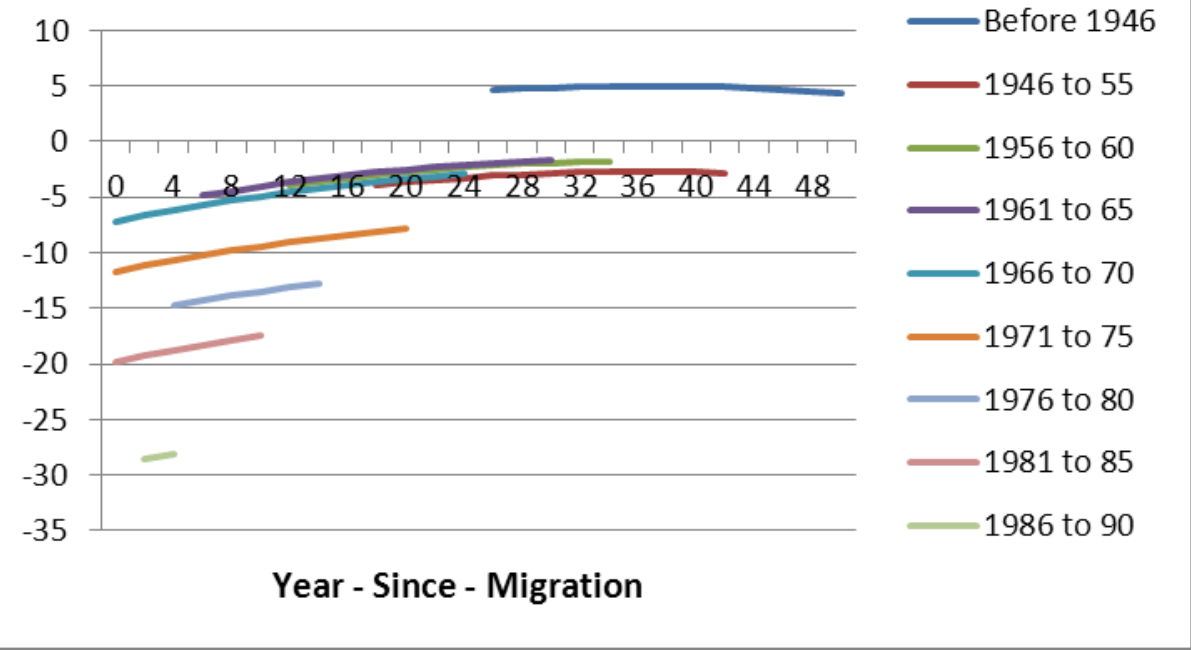


Figure 1.8

Immigrant/Canadian-born Difference in Net Change in Assets (FAMEX)

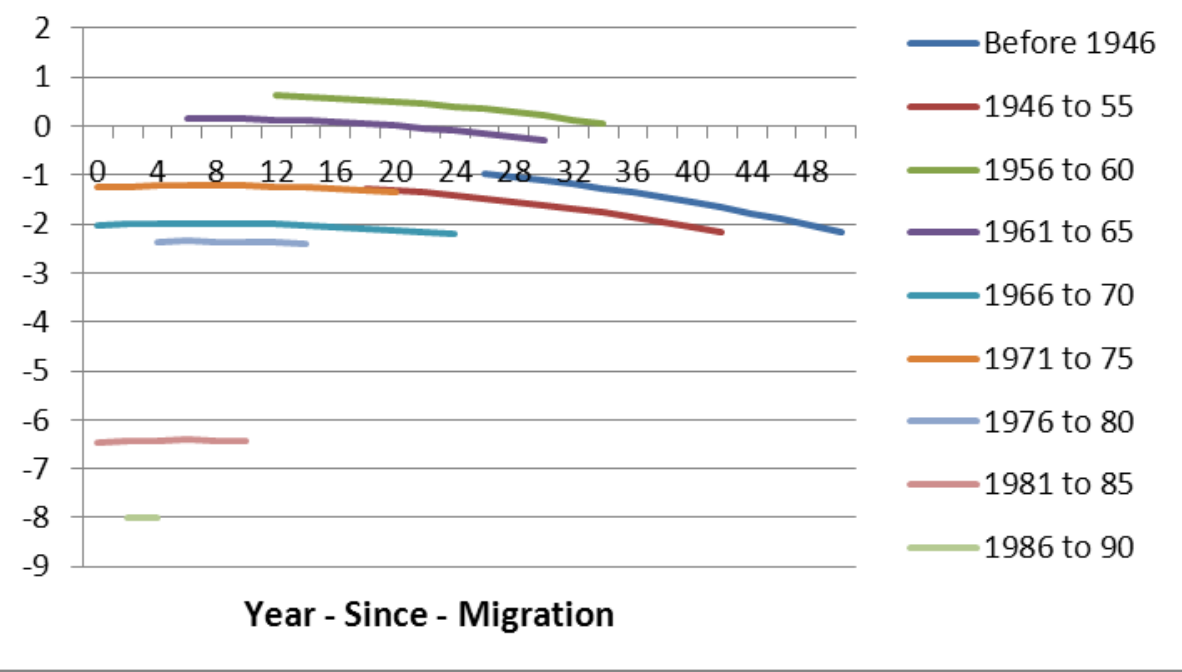


Figure 1.9

Immigrant/Canadian-born Difference in Savings (FAMEX)

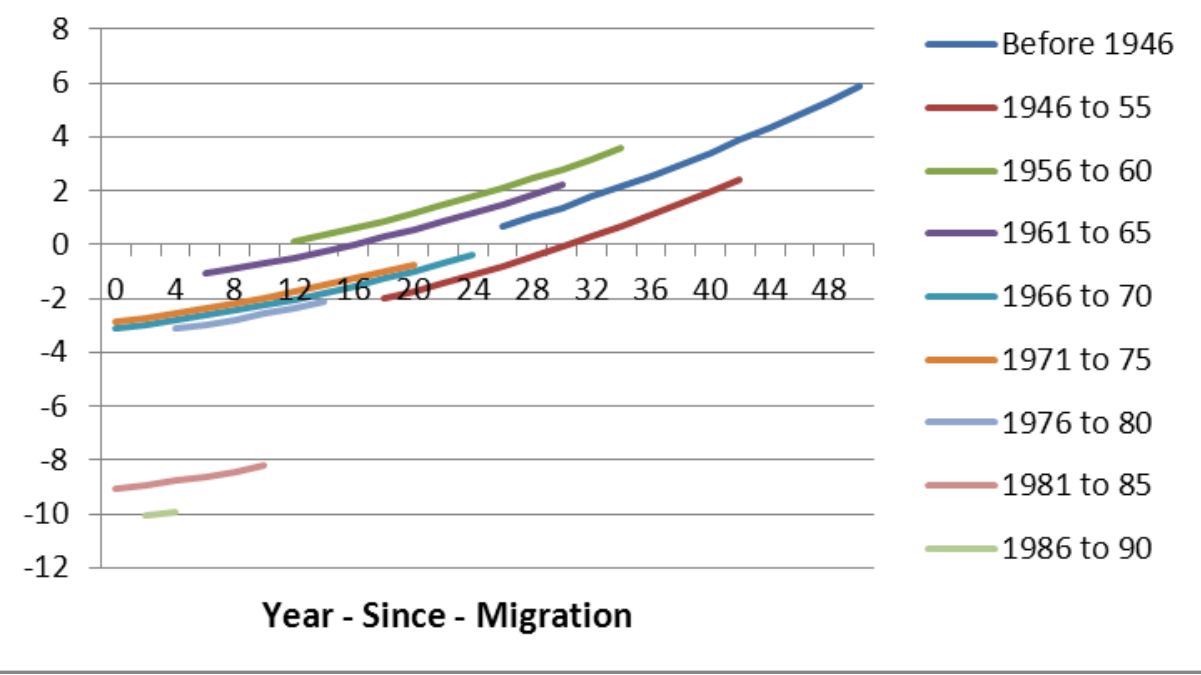


Figure 1.10

Immigrant/Canadian-born Difference in Saving Rate (FAMEX)

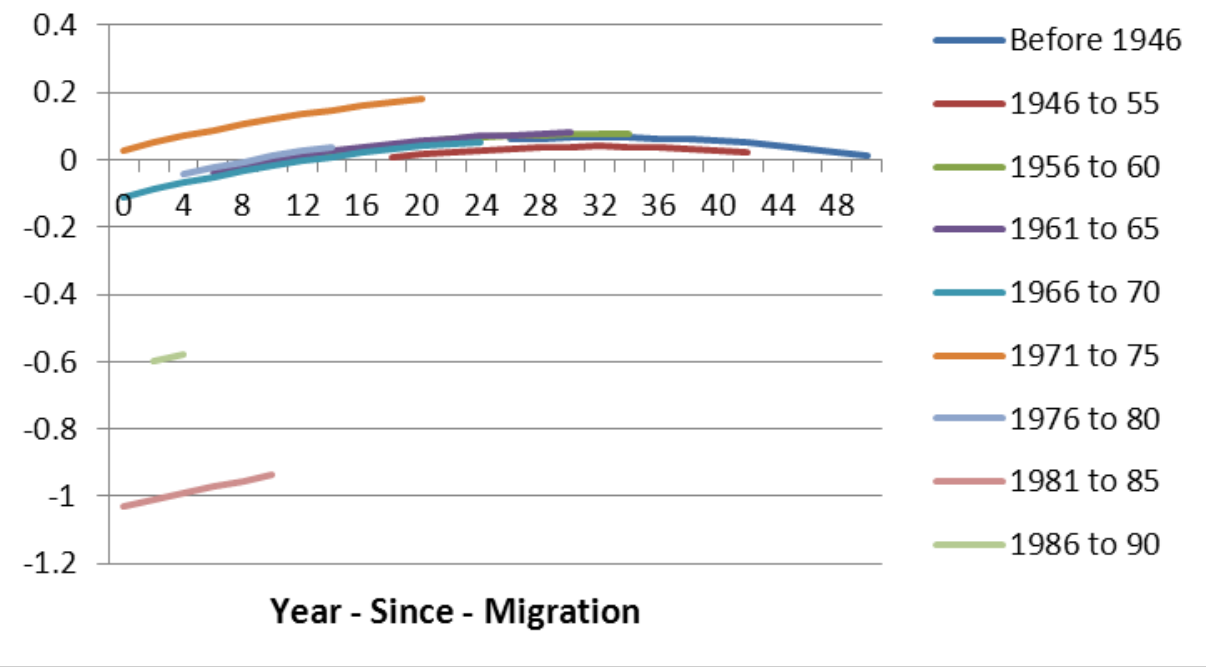




\section{Appendix E}

\section{Figures for Chapter 3}

Figure 3.1(a) Kernel Density Estimation for Housing equity (FAMEX, 1969-92)

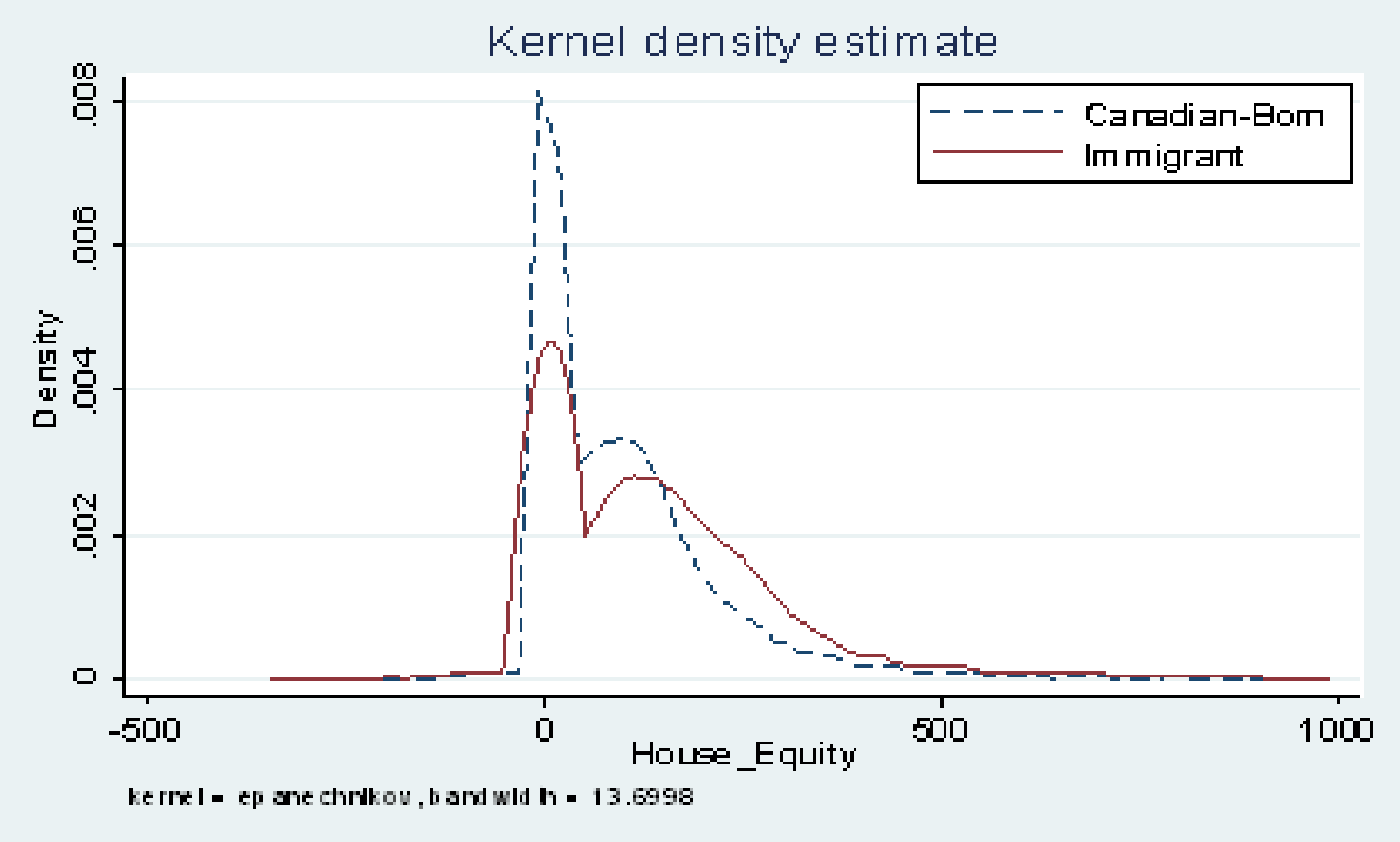


Figure 3.1(b) Kernel Density Estimation for Housing equity (SFS, 1999 \& 2005)

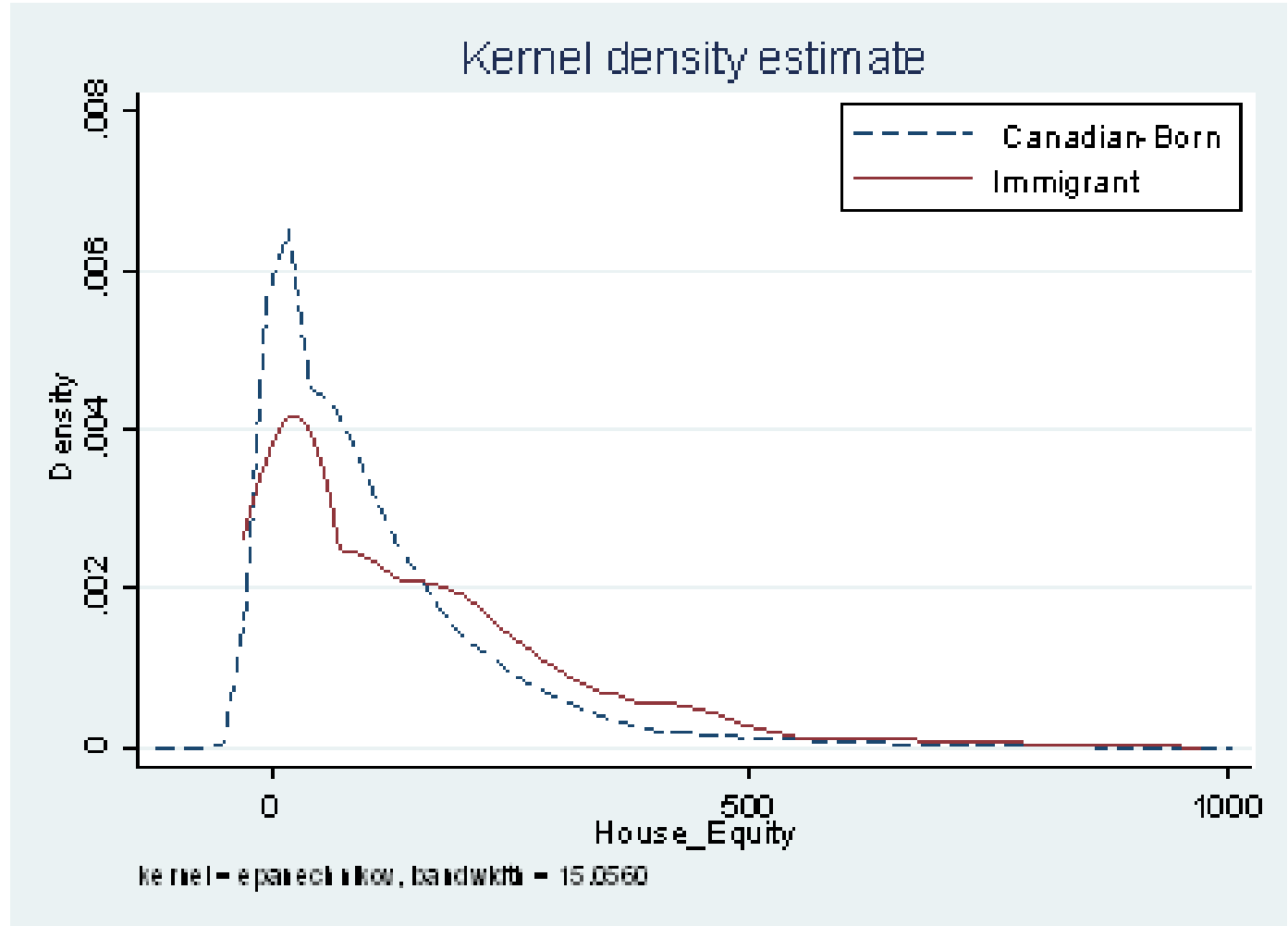


Figure 3.2(a)

Figure 2(a):Difference in Probability of Own Dwelling (FAMEX)

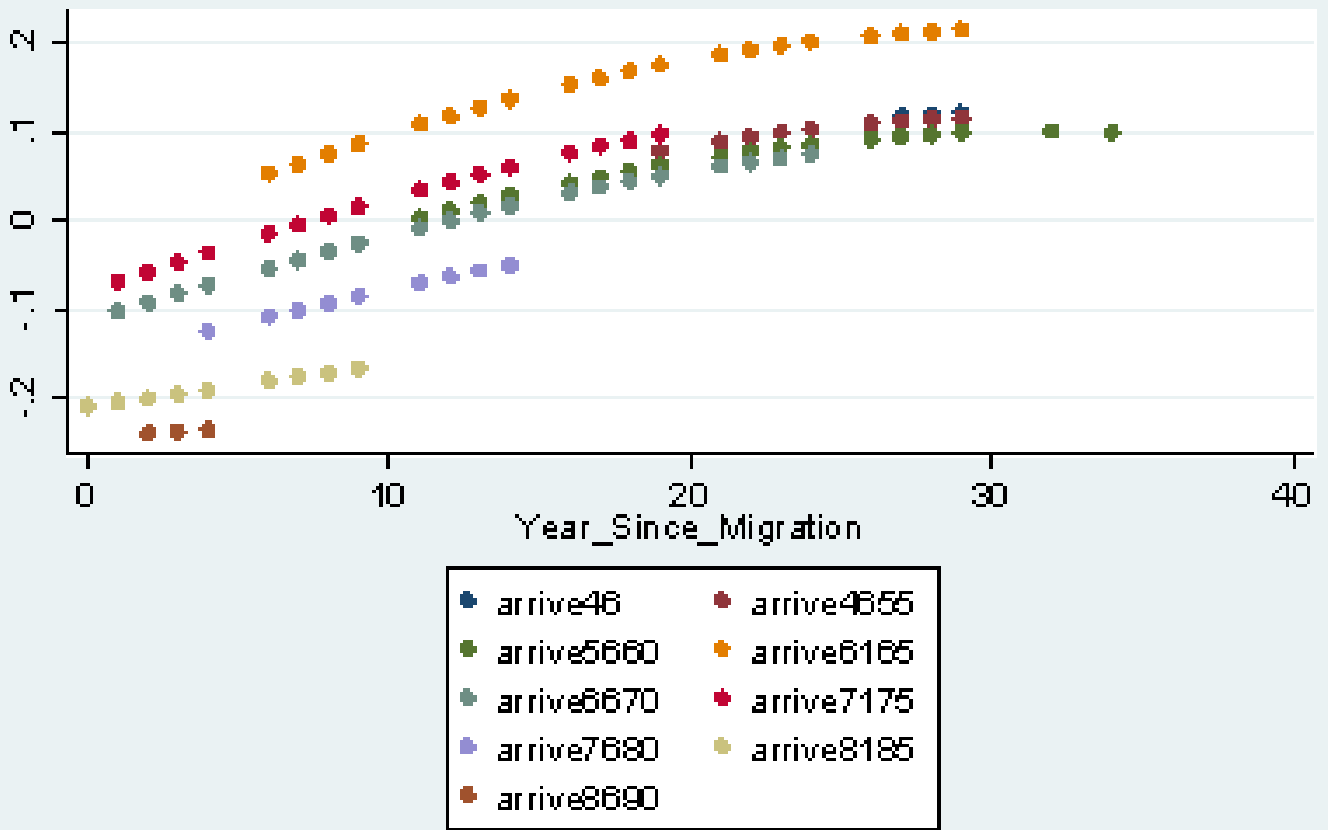

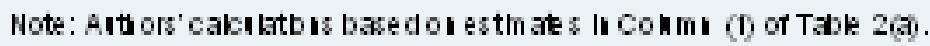


Figure 3.2(b)

Figure 2(b):Differece in Probability of Own Dwelling (SFS)

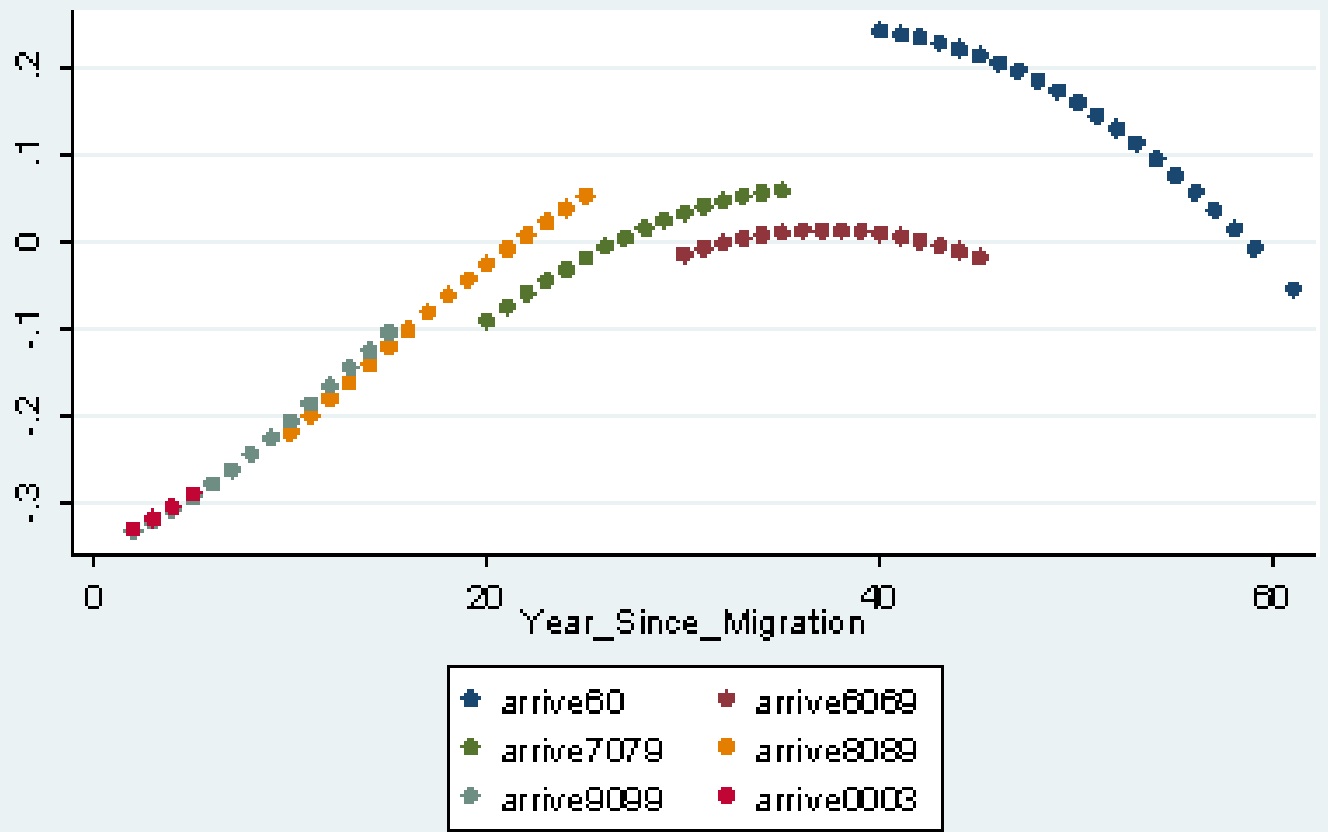

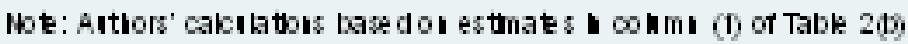


Figure 3.3(a)

Figure 3(a) Difference in Housing Equity: Home Owners (FAMEX)

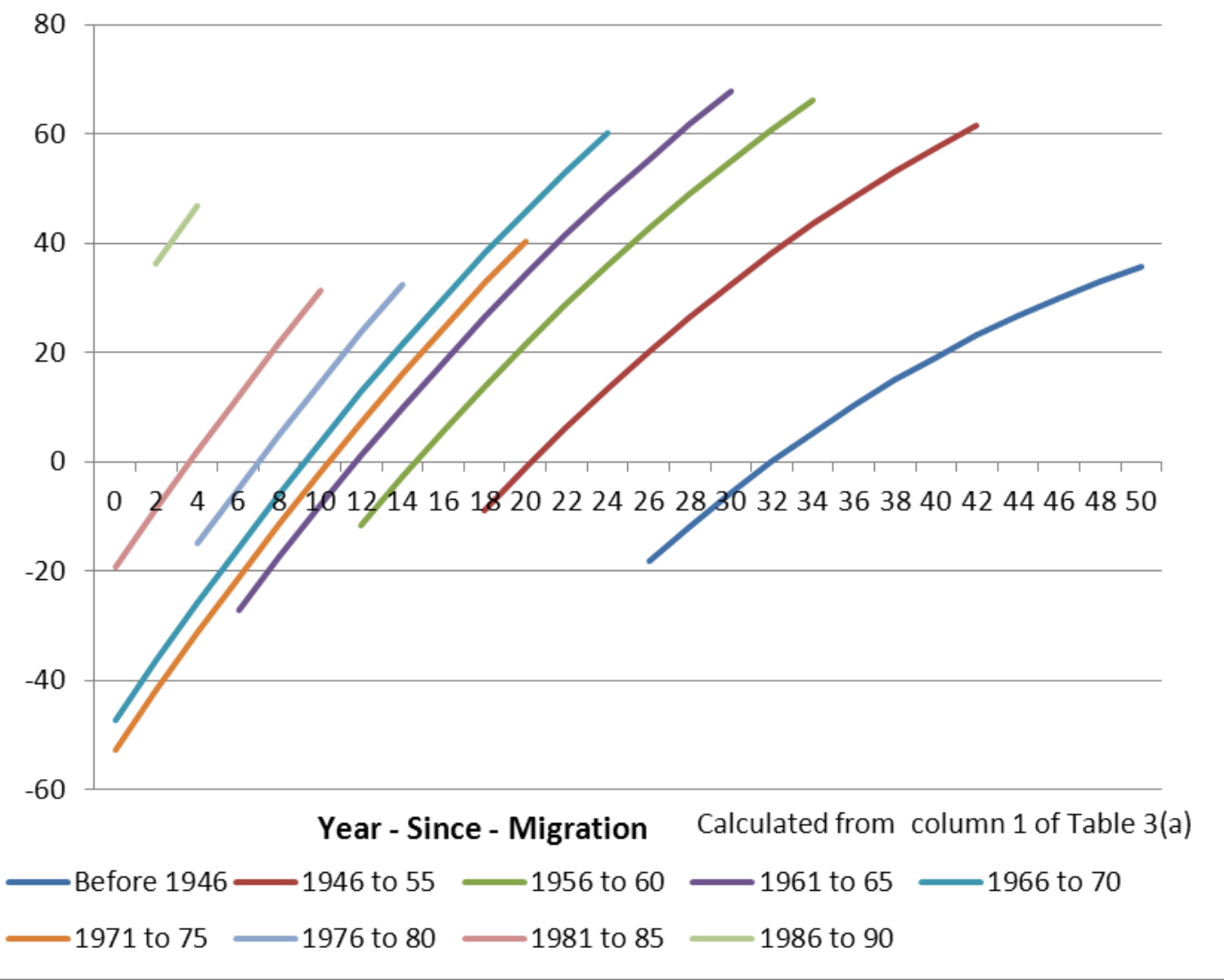


Figure 3.3(b)

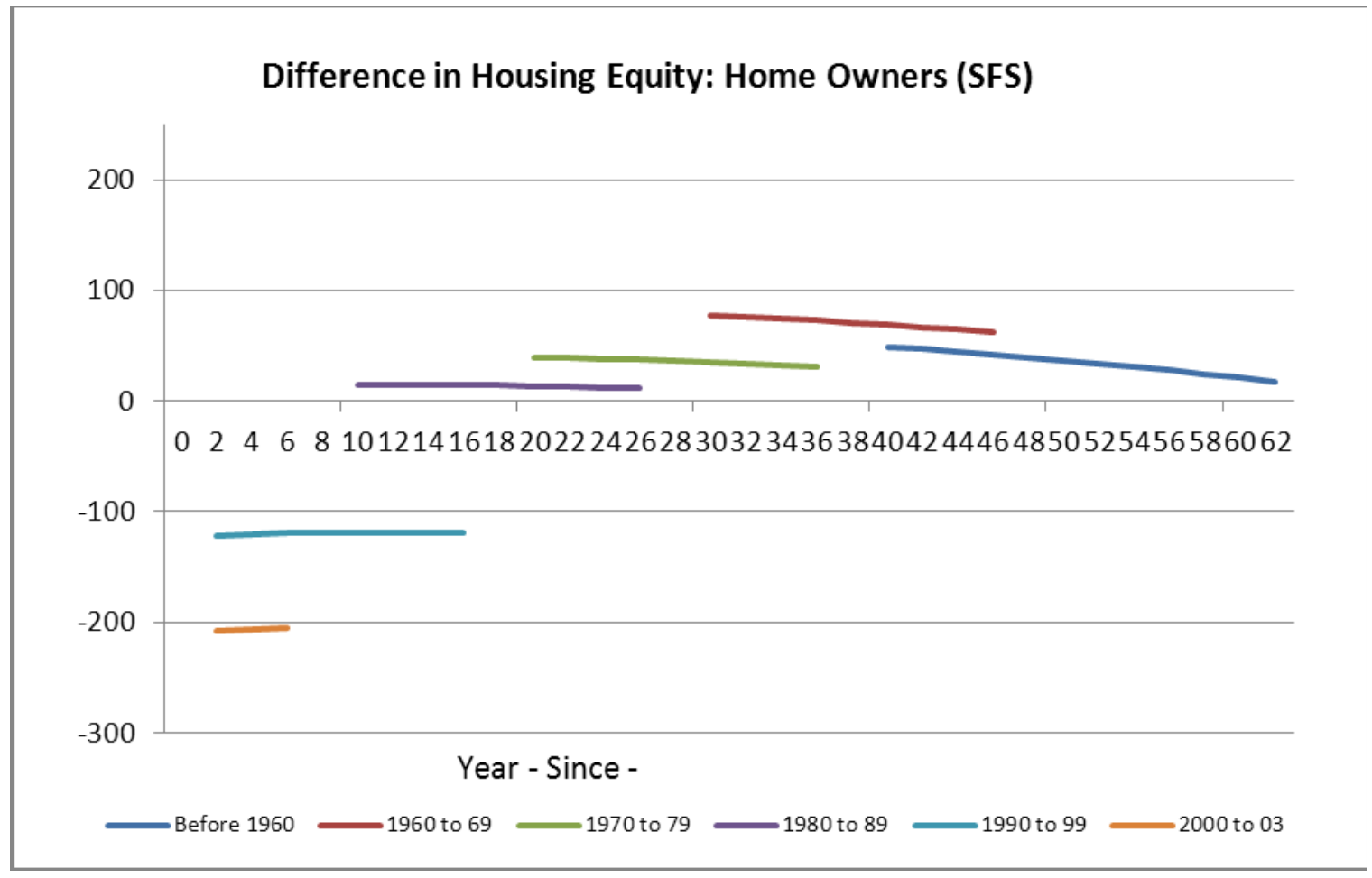


Figure 3.4(a)

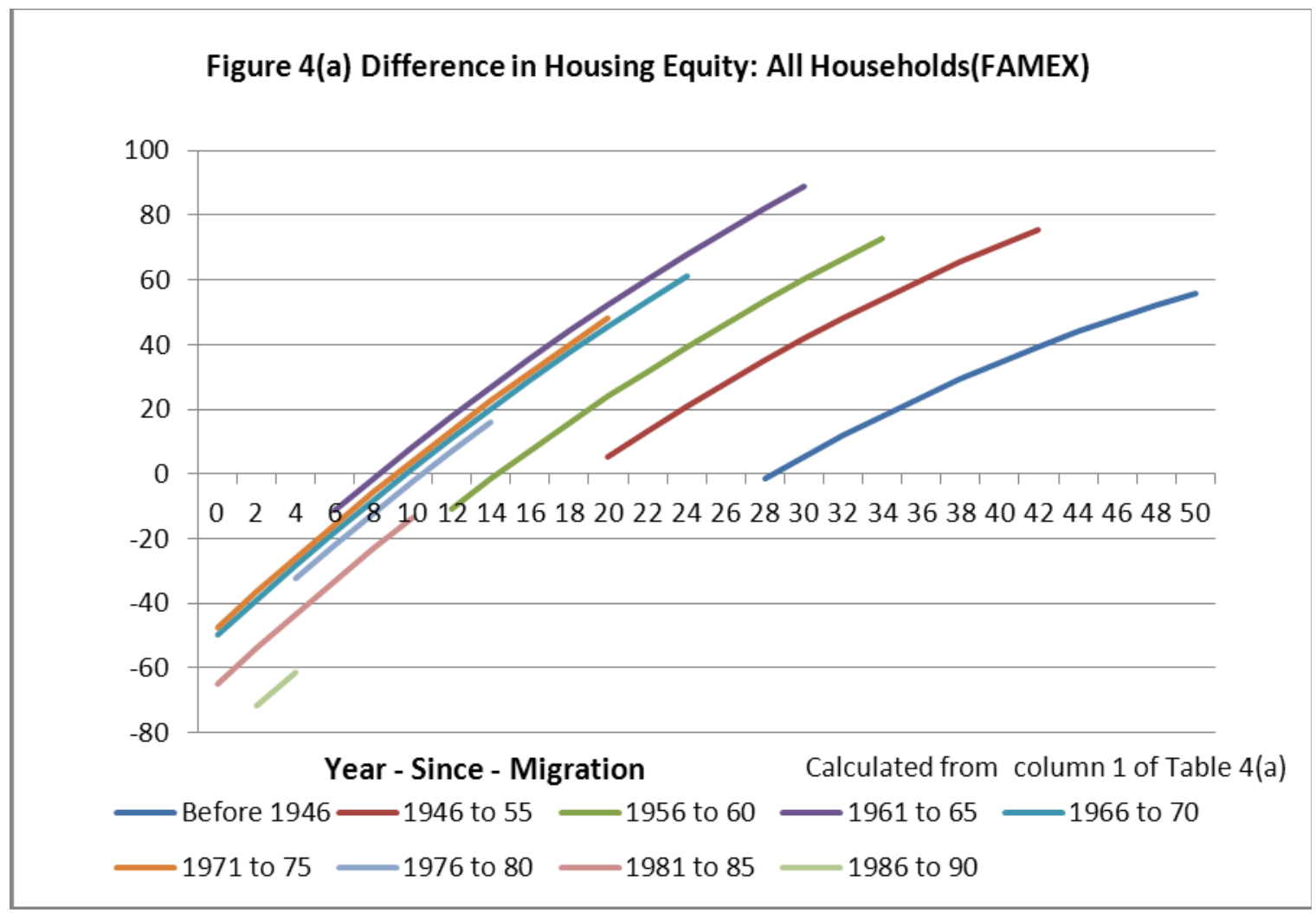


Figure 3.4(b)

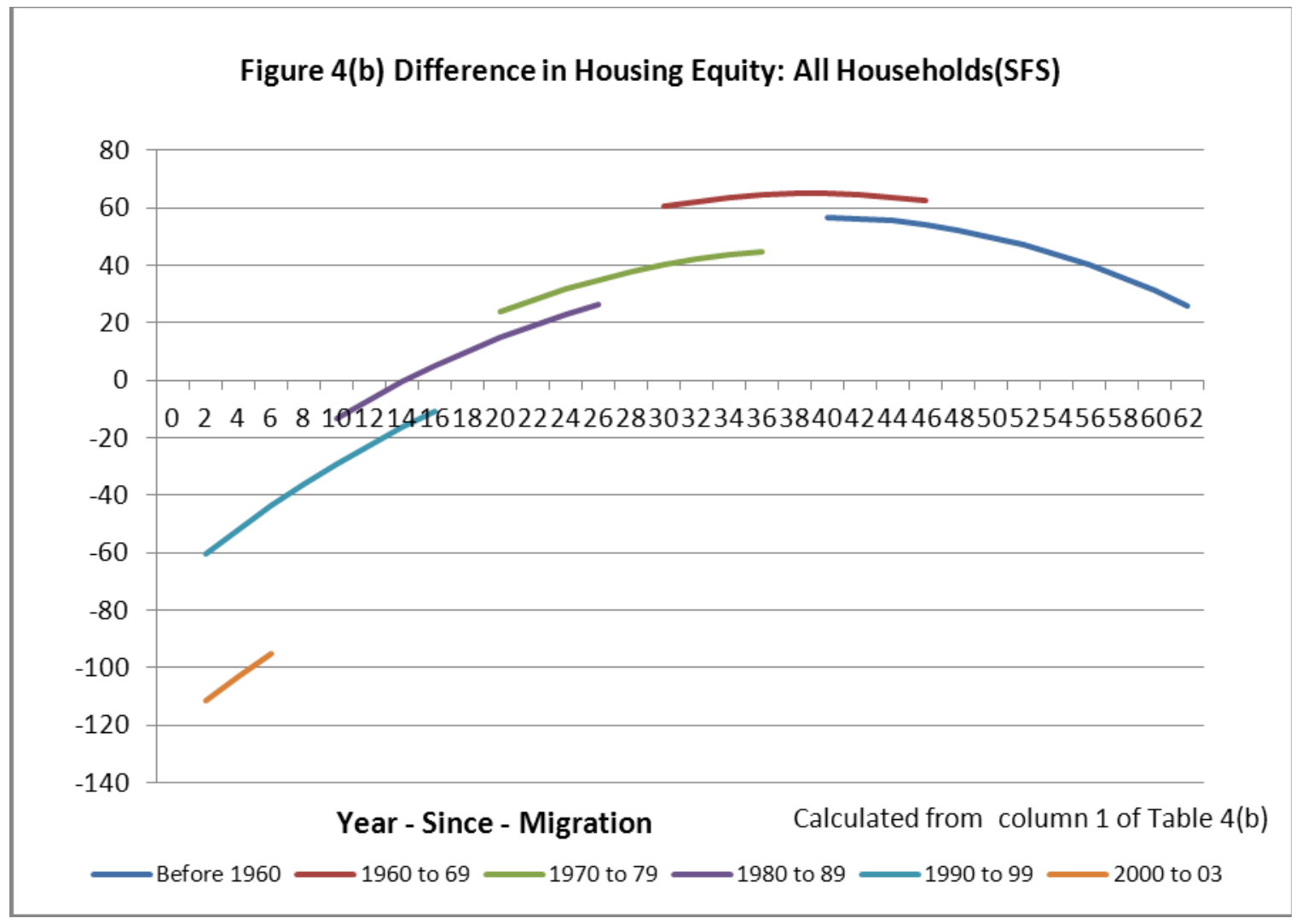


Figure 3.5

Figure 5 Bank Rate, 5-Year Mortgage Rate and New Housing Price Index in Canada

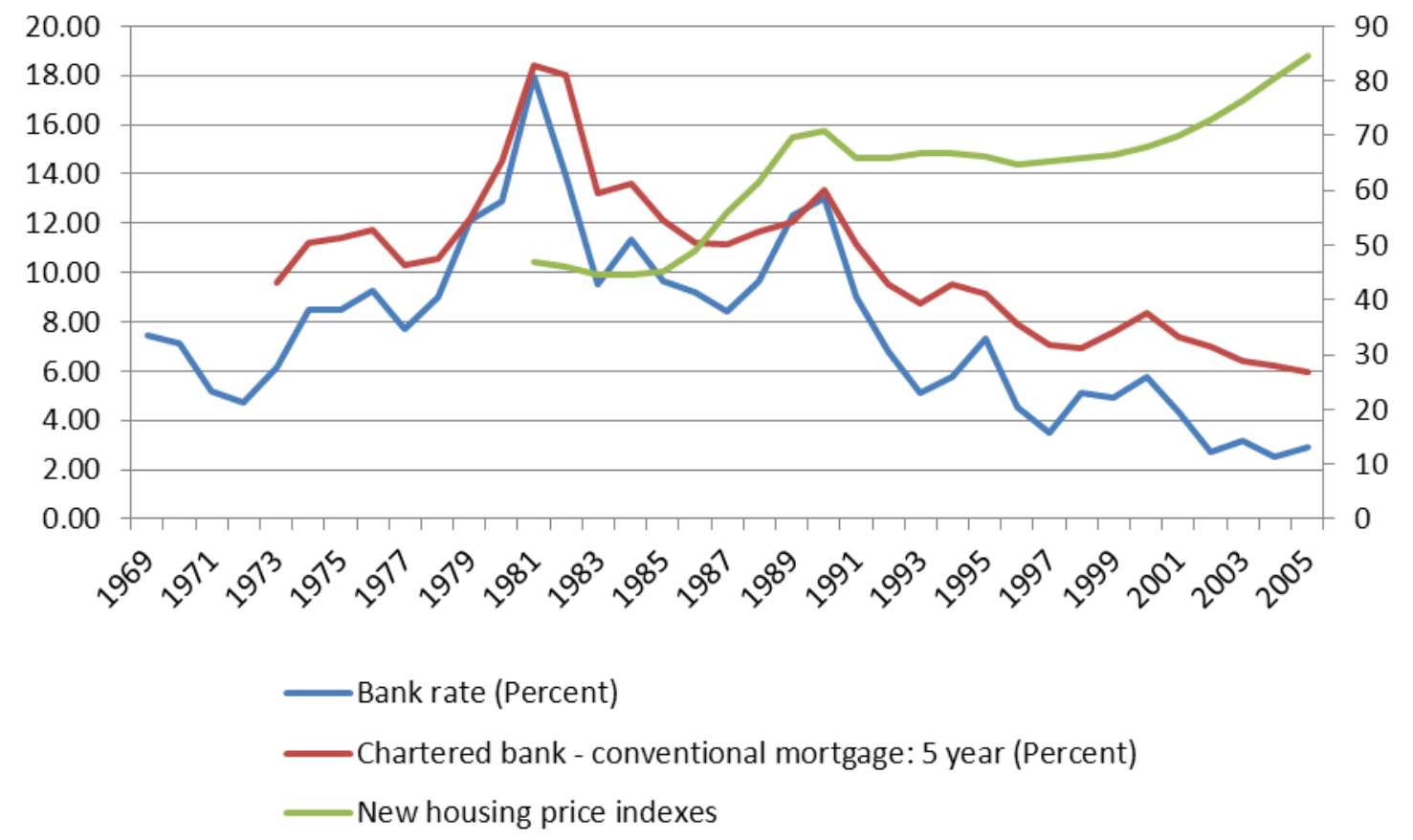

